\title{
Modulation of the Cardiac Sodium Channel Nav1.5 Peak and Late Currents by NAD ${ }^{+}$Precursors
}

Daniel S. Matasic ${ }^{a, b, c}$, Jin-Young Yoon ${ }^{a, b}$, Jared M. McLendon ${ }^{a, b}$, Haider Mehdia, ${ }^{a}$, Mark S. Schmidt $^{\mathrm{b}, \mathrm{d}}$, Alexander M. Greiner ${ }^{\mathrm{a}, \mathrm{b}}$, Pravda Quinones ${ }^{\mathrm{a}, \mathrm{b}}$, Gina M. Morgan ${ }^{\mathrm{a}, \mathrm{b}}$, Ryan L. Boudreau $^{\mathrm{a}, \mathrm{b}}$, Kaikobad Irani ${ }^{\mathrm{a}, \mathrm{b}}$, Charles Brenner ${ }^{\mathrm{b}, \mathrm{d}}$, and Barry London ${ }^{\mathrm{a}, \mathrm{b}, \mathrm{c}^{*}}$

*corresponding author

${ }^{a}$ Division of Cardiovascular Medicine, Department of Internal Medicine, University of Iowa Carver College of Medicine, Iowa City, IA

${ }^{\mathrm{b}}$ Abboud Cardiovascular Research Center, University of Iowa Carver College of Medicine, Iowa City, IA

'Department of Molecular Physiology and Biophysics, University of Iowa Carver College of Medicine, Iowa City, IA

${ }^{\mathrm{d}}$ Department of Biochemistry, University of Iowa Carver College of Medicine, Iowa City, IA

Short Title: Modulation of Nav1. 5 by NAD ${ }^{+}$Precursors

Address correspondence to:

Barry London, MD PhD

Professor and Director, Division of Cardiovascular Medicine

University of Iowa

285 Newton Road, 2283 CBRB

Iowa City, Iowa 52242

barry-london@,uiowa.edu

Conflicts of Interest: DSM: None, JY: None, JMM: None, HM: None, AMG: None, MSS: None, PQ: None, GMM: None, RLB: None, KI: None, CB: a stockholder and member of the scientific advisory board of ChromaDex and a co-founder of ProHealthspan, which manufacture, distribute and sell nicotinamide riboside as a nutritional supplement, BL: None. 


\section{ABSTRACT}

Rationale: The cardiac sodium channel Nav1.5, encoded by $S C N 5 A$, produces the rapidly inactivating depolarizing current $\mathrm{I}_{\mathrm{Na}}$ that is responsible for the initiation and propagation of the cardiac action potential. Acquired and inherited dysfunction of $\mathrm{Na}_{\mathrm{v}} 1.5$ results in either decreased peak $\mathrm{I}_{\mathrm{Na}}$ or increased residual late $\mathrm{I}_{\mathrm{Na}}\left(\mathrm{I}_{\mathrm{Na}, \mathrm{L}}\right)$, leading to tachy/bradyarrhythmias and sudden cardiac death. Previous studies have shown that increased cellular $\mathrm{NAD}^{+}$and $\mathrm{NAD}^{+} / \mathrm{NADH}$ ratio increase $\mathrm{I}_{\mathrm{Na}}$ through suppression of mitochondrial reactive oxygen species and PKC-mediated Nav1.5 phosphorylation. In addition, $\mathrm{NAD}^{+}$-dependent deacetylation of Nav1.5 at K1479 by Sirtuin 1 increases Nav1.5 membrane trafficking and $\mathrm{I}_{\mathrm{Na}}$. The role of NAD ${ }^{+}$precursors in modulating $\mathrm{I}_{\mathrm{Na}}$ remains unknown.

Objective: To determine whether and by which mechanisms the $\mathrm{NAD}^{+}$precursors nicotinamide riboside (NR) and nicotinamide (NAM) affect peak $\mathrm{I}_{\mathrm{Na}}$ and $\mathrm{I}_{\mathrm{Na}, \mathrm{L}}$ in vitro and cardiac electrophysiology in vivo.

Methods and Results: The effects of $\mathrm{NAD}^{+}$precursors on the $\mathrm{NAD}^{+}$metabolome and electrophysiology were studied using HEK293 cells expressing wild-type and mutant $\mathrm{Na}_{\mathrm{v}} 1.5$, rat neonatal cardiomyocytes (RNCMs), and mice. NR increased $\mathrm{I}_{\mathrm{Na}}$ in $\mathrm{HEK} 293$ cells expressing Nav1.5 (500 $\mu \mathrm{M}: 51 \pm 18 \%, \mathrm{p}=0.02,5 \mathrm{mM}: 59 \pm 22 \%, \mathrm{p}=0.03)$ and RNCMs $(500 \mu \mathrm{M}: 60 \pm$ $26 \%, p=0.02,5 \mathrm{mM}: 75 \pm 39 \%, \mathrm{p}=0.03)$ while reducing $\mathrm{I}_{\mathrm{Na}, \mathrm{L}}$ at the higher concentration (RNCMs, $5 \mathrm{mM}:-45 \pm 11 \%$, p=0.04). NR (5 mM) decreased Nav1.5 K1479 acetylation but increased $\mathrm{I}_{\mathrm{Na}}$ in HEK293 cells expressing a mutant form of Nav1.5 with disruption of the acetylation site (Nav1.5-K1479A). Disruption of the PKC phosphorylation site abolished the effect of NR on $\mathrm{I}_{\mathrm{Na}}$. Furthermore, NAM ( $5 \mathrm{mM}$ ) had no effect on $\mathrm{I}_{\mathrm{Na}}$ in RNCMs or in HEK293 cells expressing wild-type $\mathrm{Na}_{\mathrm{V}} 1.5$, but increased $\mathrm{I}_{\mathrm{Na}}$ in HEK293 cells expressing $\mathrm{Na}$ 1.5- 
K1479A. Dietary supplementation with NR for 10-12 weeks decreased QTc in C57BL/6J mice $(0.35 \%$ NR: $-4.9 \pm 2.0 \%, p=0.26 ; 1.0 \%$ NR: $-9.5 \pm 2.8 \%, p=0.01)$

Conclusions: $\mathrm{NAD}^{+}$precursors differentially regulate Nav1.5 via multiple mechanisms. NR increases $\mathrm{I}_{\mathrm{Na}}$, decreases $\mathrm{I}_{\mathrm{Na}, \mathrm{L}}$, and warrants further investigation as a potential therapy for arrhythmic disorders caused by Nav1.5 deficiency and/or dysfunction.

\section{KEYWORDS:}

Cardiac Sodium Channel (Nav1.5, SCN5A)

Arrhythmia

Metabolic Regulation, $\mathrm{NAD}^{+} / \mathrm{NADH}$

Nicotinamide Riboside, Nicotinamide

Sirtuins, Acetylation 


\section{INTRODUCTION}

The main cardiac sodium channel Nav1.5 generates a rapid inward depolarizing $\mathrm{Na}^{+}$current $\left(\mathrm{I}_{\mathrm{Na}}\right)$ that initiates and allows propagation of the cardiac action potential throughout the heart. ${ }^{1}$ Lossof-function mutations in $S C N 5 A$, the gene encoding the pore-forming alpha subunit of Nav1.5, result in: (1) a reduction of $\mathrm{I}_{\mathrm{Na}},(2)$ a decrease in conduction velocity, and (3) an increased risk for tachyarrythmias, bradyarrhythmias, and sudden cardiac death. ${ }^{2-5}$ Inherited deficiency in Nav1.5 can manifest as several conditions including Brugada Syndrome, sick sinus syndrome, and progressive cardiac conduction defects, whereas gain-of-function mutations in $S C N 5 \mathrm{~A}$ that limit voltage- and time-dependent inactivation increase late $\mathrm{Na}^{+}$current $\left(\mathrm{I}_{\mathrm{Na}, \mathrm{L}}\right)$ and result in Long QT syndrome type 3 (LQT3). ${ }^{6-9}$ Moreover, acquired dysfunction of Nav1.5 in conditions such as cardiomyopathies and heart failure can decrease $\mathrm{I}_{\mathrm{Na}}$ and increase $\mathrm{I}_{\mathrm{Na}, \mathrm{L}}$, contributing to fatal arrhythmias. ${ }^{10}$ Given the importance of Nav1.5 in modulating arrhythmic risk, efforts are underway to modulate $\mathrm{Na}_{\mathrm{v}} 1.5$ expression and/or activity as a potential therapeutic avenue for arrhythmogenesis in inherited and acquired conditions.

The cellular redox coenzyme nicotinamide adenine dinucleotide $\left(\mathrm{NAD}^{+}\right)$has been established as an important regulator of cardiac physiology and pathophysiology. ${ }^{11}$ Previous studies have shown that $\mathrm{NAD}^{+}$supplementation can normalize the $\mathrm{NAD}^{+} / \mathrm{NADH}$ redox ratio and increase $\mathrm{I}_{\mathrm{Na} .}{ }^{12}$ Additionally, $\mathrm{NAD}^{+}$supplementation and increased $\mathrm{NAD}^{+} / \mathrm{NADH}$ ratio have been shown to alter protein kinase $\mathrm{A}(\mathrm{PKA})$ and protein kinase $\mathrm{C}(\mathrm{PKC})$ dependent Nav1.5 phosphorylation, thereby altering Nav1.5 surface expression and/or channel conductance. ${ }^{12-14}$ More recently, we showed that the NAD ${ }^{+}$-dependent deacetylase Sirtuin-1 (SIRT1) increases Nav1.5 surface 
expression and $\mathrm{I}_{\mathrm{Na}}$ by deacetylating a lysine residue (K1479) within the Nav1.5 III-IV intracellular linking domain in vitro and in animal models. ${ }^{15,16}$

Given that $\mathrm{NAD}^{+}$has poor bioavailability, $\mathrm{NAD}^{+}$precursors are emerging as a therapeutic strategy for the prevention of cardiovascular disease. ${ }^{11}$ Nicotinamide Riboside (NR), a bioavailable and well-tolerated oral $\mathrm{NAD}^{+}$precursor, has emerged as a leading $\mathrm{NAD}^{+}$ supplement in humans. Several ongoing clinical trials examining the effects of NR supplementation on cardiovascular diseases including heart failure are currently underway. ${ }^{17-20}$ However, the effects of $\mathrm{NAD}^{+}$precursor supplementation on $\mathrm{Na}_{\mathrm{v}} 1.5$ function and cardiac electrophysiology are relatively unexplored.

In this report, we demonstrate that the $\mathrm{NAD}^{+}$precursor $\mathrm{NR}$ alters the $\mathrm{NAD}^{+}$metabolome, increasing $\mathrm{NAD}^{+}$content, Nav1.5 deacetylation, and peak $\mathrm{I}_{\mathrm{Na}}$ while reducing $\mathrm{I}_{\mathrm{Na}, \mathrm{L}}$. In addition, nicotinamide (NAM), an alternative $\mathrm{NAD}^{+}$precursor known to inhibit sirtuin activity at high doses, does not increase $\mathrm{I}_{\mathrm{Na}}$ at high dose in either HEK293 cells or rat neonatal cardiomyocytes (RNCMs). We demonstrate that the effect of NR is mediated by the PKC-phosphorylation S1503 site on Nav1.5 and that the inhibitory effect of NAM is mediated by the K1479 acetylation site. Furthermore, dietary supplementation of $1 \%$ NR in wild-type mice resulted in a reduction in QTc after 10-12 weeks, consistent with the reduction in $\mathrm{I}_{\mathrm{Na}, \mathrm{L}}$. Together, this work lays a foundation for further investigation of the $\mathrm{NAD}^{+}$precursor $\mathrm{NR}$ as a potential therapeutic agent for the prevention of arrhythmias in cardiac diseases associated with $\mathrm{Na}_{\mathrm{V}} 1.5$ deficiency and/or dysfunction. 


\section{METHODS}

All animal studies were approved by the Institutional Animal Care and Use Committees (IACUC) at the University of Iowa.

\subsection{Cell Culturing of Non-Myocytes and Myocytes}

HEK293 cells and HEK293 cells stably-expressing Nav1.5 were obtained from the American Type Culture Collection (ATCC, Manassas, VA) and Dr. Samuel Dudley (University of Minnesota), respectively, and cultured in 10\%-fetal bovine serum and $1 \%$ penicillin/streptomycin supplemented Dulbecco's Modified Eagle's Medium (DMEM). RNCMs were isolated from 1-3 day old Sprague-Dawley rat pups using a neonatal cardiomyocyte isolation system (Worthington Biochemical Co, Lakewood, $\mathrm{NJ}$ ) and cultured in 5\%-horse serum supplemented DMEM/F-12 equivolumetric mixture.

\subsection{Reagents}

Transient expression of Nav1.5 constructs in HEK293 cells was achieved utilizing Lipofectamine 2000 (Invitrogen, Carlsbad, CA). Mutant Nav1.5-K1479A and Nav1.5K1479A/S1503A were generated by site-directed mutagenesis using the Quik-Change II XL kit (Agilent Technologies, Santa Clara, CA). The following NAD ${ }^{+}$metabolites were utilized: nicotinamide riboside (NR, Niagen, Irvine, CA), nicotinamide (NAM, Sigma-Aldrich, St. Louis, MO), and 1-methlynicotinamide (meNAM, Sigma-Aldrich, St. Louis, MO). In experiments using transient transfection of $\mathrm{Na} v 1.5$, treatment of $\mathrm{NAD}^{+}$metabolites was initiated 12 hours posttransfection, continued for 48 hours, and cells were subjected to whole-cell patch clamp after 
plating onto poly-D-lysine-coated coverslips. In experiments using RNCMs, treatment with $\mathrm{NAD}^{+}$metabolites was continued for 24 hours post-plating onto laminin-coated coverslips.

\subsection{Whole-Cell-Patch Clamp of $\mathrm{Na}^{+}$Currents $\left(\mathrm{I}_{\mathrm{Na}}\right)$}

All whole-cell recordings were obtained utilizing the Axon Axopatch 200B amplifier and Digidata 1440B data acquisition system (Molecular Devices, San Jose, CA), as previously described. ${ }^{15}$ Treatment with $\mathrm{NAD}^{+}$metabolites was continued throughout experimentation with extracellular solutions containing the respective concentration of the respective metabolite. Cell capacitance was recorded directly from the amplifier after adjusting for the transient postmembrane rupture.

For HEK293 cells, patch pipettes of 2-3 M $\Omega$ were filled with an internal solution containing: 110 mM CsF, $20 \mathrm{mM} \mathrm{CsCl,} 10 \mathrm{mM} \mathrm{NaF}, 10 \mathrm{mM}$ EGTA, $10 \mathrm{mM}$ HEPES, with the $\mathrm{pH}$ adjusted to 7.35 with $\mathrm{CsOH}$. The extracellular solution contained: $25 \mathrm{mM} \mathrm{NaCl}, 128 \mathrm{mM}$ NMDG, $4.5 \mathrm{mM}$ $\mathrm{KCl}, 10 \mathrm{mM}$ HEPES, $1 \mathrm{mM} \mathrm{MgCl} 2,1.5 \mathrm{mM} \mathrm{CaCl}_{2}, 5 \mathrm{mM}$ glucose, and $\mathrm{pH}$ adjusted to 7.35 using $\mathrm{HCl}$. To test the steady-state activation of $\mathrm{I}_{\mathrm{Na}}$ in HEK293 cells, a 500-ms prepulse to -120 $\mathrm{mV}$ was initiated to recover any channels from inactivation and then cells were subjected to a 20 or 200 -ms test pulse between $-90 \mathrm{mV}$ and $+40 \mathrm{mV}$ in increments of $5 \mathrm{mV}$. The peak current density was assessed at the test potential of largest inward current. To test the steady-state inactivation, a two-pulse protocol was employed with 500-ms conditioning pulses varying from $140 \mathrm{mV}$ to $-30 \mathrm{mV}$, followed by a $20-\mathrm{ms}$ test pulse at $-20 \mathrm{mV}$. 
For RNCMs, patch pipettes of 2-3 M $\Omega$ were filled with an internal solution containing: $10 \mathrm{mM}$ $\mathrm{NaCl}, 90 \mathrm{mM}$ aspartic acid, $70 \mathrm{mM} \mathrm{CsOH}, 10$ mM EGTA, $20 \mathrm{mM} \mathrm{CsCl,} 10 \mathrm{mM}$ HEPES, and pH adjusted to 7.35 using $\mathrm{CsOH}$. The extracellular solution contained: $25 \mathrm{mM} \mathrm{NaCl}, 120 \mathrm{mM}$ $\mathrm{CsCl}, 4.5 \mathrm{mM} \mathrm{KCl}, 10 \mathrm{mM}$ HEPES, $2 \mathrm{mM} \mathrm{MgCl}_{2}, 0.5 \mathrm{mM} \mathrm{CaCl}_{2}$, and $\mathrm{pH}$ adjusted to 7.35 using $\mathrm{CsCl}$. To test the steady-state activation of $\mathrm{I}_{\mathrm{Na}}$ in RNCMs, a $200-\mathrm{ms}$ prepulse to $-120 \mathrm{mV}$ was used to eliminate any inactivated channels and then cells were subjected to a $200-\mathrm{ms}$ test pulse between $-80 \mathrm{mV}$ and $+15 \mathrm{mV}$ in increments of $5 \mathrm{mV}$. To test the steady-state inactivation, a twopulse protocol was employed with 1 -s conditioning pulses varying from $-150 \mathrm{mV}$ to $+30 \mathrm{mV}$ followed by a $200-\mathrm{ms}$ test pulse at $-20 \mathrm{mV}$. $\mathrm{I}_{\mathrm{Na}, \mathrm{L}}$ was calculated by averaging the current between 50-ms and 150-ms of the 200-ms depolarization at three test-potentials: $20 \mathrm{mV}, 25 \mathrm{mV}, 30 \mathrm{mV}$ ). To verify the measurements of $\mathrm{I}_{\mathrm{Na}, \mathrm{L}}$ in $\mathrm{RNCMs}$, a $143 \mathrm{mM} \mathrm{NaCl}$ extracellular solution was used and RNCMs were subjected to a continuous protocol of a $200-\mathrm{ms}$ prepulse to $-120 \mathrm{mV}$ followed by a $200-\mathrm{ms}$ depolarizing test-pulse to $-20 \mathrm{mV}$ with a 5 -s interpulse duration at a holding potential of $-80 \mathrm{mV}$ before and after application of $10 \mu \mathrm{M}$ tetrodotoxin (TTX). TTX-sensitive $\mathrm{I}_{\mathrm{Na}, \mathrm{L}}$ was calculated by the difference of measured late current before and after TTX.

pClamp software (version 10.4) was utilized for data analysis. To calculate $\mathrm{I}_{\mathrm{Na}}$, peak current was normalized to the membrane capacitance. Steady-state activation and inactivation curves were generated and fitted to the Boltzmann equation, whereupon half-maximal potential $\left(\mathrm{V}_{1 / 2}\right)$ and slope factor $(k)$ were derived. 


\subsection{Whole-Cell-Patch Clamp of $\mathrm{K}^{+}$and $\mathrm{Ca}^{2+}$ Currents}

Conventional whole-cell patch clamp techniques were used to record $\mathrm{K}^{+}$and $\mathrm{Ca}^{2+}$ currents from RNCM. Total potassium current was evoked during 4-s depolarizing voltage steps to potentials between -110 and $50 \mathrm{mV}$ from a holding potential of $-80 \mathrm{mV}$ in $10 \mathrm{mV}$ increments. Each trial was preceded by a short $(20-\mathrm{ms})$ depolarization to $-20 \mathrm{mV}$ to eliminate contamination of $\mathrm{Na}^{+}$ currents. $\mathrm{I}_{\mathrm{K} \text {,total }}$ was defined as the currents taken 20-ms into depolarization, and $\mathrm{I}_{\mathrm{K} \text {,sustained }}$ as the currents taken just prior to repolarization. $\mathrm{I}_{\text {to }}$ was determined by the difference between $\mathrm{I}_{\mathrm{K} \text {,total }}$

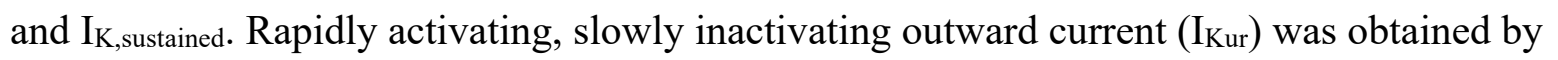
subtraction of currents evoked by depolarizing voltage steps $(-110$ to $50 \mathrm{mV}$ in $10 \mathrm{mV}$ increments) from a holding potential of $-40 \mathrm{mV}$ and $-80 \mathrm{mV}$ followed by a $100-\mathrm{ms}-40 \mathrm{mV}$ inactivating prepulse. $\mathrm{Ca}^{2+}$ current $\left(\mathrm{I}_{\mathrm{Ca}}\right)$ was elicited by holding at $-80 \mathrm{mV}$ and stepping between -70 and $70 \mathrm{mV}\left(10 \mathrm{mV}\right.$ steps) for $500-\mathrm{ms}$ after a prepulse to $-40 \mathrm{mV}$ for $1-\mathrm{s}$ to inactivate $\mathrm{Na}^{+}$ currents.

The internal pipette solution for $\mathrm{I}_{\mathrm{K}}$ voltage clamp studies was: $140 \mathrm{mM} \mathrm{KCl,} 4 \mathrm{mM} \mathrm{Mg-ATP,} 1$ $\mathrm{mM} \mathrm{MgCl} 2,5 \mathrm{mM}$ EGTA, $10 \mathrm{mM}$ HEPES; the extracellular solution contained: $143 \mathrm{mM} \mathrm{NaCl}$, 4.5 $\mathrm{mM} \mathrm{KCl,} 10 \mathrm{mM}$ HEPES, $2.5 \mathrm{mM} \mathrm{CaCl}_{2}, 1 \mathrm{mM} \mathrm{MgCl}_{2}$, and $0.1 \mathrm{mM} \mathrm{CdCl}_{2}$. The $\mathrm{pH}$ was adjusted to 7.4 with $\mathrm{NaOH}$. The internal pipette solution for $\mathrm{I}_{\mathrm{Ca}}$ recording was: $110 \mathrm{mM} \mathrm{CsCl,} 20$ mM TEACl, 5 mM Mg-ATP, 2 mM Na2-ATP, 5 mM Na Creatine Phosphate, 5 mM HEPES, 3 mM EGTA, and $\mathrm{pH}$ was adjusted to 7.2 with TRIS. The extracellular solution was: $130 \mathrm{mM}$ NMDG, $20 \mathrm{mM}$ Tetraethylammonium chloride (TEACl), $2 \mathrm{mM} \mathrm{CaCl}_{2}, 2 \mathrm{mM} \mathrm{MgCl}_{2}, 10 \mathrm{mM}$ HEPES, $10 \mathrm{mM}$ Glucose, and the $\mathrm{pH}$ was adjusted to 7.4 with $\mathrm{HCl}$. Cells were dialyzed for 5 min prior to initiating experimental protocols. 


\subsection{Quantification of the NAD ${ }^{+}$NADH Ratio and the NAD ${ }^{+}$Metabolome}

$\mathrm{NAD}^{+}, \mathrm{NADH}$, and $\mathrm{NAD}^{+} / \mathrm{NADH}$ ratios was quantified in cellular extracts using the NAD/NADH-Glo ${ }^{\mathrm{TM}}$ Assay Kit (Promega Co, Madison, WI). Direct measurements of NAD ${ }^{+}$and other metabolites in the $\mathrm{NAD}^{+}$metabolome were performed on cell extracts using Liquid Chromatography-Mass Spectrometry (LC-MS), as previously described. ${ }^{21}$ Measurements below the quantitation limit were set to the minimum value of quantitation.

\subsection{Western Blotting}

Conventional techniques were utilized as previously described. ${ }^{15}$ To assess the acetylation of K1479, a custom-designed anti-acetyl K1479 Nav1.5 antibody was utilized, as previously described and used. ${ }^{15}$ Total Nav1.5 expression in whole cell lysates (Alomone ASC-005) was normalized to GAPDH ( Trevigen 2275-PC). To measure the membrane expression of Nav1.5, the membrane-enriched protein fraction was harvested with the Compartmentalization Protein Extraction Kit (Millipore, Burlington, MA).

\subsection{Assessment of Nav1.5 Surface Expression by Microscopy}

HEK293 cells that stably express Nav1.5 with an extracellular FLAG epitope in the extracellular region of Domain I were seeded on gelatin coated glass bottom 24-well plates (Cellvis, Sunnyvale, CA). These FLAG-Nav1.5 HEK293 cells were treated for 48 hours with 5 mM NR (replenished media at treatment at 24 hours) and subsequently fixed for 15 minutes with $4 \%$ paraformaldehyde (diluted from 16\%, Electron Microscopy Sciences, Hatfield, PA). Without cell permeabilization, cells were incubated in blocking buffer (PBS with 2\% BSA 5\% goat serum) 
for 1 hour, and then incubated overnight with Anti-FLAG M2 Antibody (Sigma Aldrich, St.

Louis MO), diluted 1:1000 in blocking buffer, followed by a one hour incubation in Alexa-568 conjugated anti-mouse antibody (Abcam, Cambridge UK) diluted 1:1000 in blocking buffer. Surface Expression of FLAG-Nav1.5 was assessed by confocal microscopy using a Zeiss LSM510 microscope with a 63x objective (Plan Apochromat 63x/1.4 oil DIC) and Zeiss ZEN software.

\subsection{Dietary Supplementation of Nicotinamide Riboside in Mice}

4-5-month-old C57BL/6J mice of both sexes were randomly placed on a control diet (Teklad 2920X, Envigo) or a diet supplemented with NR at either $0.35 \%$ or $1 \%$ (3.5 g or $10 \mathrm{~g}$ of NR, respectively, in $1 \mathrm{~kg}$ of Teklad 2920X, Envigo) for 10-12 weeks. Food was prepared fresh every 3-4 days and mice were weighed to assess for any changes in body weight throughout the experiment.

\subsection{Electrocardiography and Echocardiography in Mice}

Electrocardiograms (EKGs) were performed at baseline, 4-6 weeks of diet, and 10-12 weeks of diet using the iWork IX/100B EKG recording system. The mice were anesthetized with 1-2\% isoflurane, and high resolution multi-lead EKGs were obtained by placing bipolar electrodes subcutaneously in positions corresponding to human leads: I (right to left arm), II (right arm to left leg), III (left arm to left leg), and modified chest V (back to left sternal border), as previously described. ${ }^{22}$ Data was collected, digitized, and analyzed using LabScribe 2.0 software (iWorx, Dover, NH). An investigator blinded by treatment group analyzed R-R interval, PR interval, 
QRS duration, and QT interval for leads I, II, III, and V. QTc was calculated as previously described. ${ }^{23}$ Maximum values among leads for PR, QRS, and QTc are reported.

Transthoracic echocardiography was performed to assess cardiac size and function at baseline and 10-12 weeks of diet (Vevo 2700 VisualSonics System). Mice were anesthetized with midazolam; measurements included heart rate, end diastolic volume, end systolic volume, and ejection fraction as previously described. ${ }^{24}$

\subsection{Statistical Analysis}

All statistical analysis was performed with GraphPad Prism. Results are represented as the mean \pm standard error of the mean and considered statistically significant if $p$-values were $\leq 0.05$. All analyses were performed blinded to treatment or construct, as appropriate. Significance of difference between two groups was evaluated using independent sample t-tests. In addition, two-way ANOVAs were used to evaluate differences between groups over time. 


\section{RESULTS}

\subsection{Nicotinamide Riboside Increases $I_{\mathrm{Na}}$ in HEK293 Cells Expressing Nav1.5 and in RNCMs}

Previous studies showed that extracellular application of $\mathrm{NAD}^{+}$reversed the downregulation of $\mathrm{I}_{\mathrm{Na}}$ that resulted from increased NADH levels in HEK293 cells expressing Nav1.5. ${ }^{12}$ We tested whether NR (Figure 1A), a bioavailable precursor of NAD ${ }^{+}$, can influence $\mathrm{I}_{\mathrm{Na}}$. NR $(500 \mu \mathrm{M})$ supplementation of HEK293 cells constitutively expressing Nav1.5 increased NAD ${ }^{+}$and NADH levels without changing the $\mathrm{NAD}^{+} / \mathrm{NADH}$ ratio (Figure 1B), and increased $\mathrm{I}_{\mathrm{Na}}(51 \pm 18 \%$, $\mathrm{p}=0.02$; Figure $1 \mathrm{C}-\mathrm{E}$, Table S1) with only minor changes to Nav1.5 gating properties $(4 \mathrm{mV}$ hyperpolarizing shift in the steady-state activation half-potential; Figures 1F, S1). Similarly, 5 mM NR significantly increased $\mathrm{I}_{\mathrm{Na}}$ in HEK293 cells transiently-transfected with the wild-type Nav1.5 channel $(59 \pm 22 \%, \mathrm{p}=0.03$, Figure $1 \mathrm{G}-\mathrm{H}$, Table S1) with no effects on their gating properties (Figures 1I, S1, Table S5). Surface expression of the channel was not increased in response to NR (Figures S2, S3).

Comparable results were observed in RNCMs (Figure 2). Representative whole-cell traces and IV curves illustrated the stimulatory effects of $\mathrm{NR}$ on $\mathrm{I}_{\mathrm{Na}}(500 \mu \mathrm{M}$ NR: $60 \pm 26 \%, \mathrm{p}=0.02 ; 5 \mathrm{mM}$ NR: $74 \pm 39 \%, p=0.03$; Figure $2 \mathrm{~A}-\mathrm{C}$, Table S2). Changes in gating properties including steadystate activation and inactivation were observed after treatment with $5 \mathrm{mM} \mathrm{NR}$ but not $500 \mu \mathrm{M}$ NR, with a depolarizing shift of steady-state activation and inactivation (Figures 2D, S4, Table S5). Interestingly, $5 \mathrm{mM}$ NR reduced $\mathrm{I}_{\mathrm{Na}, \mathrm{L}}(-45 \pm 11 \%, \mathrm{p}=0.04$, measured at $-25 \mathrm{mV}$; Figure 2EF). The absolute late current densities, measured at $-25 \mathrm{mV}$, for $5 \mathrm{mM}$ NR relative to control ($1.88 \pm 0.23 \mathrm{pA} / \mathrm{pF}$ vs. $-3.32 \pm 0.26 \mathrm{pA} / \mathrm{pF}, \mathrm{p}=0.002$, Figure S5) also decreased. To verify that the 
observed changes in $\mathrm{I}_{\mathrm{Na}, \mathrm{L}}$ were not attributed to contaminated leak currents, $\mathrm{I}_{\mathrm{Na}, \mathrm{L}}$ was also determined by measuring the TTX-sensitive current. $5 \mathrm{mM}$ NR significantly decreased the TTXsensitive $\mathrm{I}_{\mathrm{Na}, \mathrm{L}}$ compared to control in $\mathrm{RNCMs}(-1.98 \pm 0.48 \mathrm{pA} / \mathrm{pF}$ vs. $-4.43 \pm 1.24 \mathrm{pA} / \mathrm{pF}$, $\mathrm{p}=0.04$, Figure $2 \mathrm{G}-\mathrm{H})$. NR increased $\mathrm{NAD}^{+}$and $\mathrm{NADH}$ content in RNCMs, similar to the findings in HEK293 cells; however, NR also significantly increased the NAD ${ }^{+} / \mathrm{NADH}$ ratio in RNCMs (Figure 2I).

\subsection{Nicotinamide Riboside Drives Deacetylation of Nav1.5}

Our group recently showed that the $\mathrm{NAD}^{+}$-consuming enzyme Sirtuin 1 regulates $\mathrm{Na}_{\mathrm{v}} 1.5$ trafficking by deacetylation of a lysine residue at the 1479 position within the III-IV intracellular linker domain. ${ }^{15} \mathrm{NR}$ supplementation of HEK293 cells transiently transfected with Nav1.5 decreased the acetylation of K1479 only at the higher $5 \mathrm{mM}$ dose, with no effect on total Nav1.5 mRNA or protein expression (Figures $3, \underline{\mathrm{S} 6}$ ).

\subsection{Nicotinamide Riboside does not alter $\mathrm{K}^{+}$currents or $\mathrm{Ca}^{2+}$ currents}

To assess whether NR has an influence on other currents regulating the cardiac action potential, $\mathrm{K}^{+}$currents and $\mathrm{Ca}^{2+}$ currents were assessed by whole-cell patch clamp in RNCMs after a 24 hour treatment with $5 \mathrm{mM}$ NR. NR had no significant effect on $\mathrm{K}^{+}$currents including total $\mathrm{I}_{\mathrm{K}}$, sustained $\mathrm{I}_{\mathrm{K}}, \mathrm{I}_{\mathrm{to}}$, and $\mathrm{I}_{\mathrm{Kur}}$. NR had no effect on $\mathrm{Ca}^{2+}$ current density and inactivation kinetics in RNCMs as assessed by whole cell patch clamp (Figure S7).

\subsection{Nicotinamide has Differential Effects on $\mathbf{I}_{\mathrm{Na}}$ between HEK293 Cells and RNCMs}


NAM (Figure 4A), an alternate $\mathrm{NAD}^{+}$precursor to NR known to inhibit sirtuins at high dose, had no significant effect on $\mathrm{I}_{\mathrm{Na}}$ in HEK293 cells transiently-transfected with Nav1.5 (500 $\mu \mathrm{M}$ : $19 \pm 26 \%, p=0.56 ; 5 \mathrm{mM}:+21 \pm 26 \%, \mathrm{p}=0.49$; Figure 4B-C, Table S3). No significant changes were observed in steady-state activation and inactivation after NAM administration (Figure S8). Interestingly, NAM stimulated $\mathrm{I}_{\mathrm{Na}}$ in RNCMs at a lower dose $(500 \mu \mathrm{M}: 84 \pm 33 \%, \mathrm{p}=0.003)$ but had no significant effect on $\mathrm{I}_{\mathrm{Na}}$ at a higher dose $(5 \mathrm{mM}$ : $-11 \pm 24 \%, \mathrm{p}=\mathrm{NS}$; Figure 4D-E, Table S3). Gating properties were unchanged (Figures 4F, S9, Table S5). Unlike NR, NAM had no effect of $\mathrm{I}_{\mathrm{Na}, \mathrm{L}}$ (Figure 4G). Measurement of NAD ${ }^{+}$and NADH showed that NAM increased both $\mathrm{NAD}^{+}$and NADH content in a dose-dependent manner with a significant increase in the overall $\mathrm{NAD}^{+} / \mathrm{NADH}$ ratio $(500 \mu \mathrm{M}: 7.5 \pm 2.0 \%, \mathrm{p}=0.007,5 \mathrm{mM}: 23.8 \pm 3.9 \%, \mathrm{p}<0.0001 ;$ Figure $4 \mathrm{H})$.

\subsection{1-methyl-Nicotinamide, an inert Nicotinamide Metabolite, has no effect on $\mathbf{I}_{\mathrm{Na}}$}

1-methyl-Nicotinamide (meNAM), an inert byproduct of NAM degradation and not an NAD

precursor, had no significant effect on $\mathrm{I}_{\mathrm{Na}}(500 \mu \mathrm{M}:-7 \pm 14 \%, \mathrm{p}=\mathrm{NS} ; 5 \mathrm{mM}:-5 \pm 9.9 \%, \mathrm{p}=\mathrm{NS})$

channel gating properties, or $\mathrm{I}_{\mathrm{Na}, \mathrm{L}}$ in RNCMs (Figure S10A-G). MeNAM tended to increase $\mathrm{NAD}^{+}$and decrease NADH content in a dose-dependent manner, leading to a significant increase in $\mathrm{NAD}^{+} / \mathrm{NADH}$ ratio (Figure $\left.\mathrm{S} 10 \mathrm{H}\right)$.

\section{6 $\mathrm{NAD}^{+}$Metabolome Following NAD ${ }^{+}$Metabolite Supplementation in RNCMs}

$\mathrm{NAD}^{+}$metabolite supplementation in cardiomyocytes has been relatively unexplored. The effect of supplementation with NR, NAM or meNAM on the RNCM NAD ${ }^{+}$metabolome was assessed by LC-MS (Figure 5). Both NR and NAM caused dose-dependent increases in NAD ${ }^{+}$whereas the inert meNAM had no effect on $\mathrm{NAD}^{+}$content (Figure 5A). NR was superior to NAM in 
increasing $\mathrm{NAD}^{+}$and nicotinamide adenine dinucleotide phosphate $\left(\mathrm{NADP}^{+}\right)$at equimolar concentrations (Figure 5A,B). However, NAM was superior in increasing nicotinic acid adenine dinucleotide (NAAD, Figure 5C). NR markedly depressed levels of ADP-ribose (ADPR), a substrate for another class of $\mathrm{NAD}^{+}$-consuming enzymes, Poly-ADP-Ribose Polymerases (PARPs, Figure 5I). NAM, an inhibitor of PARPs, had no significant effect on ADPR levels.

\subsection{Disruption of the Nav1.5-K1479 Acetylation Site and Nav1.5-S1503 Phosphorylation} sites Modulates the Effects of $\mathrm{NAD}^{+}$Precursors on $\mathbf{I}_{\mathrm{Na}}$ SIRT1-dependent deacetylation of Nav1.5 in the intracellular Domain III-IV linker at K1479 increased $\mathrm{I}_{\mathrm{Na}}$ by enhancing membrane trafficking, and disruption of the acetylation by sitedirected mutagenesis (Nav1.5-K1479A) eliminated the effect of SIRT1 on $\mathrm{I}_{\mathrm{Na}}$ in HEK293 cells. ${ }^{15}$ To determine the role of acetylation following treatment with NAD ${ }^{+}$precursors, HEK293 cells transiently transfected with wild-type Nav1.5 or Nav1.5-K1479A channels were treated with NR or NAM. No differences in the magnitude and gating properties of $\mathrm{I}_{\mathrm{Na}}$ were observed between the wild-type and K1479A Nav1.5 channels under basal conditions (Figure S11). Similar to its effect on wild-type channels (Figure $1 \mathrm{G}-\mathrm{H}$ ), NR increased $\mathrm{I}_{\mathrm{Na}}$ in HEK293 cells expressing Nav1.5-K1479A (5 mM: $75 \pm 29 \%, p=0.02$; Figure 6A,B) and significantly shifted steady-state activation and inactivation to more hyperpolarized potentials (Figures 6C, S12, Table S5). However, NR had no effect on $\mathrm{I}_{\mathrm{Na}}$ in HEK293 cells expressing Nav1.5-K1479A/S1503A (5 mM: $16 \pm 12 \%, p=0.38$; Figure $6 \mathrm{D}, \mathrm{E})$ while maintaining the hyperpolarizing shift in steady-state activation and inactivation (Figures 6F, S12, Table S5). Therefore, disruption of the PKC site abolished the effect of NR on increasing $\mathrm{I}_{\mathrm{Na}}$. 
Administration of NAM to HEK293 cells expressing Nav1.5-K1479A increased $\mathrm{I}_{\mathrm{Na}}(500 \mu \mathrm{M}: 81$ $\pm 47 \%, \mathrm{p}=0.10 ; 5 \mathrm{mM}: 66 \pm 25 \%, \mathrm{p}=0.04$; Figure $6 \mathrm{G}-\mathrm{I})$, unlike our prior finding that NAM had no effect on HEK293 cells expressing wild-type Nav1.5 (Figure 4). NAM had no effect on steady-state activation or inactivation (Figure S8). Thus, elimination of the SIRT1-deacetylation site allowed NAM to increase $\mathrm{I}_{\mathrm{Na}}$.

Together these results suggest that both SIRT1-dependent and SIRT1-independent mechanism are modulating $\mathrm{Na}_{\mathrm{V}} 1.5$ in response to $\mathrm{NAD}^{+}$metabolites that increase $\mathrm{NAD}^{+}$.

\subsection{Dietary Supplementation of Nicotinamide Riboside Decreases QTc in Wild-type Mice}

To assess for changes in cardiac electrophysiology with $\mathrm{NAD}^{+}$supplementation in vivo, C57BL/ $6 \mathrm{~J}$ mice were either placed on a diet with $(0.35 \%$ or $1.0 \%$ by weight $)$ or without (control) supplemental NR. Over the time course of dietary supplementation, no differences in body weight were observed demonstrating that the NR diets are tolerated and did not alter growth (Figure S13). Electrophysiological properties were assessed by high-resolution EKG (Figure 7AB). No differences in PR and QRS intervals were observed between groups at different timepoints (Figure 7C-D, Table S6). However, mice supplemented with NR demonstrated a decrease in QTc $(0.35 \%$ NR: $-4.9 \pm 2.0 \%, p=0.22,1.0 \%$ NR: $-9.5 \pm 2.8 \%, p=0.01)$ after $10-12$ weeks compared to baseline, with no change in mice on a control diet $(+1.8 \pm 2.3 \%, p=0.99$, Figure 7A,B,E, Table S6). NR supplementation had no effect on cardiac function as assessed by echocardiography (Table S7). 


\section{DISCUSSION}

Our group and others have explored the molecular basis for the regulation of the cardiac sodium channel $\mathrm{Na}_{\mathrm{v}} 1.5$ by $\mathrm{NAD}^{+}, \mathrm{NADH}$, and the NAD ${ }^{+} / \mathrm{NADH}$ ratio. Previous studies demonstrated that exogenous application of $100 \mu \mathrm{M} \mathrm{NAD}^{+}$on Langendorff-perfused hearts from Scn5a haploinsufficient mice was protective against programmed electrical stimulation induced polymorphic ventricular tachycardia. ${ }^{12}$ In addition, exogenous in vitro application and in vivo intraperitoneal injection of $\mathrm{NAD}^{+}$rescued the decrease in peak $\mathrm{I}_{\mathrm{Na}}$ in myocytes from mice with a non-ischemic cardiomyopathy (with hypertension from unilateral nephrectomy, deoxycorticosterone acetate pellet implantation, and salt water substitution). ${ }^{25}$ Furthermore, application of $\mathrm{NAD}^{+}$on failing human heart wedge preparations improved conduction velocity. ${ }^{25}$

In this study, we demonstrate that NR, a commercially bioavailable $\mathrm{NAD}^{+}$precursor, ${ }^{26}$ can increase peak $\mathrm{I}_{\mathrm{Na}}$ in heterologous expression systems and RNCMs without influencing the $\mathrm{NAD}^{+} / \mathrm{NADH}$ ratio. We also show, for the first time, that $\mathrm{NAD}^{+}$precursor supplementation reduces $\mathrm{I}_{\mathrm{Na}, \mathrm{L}}$ in RNCMs and shortens QTc in mice, collectively suggesting that both an increase in peak $\mathrm{I}_{\mathrm{Na}}$ and a decrease in $\mathrm{I}_{\mathrm{Na}, \mathrm{L}}$ are novel potential antiarrhythmic mechanisms following $\mathrm{NAD}^{+}$supplementation. Together, these findings provide substantial evidence for a direct role of $\mathrm{NAD}^{+}$in regulating the electrical activity of the heart through modulation of $\mathrm{Nav} 1.5$.

Translation and trafficking of $\mathrm{Na}_{v} 1.5$ to the cellular membrane surface is tightly regulated by a series of processes involving microRNA-based mRNA degradation, translation, assembly, transport through the endoplasmic reticulum and Golgi complex, anchoring at the cellular surface, recycling of the channel through internalization, and degradation. ${ }^{27,28}$ A variety of 
mechanisms coordinate the trafficking of Nav1.5 and involve a collection of accessory interacting proteins and post-translational modifications. At the surface, Nav1.5 function can be dictated by open probability, conductance, and gating properties. We previously reported that acetylation of $\mathrm{Na}_{\mathrm{V}} 1.5$ at a highly conserved lysine (K1479) in the Domain III-IV intracellular linker, a region of the channel historically known for its role in channel inactivation, regulates channel surface expression but not gating properties. ${ }^{15}$ However, the mechanisms regulating $\mathrm{Nav} 1.5$ amplitude and properties in response to $\mathrm{NAD}^{+}$precursor supplementation remain unknown.

Our data here demonstrates that the application of $500 \mu \mathrm{M}$ to $5 \mathrm{mM}$ of the $\mathrm{NAD}^{+}$precursor NR increased peak $\mathrm{I}_{\mathrm{Na}}$ by approximately $40-60 \%$ in HEK293 cells stably-expressing Nav1.5, HEK293 cells transiently-transfected with Nav1.5, and RNCMs with no significant change in Nav1.5 expression, channel steady-state gating properties, or channel surface and membrane expression. We also show that NR decreases K1479 Nav1.5 acetylation only at the higher $5 \mathrm{mM}$ dose. Together, these findings suggest suggestive that the increase in $\mathrm{I}_{\mathrm{Na}}$ observed at both doses $(500 \mu \mathrm{M}$ and $5 \mathrm{mM})$ is independent of acetylation in heterologous cell systems are cardiac myocytes.

$\mathrm{NAD}^{+}$is utilized as a substrate for sirtuins (SIRTs) and activity is dependent on NAD ${ }^{+}$levels. NR drives sirtuin activity by increase $\mathrm{NAD}^{+}$content. SIRT1 (Sirtuin 1 ), the primary and most evolutionary conserved sirtuin, deacetylates $\mathrm{Na}_{\mathrm{V}} 1.5$ at K1479 in heterologous cell systems, RNCMs, and mice. ${ }^{15}$. The enzymatic reaction of sirtuin deacetylation results in the breakdown of $\mathrm{NAD}^{+}$to NAM and ADP-ribose. NAM also holds the potential to regenerate $\mathrm{NAD}^{+}$but at high 
doses can be a competitive feedback inhibitor on sirtuins and other $\mathrm{NAD}^{+}$-consuming enzymes, and we have previously shown that 5 mM NAM increases K1479 acetylation. ${ }^{15}$ In this study, the application of NAM on RNCMs demonstrated a dose-dependent effect on $\mathrm{I}_{\mathrm{Na}}$, with low doses stimulating $\mathrm{I}_{\mathrm{Na}}$ but higher doses having no effect on $\mathrm{I}_{\mathrm{Na}}$ despite increasing $\mathrm{NAD}^{+}$content and $\mathrm{NAD}^{+} / \mathrm{NADH}$ ratio. This illustrates the effects of NAM in boosting $\mathrm{NAD}^{+}$synthesis but inhibitory of sirtuins. NAM at either dose $(500 \mu \mathrm{M}$ or $5 \mathrm{mM})$ had no effect of $\mathrm{I}_{\mathrm{Na}}$ in HEK293 cells transiently transfected with wild-type Nav1.5. Furthermore, we confirmed the importance of acetylation in modulating the response of $\mathrm{I}_{\mathrm{Na}}$ to NAM using the Nav1.5 K1479A mutant. The absence of the Nav1.5-K1479 acetylation site did not significantly blunt the effect of NR on $\mathrm{I}_{\mathrm{Na}}$, suggesting that sirtuin-mediated deacetylation is not primarily responsible for the increase on $\mathrm{I}_{\mathrm{Na}}$ following NR administration. However, disruption of the acetylation site enabled NAM to increase $\mathrm{I}_{\mathrm{Na}}$ in HEK293 cells transiently-transfected with Nav1.5-K1479A. This illustrates that $\mathrm{NAD}^{+}$metabolites can modulate $\mathrm{Na}_{\mathrm{v}} 1.5$ through both sirtuin-dependent and sirtuin-independent mechanisms.

In addition to acetylation, both protein kinase $\mathrm{C}(\mathrm{PKC})$ and protein kinase $\mathrm{A}$ (PKA) phosphorylation of Nav1.5 has been identified as being sensitive to $\mathrm{NAD}^{+}, \mathrm{NADH}$, and metabolic stress. Increased levels of NADH activate PKC, resulting in the production of mitochondrial reactive oxygen species (ROS) and the direct phosphorylation of Nav1.5 at S1503 within the Domain III-IV linker region. ${ }^{13}$ These actions have been shown to decrease single channel conductance as well as decrease channel surface expression. ${ }^{13,14}$ By increasing NAD ${ }^{+}$ content, the production of reactive oxidant species is reduced and therefore, the application of NR may modulate the PKC-mediated phosphorylation and oxidant stress production in the 
regulation of Nav1.5. ${ }^{25}$ Our data demonstrates that the disruption of the PKC site at S1503 abolished the effect of NR, suggesting that the effect of $\mathrm{NR}$ on increasing $\mathrm{I}_{\mathrm{Na}}$ is dependent on the PKC phosphorylation site, which is known to decrease single channel conductance. As opposed to $\mathrm{PKC}$, the stimulation of PKA phosphorylation, shown to be mediated by $\mathrm{NAD}^{+}$, blunts the effects of NADH on decreasing $\mathrm{I}_{\mathrm{Na}} \cdot{ }^{12,29,30}$ PKA stimulation has been shown to have no effect on $\mathrm{I}_{\mathrm{Na}, \mathrm{L}}$ in wild-type Nav1.5 channels. ${ }^{31}$ Together, the interplay between acetylation, phosphorylation, and mitigation of oxidant stress may provide an explanation of $\mathrm{NAD}^{+}$-mediated modulation of peak $\mathrm{I}_{\mathrm{Na}}$ through the cardiac sodium channel Nav1.5 (Figure 8).

$\mathrm{NAD}^{+}$supplementation may also drive other unidentified post-translational modifications of Nav1.5 including ADP-ribosylation. In addition to sirtuins, $\mathrm{NAD}^{+}$is consumed as a substrate by poly(ADP)-ribose polymerases (PARPs) to catalyze the addition of ADP-ribose moieties onto target proteins. ${ }^{32}$ Our data illustrates that $\mathrm{NAD}^{+}$supplementation with NR may be stimulating ADP-ribosylation, as ADP-ribose levels are markedly depressed after NR treatment in RNCMs (Figure 5). Of note, similar decreases of ADP-ribose are not observed after NAM treatment as NAM inhibits PARP activity. ${ }^{33}$ Investigation of ADP-ribosylation may provide further insight into the $\mathrm{NAD}^{+}$-dependent regulation of Nav1.5.

Previous reports have indicated that CD38 mediates the effect of extracellular $\mathrm{NAD}^{+}$in rescuing $\mathrm{I}_{\mathrm{Na}}$ in response to increased intracellular $\mathrm{NADH} .{ }^{25} \mathrm{CD} 38$ has been shown catalyze intracellular $\mathrm{NAD}^{+}$to cyclic ADP-ribose in addition to metabolizing extracellular NAD ${ }^{+}$precursors. ${ }^{34}$ Although HEK293 cells do not express CD38, HEK293 cells and fetal bovine serum have been shown to metabolize $\mathrm{NAD}^{+}$precursors into other intermediates. ${ }^{35}$ In our in vitro studies, media 
and treatment was replenished every 24 hours to prevent precursor degradation over the time course of the experiment. Collectively, CD38 activity and other $\mathrm{NAD}^{+}$intermediates may play additional roles in regulating the cardiac sodium channels and cardiac electrophysiology that are not yet known.

An increase in the sustained or late cardiac $\mathrm{Na}^{+}$current, $\mathrm{I}_{\mathrm{Na}, \mathrm{L}}$, seen in congenital long QT syndrome type 3 (LQT3) and in acquired disorders including cardiomyopathies, can induce a pro-arrhythmic state through prolongation of the action potential leading to early afterdepolarizations while also contributing to myocyte sodium and calcium loading. ${ }^{36-38}$ Blockers of $\mathrm{I}_{\mathrm{Na}, \mathrm{L}}$ including flecainide in LQT3 and ranolazine have been studied as potential antiarrhythmic agents. ${ }^{39-41}$ Our data demonstrates a reduction in $\mathrm{I}_{\mathrm{Na}, \mathrm{L}}$ with NR treatment in RNCMs in vitro and QTc shortening after NR supplementation in mice in vivo. A potential mechanism of NR reducing $\mathrm{I}_{\mathrm{Na}, \mathrm{L}}$ may be mitigating oxidative stress. Oxidative stress and reactive oxygen species (ROS) decrease $\mathrm{I}_{\mathrm{Na}}$ and increase $\mathrm{I}_{\mathrm{Na}, \mathrm{L}}$, contributing to electrical and contractile dysfunction in heart failure. ${ }^{42,43}$ The activation of Ca/Calmodulin-Kinase II (CaMKII) and the CaMKII-dependent phosphorylation of $\mathrm{Na}_{\mathrm{V}} 1.5$ is required for oxidative stress to increase $\mathrm{I}_{\mathrm{Na}, \mathrm{L} \cdot{ }^{44}}$ NR supplementation and increased $\mathrm{NAD}^{+}$metabolites may decrease oxidative stress and ROS, leading to lower CaMKII activity and decreased $\mathrm{I}_{\mathrm{Na}, \mathrm{L}}$. NR may have additional effects on other ion channels and their subunits including voltage-gated $\mathrm{K}^{+}$and $\mathrm{Ca}^{+}$channels that mediate repolarizing outward potassium currents and QTc. ${ }^{45} \mathrm{We}$ did not see changes in $\mathrm{K}^{+}$or $\mathrm{Ca}^{2+}$ currents in RNCMs following NR supplementation that would shorten action potential duration and QTc. It is important to note the differences between mouse and human cardiac 
electrophysiology as mouse action potentials are much shorter and regulated by different repolarizing $\mathrm{K}^{+}$currents. $^{46}$

Modulating $\mathrm{Na}_{\mathrm{V}} 1.5$ provides the therapeutic potential for preventing arrhythmias in a variety of inherited and acquired diseases associated with Nav1.5 dysfunction including Brugada Syndrome, sick sinus syndrome, progressive conduction disease, LQT3 and ischemic/nonischemic cardiomyopathies. Our data demonstrates the ability of NR to increase peak $\mathrm{I}_{\mathrm{Na}}$ while reducing $\mathrm{I}_{\mathrm{Na}, \mathrm{L}}$ in heterologous systems and RNCMs. The potential relevance of these findings was reinforced by QTc shortening in mice after dietary supplementation of NR. Collectively, these novel findings provide preclinical evidence and the foundation for further testing of select $\mathrm{NAD}^{+}$precursors for the prevention of arrhythmias in conditions associated with Nav1.5 dysfunction that decreases $\mathrm{I}_{\mathrm{Na}}$ and/or increases $\mathrm{I}_{\mathrm{Na}, \mathrm{L}}$. 


\section{CONCLUSIONS}

Boosting $\mathrm{NAD}^{+}$content using the $\mathrm{NAD}^{+}$precursor NR but not NAM increased peak $\mathrm{I}_{\mathrm{Na}}$ in heterologous expression systems and RNCMs through both acetylation-independent and acetylation-dependent mechanisms. In addition, NR supplementation decreased $\mathrm{I}_{\mathrm{Na}, \mathrm{L}}$ in RNCMs and shortened QTc in mice. These findings reinforce the potential role of the NAD ${ }^{+}$ supplementation in cardiac electrophysiology and warrant investigation of NR supplementation as an antiarrhythmic strategy in inherited and acquired disorders associated with abnormal $\mathrm{Na}^{+}$ currents.

\section{ACKNOWLEDGEMENTS}

We thank Dr. Samuel Dudley (University of Minnesota) for graciously providing the Nav1.5stably expressing HEK293 cell line and Drs. Christopher Ahern and Daniel Infield for helpful discussions and critical reading of the manuscript. Additionally, we would like to thank Julie S. Jacobs for her technical advice throughout the project.

\section{FUNDING}

The work is supported by National Institutes of Health (BL, KI: R01HL115955, BL, KI, CB: R01HL147545, RLB: R01HL144717, DSM: F30HL137272, AMG: F30HL143908), the American Heart Association (DSM: Midwest Affiliate Predoctoral Fellowship \#17PRE33410450, JMM: Postdoctoral Fellowship 19POST34380640). DSM and AMG are supported by the National Institutes of Health supported Medical Scientist Training Program at the University of Iowa (T32GM007337). JMM was supported by the National Institutes of Health Institutional Cardiovascular Research Fellowship (T32HL007121). This research is also 
supported by the American Federation for Aging Research Scholarship for Research in the Biology of Aging (DSM).

\section{Abbreviations}

\begin{tabular}{|c|c|}
\hline $\mathrm{Na}_{\mathrm{v}} 1.5$ & cardiac sodium channel \\
\hline $\mathrm{I}_{\mathrm{Na}}$ & $\mathrm{Na}^{+}$current \\
\hline $\mathrm{I}_{\mathrm{Na}, \mathrm{L}}$ & late $\mathrm{Na}^{+}$current \\
\hline SCN5A & $\begin{array}{l}\text { cardiac sodium channel } \\
\text { gene }\end{array}$ \\
\hline $\mathrm{PKC}$ & Protein Kinase C \\
\hline PKA & Protein Kinase A \\
\hline SIRT1 & Sirtuin 1 \\
\hline RNCM & $\begin{array}{l}\text { Neonatal Rat } \\
\text { Cardiomyocyte }\end{array}$ \\
\hline meNAM & N1-methylnicotinamide \\
\hline NAM & Nicotinamide \\
\hline $\mathrm{NR}$ & Nicotinamide Riboside \\
\hline LQT3 & $\begin{array}{l}\text { Long QT Syndrome Type } \\
3\end{array}$ \\
\hline CD38 & $\begin{array}{l}\text { cluster of differentiation } \\
38\end{array}$ \\
\hline PARP & $\begin{array}{l}\text { Poly-ADP-Ribose } \\
\text { Polymerases }\end{array}$ \\
\hline $\mathrm{NADP}^{+}$ & \begin{tabular}{|l} 
nicotinamide adenine \\
dinucleotide phosphate
\end{tabular} \\
\hline $\mathrm{NAD}^{+}$ & $\begin{array}{l}\beta \text { - nicotinamide adenine } \\
\text { dinucleotide }\end{array}$ \\
\hline $\mathrm{NADH}$ & $\begin{array}{l}\text { reduced form of } \\
\text { nicotinamide adenine } \\
\text { dinucleotide }\end{array}$ \\
\hline
\end{tabular}




\section{REFERENCES}

1. Veerman CC, Wilde AA and Lodder EM. The cardiac sodium channel gene SCN5A and its gene product NaV1.5: Role in physiology and pathophysiology. Gene. 2015;573:177-87.

2. Brugada $J$ and Brugada P. Further characterization of the syndrome of right bundle branch block, ST segment elevation, and sudden cardiac death. J Cardiovasc Electrophysiol. 1997;8:325-31.

3. Grant AO. Electrophysiological basis and genetics of Brugada syndrome. J Cardiovasc Electrophysiol. 2005;16 Suppl 1:S3-7.

4. Wang DW, Viswanathan PC, Balser JR, George AL, Jr. and Benson DW. Clinical, genetic, and biophysical characterization of SCN5A mutations associated with atrioventricular conduction block. Circulation. 2002;105:341-6.

5. Yan GX and Antzelevitch C. Cellular basis for the Brugada syndrome and other mechanisms of arrhythmogenesis associated with ST-segment elevation. Circulation. 1999;100:1660-6.

6. Liu M, Yang KC and Dudley SC, Jr. Cardiac Sodium Channel Mutations: Why so Many Phenotypes? Curr Top Membr. 2016;78:513-59.

7. Remme CA. Cardiac sodium channelopathy associated with SCN5A mutations: electrophysiological, molecular and genetic aspects. J Physiol. 2013;591:4099-116.

8. Savio-Galimberti E, Argenziano M and Antzelevitch C. Cardiac Arrhythmias Related to Sodium Channel Dysfunction. Handb Exp Pharmacol. 2018;246:331-354.

9. Makielski JC. Late sodium current: A mechanism for angina, heart failure, and arrhythmia. Trends Cardiovasc Med. 2016;26:115-22.

10. Remme CA and Bezzina CR. Sodium channel (dys)function and cardiac arrhythmias. Cardiovasc Ther. 2010;28:287-94.

11. Matasic DS, Brenner C and London B. Emerging potential benefits of modulating NAD(+) metabolism in cardiovascular disease. Am J Physiol Heart Circ Physiol. 2018;314:H839H852.

12. Liu M, Sanyal S, Gao G, Gurung IS, Zhu X, Gaconnet G, Kerchner LJ, Shang LL, Huang CL, Grace A, London B and Dudley SC, Jr. Cardiac Na+ current regulation by pyridine nucleotides. Circ Res. 2009;105:737-45.

13. Liu M, Shi G, Yang KC, Gu L, Kanthasamy AG, Anantharam V and Dudley SC, Jr. Role of protein kinase $\mathrm{C}$ in metabolic regulation of the cardiac $\mathrm{Na}(+)$ channel. Heart Rhythm. 2017; 14:440-447.

14. Valdivia CR, Ueda K, Ackerman MJ and Makielski JC. GPD1L links redox state to cardiac excitability by PKC-dependent phosphorylation of the sodium channel SCN5A. Am J Physiol Heart Circ Physiol. 2009;297:H1446-52.

15. Vikram A, Lewarchik CM, Yoon JY, Naqvi A, Kumar S, Morgan GM, Jacobs JS, Li Q, Kim YR, Kassan M, Liu J, Gabani M, Kumar A, Mehdi H, Zhu X, Guan X, Kutschke W, Zhang X, Boudreau RL, Dai S, Matasic DS, Jung SB, Margulies KB, Kumar V, Bachschmid MM, London B and Irani K. Sirtuin 1 regulates cardiac electrical activity by deacetylating the cardiac sodium channel. Nat Med. 2017;23:361-367.

16. Xu Q, Patel D, Zhang X and Veenstra RD. Changes in cardiac Nav1.5 expression, function, and acetylation by pan-histone deacetylase inhibitors. Am J Physiol Heart Circ Physiol. 2016;311:H1139-H1149.

17. Nicotinamide Riboside in LVAD Recipients (PilotNR-LVAD, NCT03727646). US National Library of Medicine. 2018; clinicaltrials.gov. 
18. Nicotinamide Riboside in Systolic Heart Failure (NCT03423342). US National Library of Medicine. 2018; clinicaltrials.gov.

19. Effects of Nicotinamide Riboside on Metabolism and Vascular Function (NCT03501433). US National Library of Medicine. 2018; clinicaltrials.gov.

20. Nicotinamide Riboside for Treating Elevated Systolic Blood Pressure and Arterial Stiffness in Middle-aged and Older Adults (NCT03821623). US National Library of Medicine. 2019; clinicaltrials.gov.

21. Trammell SA and Brenner C. Targeted, LCMS-based Metabolomics for Quantitative Measurement of NAD(+) Metabolites. Comput Struct Biotechnol J. 2013;4:e201301012.

22. London B, Jeron A, Zhou J, Buckett P, Han X, Mitchell GF and Koren G. Long QT and ventricular arrhythmias in transgenic mice expressing the $\mathrm{N}$ terminus and first transmembrane segment of a voltage-gated potassium channel. Proc Natl Acad Sci US A. 1998;95:2926-31.

23. Mitchell GF, Jeron A and Koren G. Measurement of heart rate and Q-T interval in the conscious mouse. Am J Physiol. 1998;274:H747-51.

24. Rasmussen TP, Wu Y, Joiner ML, Koval OM, Wilson NR, Luczak ED, Wang Q, Chen B, Gao Z, Zhu Z, Wagner BA, Soto J, McCormick ML, Kutschke W, Weiss RM, Yu L, Boudreau RL, Abel ED, Zhan F, Spitz DR, Buettner GR, Song LS, Zingman LV and Anderson ME. Inhibition of MCU forces extramitochondrial adaptations governing physiological and pathological stress responses in heart. Proc Natl Acad Sci US A. 2015;112:9129-34.

25. Liu M, Gu L, Sulkin MS, Liu H, Jeong EM, Greener I, Xie A, Efimov IR and Dudley SC, Jr. Mitochondrial dysfunction causing cardiac sodium channel downregulation in cardiomyopathy. J Mol Cell Cardiol. 2013;54:25-34.

26. Ratajczak J, Joffraud M, Trammell SA, Ras R, Canela N, Boutant M, Kulkarni SS, Rodrigues M, Redpath P, Migaud ME, Auwerx J, Yanes O, Brenner C and Canto C. NRK1 controls nicotinamide mononucleotide and nicotinamide riboside metabolism in mammalian cells. Nat Commun. 2016;7:13103.

27. Herfst LJ, Rook MB and Jongsma HJ. Trafficking and functional expression of cardiac $\mathrm{Na}+$ channels. J Mol Cell Cardiol. 2004;36:185-93.

28. Zhang X, Yoon JY, Morley M, McLendon JM, Mapuskar KA, Gutmann R, Mehdi H, Bloom HL, Dudley SC, Ellinor PT, Shalaby AA, Weiss R, Tang WHW, Moravec CS, Singh M, Taylor AL, Yancy CW, Feldman AM, McNamara DM, Irani K, Spitz DR, Breheny P, Margulies KB, London B and Boudreau RL. A common variant alters SCN5A-miR-24 interaction and associates with heart failure mortality. J Clin Invest. 2018;128:1154-1163.

29. Aiba T, Farinelli F, Kostecki G, Hesketh GG, Edwards D, Biswas S, Tung L and Tomaselli GF. A mutation causing Brugada syndrome identifies a mechanism for altered autonomic and oxidant regulation of cardiac sodium currents. Circ Cardiovasc Genet. 2014;7:249-56.

30. Zhou J, Shin HG, Yi J, Shen W, Williams CP and Murray KT. Phosphorylation and putative ER retention signals are required for protein kinase A-mediated potentiation of cardiac sodium current. Circ Res. 2002;91:540-6.

31. Tateyama M, Rivolta I, Clancy CE and Kass RS. Modulation of cardiac sodium channel gating by protein kinase A can be altered by disease-linked mutation. J Biol Chem. 2003;278:46718-26.

32. Bai P. Biology of Poly(ADP-Ribose) Polymerases: The Factotums of Cell Maintenance. Mol Cell. 2015;58:947-58. 
33. Virag L and Szabo C. The therapeutic potential of poly(ADP-ribose) polymerase inhibitors. Pharmacol Rev. 2002;54:375-429.

34. Camacho-Pereira J, Tarrago MG, Chini CCS, Nin V, Escande C, Warner GM, Puranik AS, Schoon RA, Reid JM, Galina A and Chini EN. CD38 Dictates Age-Related NAD Decline and Mitochondrial Dysfunction through an SIRT3-Dependent Mechanism. Cell Metab. 2016;23:1127-1139.

35. Kulikova V, Shabalin K, Nerinovski K, Yakimov A, Svetlova M, Solovjeva L, Kropotov A, Khodorkovskiy M, Migaud ME, Ziegler M and Nikiforov A. Degradation of Extracellular NAD(+) Intermediates in Cultures of Human HEK293 Cells. Metabolites. 2019;9.

36. Moreno JD and Clancy CE. Pathophysiology of the cardiac late Na current and its potential as a drug target. J Mol Cell Cardiol. 2012;52:608-19.

37. Rivaud MR, Baartscheer A, Verkerk AO, Beekman L, Rajamani S, Belardinelli L, Bezzina $\mathrm{CR}$ and Remme CA. Enhanced late sodium current underlies pro-arrhythmic intracellular sodium and calcium dysregulation in murine sodium channelopathy. Int J Cardiol. 2018;263:54-62.

38. Song Y, Shryock JC and Belardinelli L. An increase of late sodium current induces delayed afterdepolarizations and sustained triggered activity in atrial myocytes. Am J Physiol Heart Circ Physiol. 2008;294:H2031-9.

39. Nagatomo T, January CT and Makielski JC. Preferential block of late sodium current in the LQT3 DeltaKPQ mutant by the class I(C) antiarrhythmic flecainide. Mol Pharmacol. 2000;57:101-7.

40. Doshi D and Morrow JP. Potential application of late sodium current blockade in the treatment of heart failure and atrial fibrillation. Rev Cardiovasc Med. 2009;10 Suppl 1:S4652.

41. Fukaya H, Plummer BN, Piktel JS, Wan X, Rosenbaum DS, Laurita KR and Wilson LD. Arrhythmogenic cardiac alternans in heart failure is suppressed by late sodium current blockade by ranolazine. Heart Rhythm. 2019;16:281-289.

42. Valdivia CR, Chu WW, Pu J, Foell JD, Haworth RA, Wolff MR, Kamp TJ and Makielski JC. Increased late sodium current in myocytes from a canine heart failure model and from failing human heart. J Mol Cell Cardiol. 2005;38:475-83.

43. Liu M, Liu H and Dudley SC, Jr. Reactive oxygen species originating from mitochondria regulate the cardiac sodium channel. Circ Res. 2010;107:967-74.

44. Xie LH, Chen F, Karagueuzian HS and Weiss JN. Oxidative-stress-induced afterdepolarizations and calmodulin kinase II signaling. Circ Res. 2009;104:79-86.

45. Kilfoil PJ, Tipparaju SM, Barski OA and Bhatnagar A. Regulation of ion channels by pyridine nucleotides. Circ Res. 2013;112:721-41.

46. Salama G and London B. Mouse models of long QT syndrome. J Physiol. 2007;578:43-53. 


\section{A}

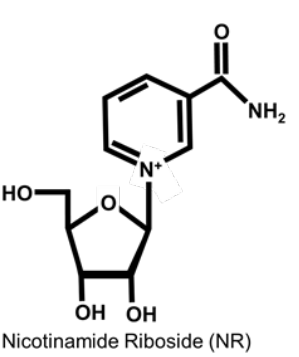

D

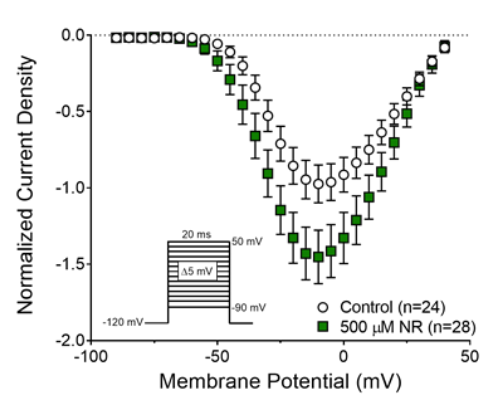

G

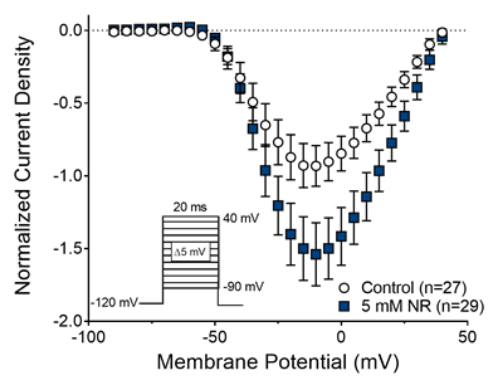

B

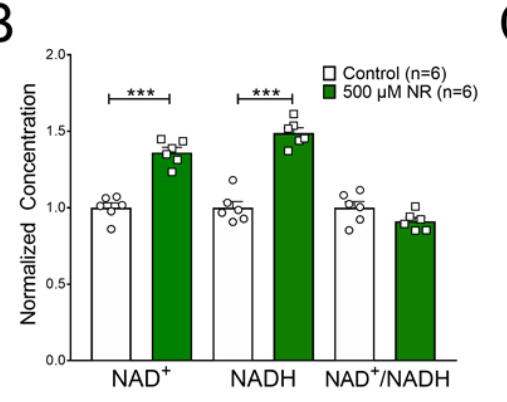

E

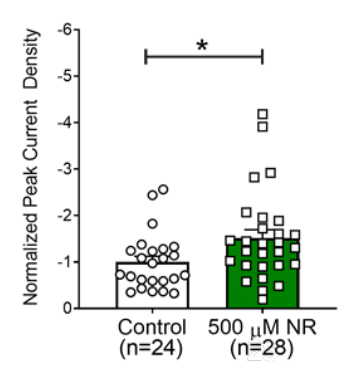

$\mathrm{H}$

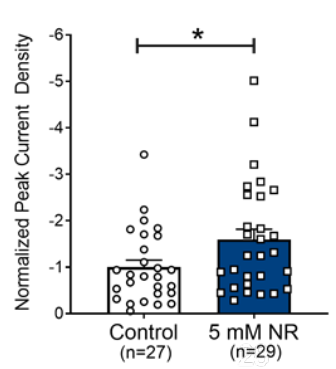

C
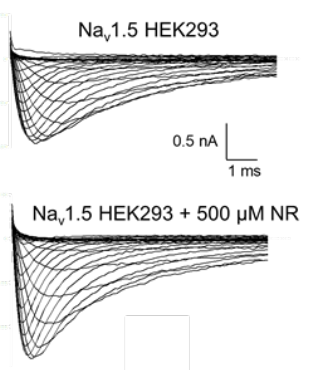

F

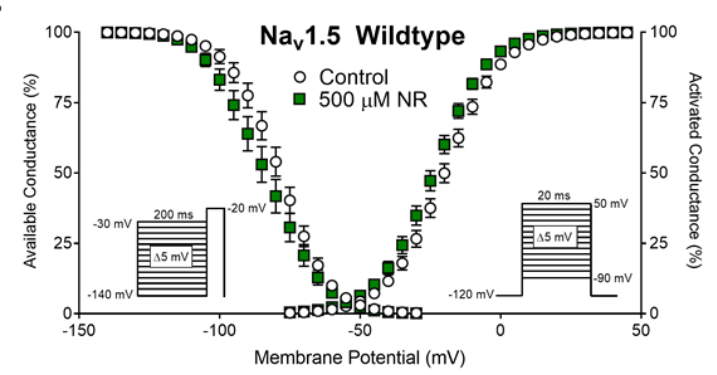

I

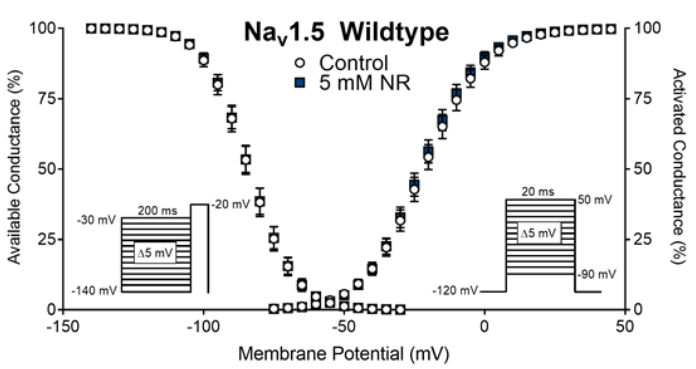

Figure 1. Nicotinamide Riboside (NR) increases $\mathrm{I}_{\mathrm{Na}}$ without a change in $\mathrm{NAD}^{+} / \mathrm{NADH}$ ratio in HEK293 cells stably-expressing and transiently-expressing Nav1.5. (A) Structure of NR, (B) Quantification of $\mathrm{NAD}^{+}$and NADH demonstrating significantly elevated levels of both metabolites, without altering the $\mathrm{NAD}^{+} / \mathrm{NADH}$ ratio, with $\mathrm{NR}$ supplementation (C) Representative traces of $\mathrm{I}_{\mathrm{Na}}$, (D) current-voltage (I-V) relationship, and (E) normalized peak current density between HEK293 cells stably-expressing Nav1.5 with and without NR supplementation (500 $\mu \mathrm{M}, 48$ hours) illustrate that NR increases $\mathrm{I}_{\mathrm{Na}}$. (F) Gating properties including steady-state activation and inactivation are relatively unchanged, with only a $4 \mathrm{mV}$ hyperpolarizing shift in activation, with NR supplementation. (G-I) Similar results are observed in HEK293 cells transiently-transfected with $\mathrm{Na}_{\mathrm{V}} 1.5$ (5 mM NR, 48 hours). Differences between groups were statistically determined utilizing unpaired t-tests $(* \mathrm{p}<0.05, * * * \mathrm{p}<0.001)$. 
A

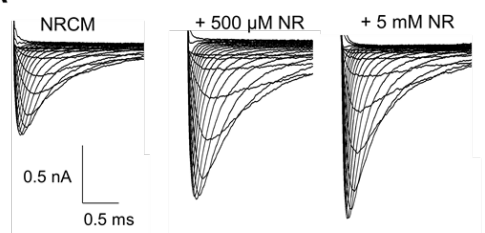

D

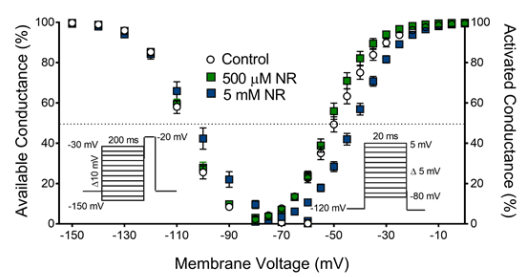

G

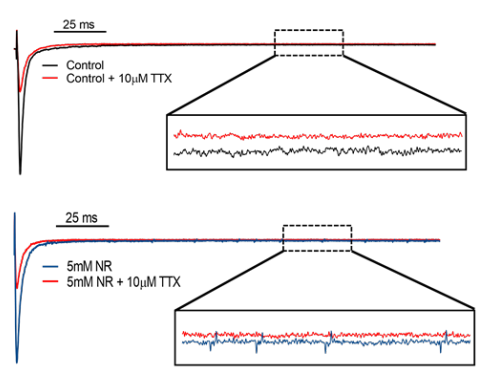

$\mathrm{B}$

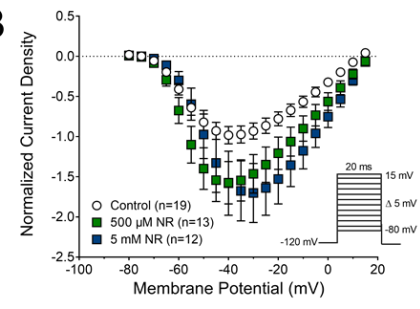

E
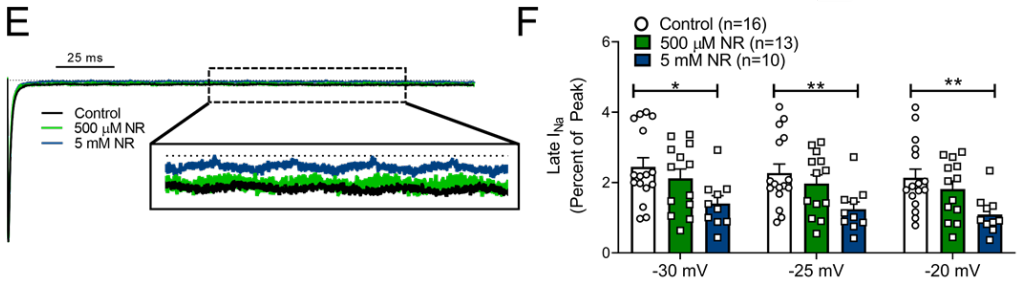

$\mathrm{H}$

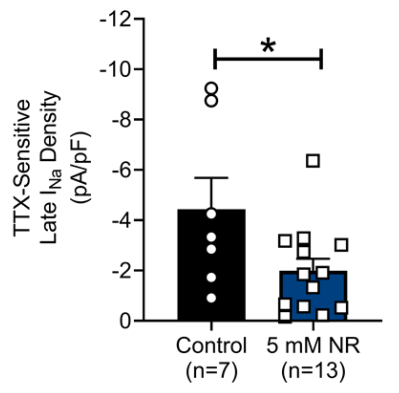

F

C

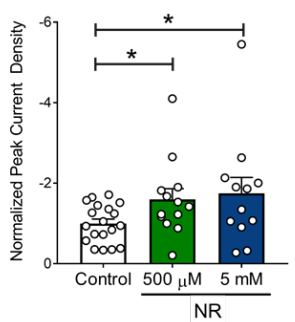

I

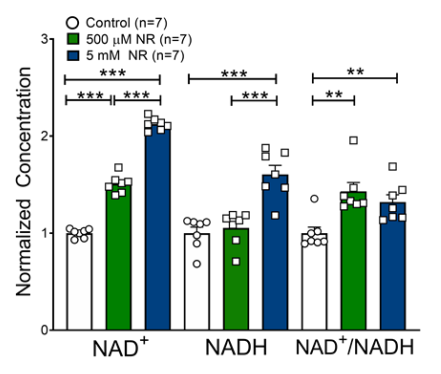

Figure 2. Nicotinamide Riboside (NR) increases $I_{\mathrm{Na}}$ with dose-dependent effects on gating properties in Neonatal Rat Cardiomyocytes. (A) Representative current traces, (B) I-V curve, and (C) normalized peak current density of rat myocytes treated with NR for 48 hours. (D) Gating properties of steady-state activation and inactivation (E-F) Representative traces and quantification of $\mathrm{I}_{\mathrm{Na}, \mathrm{L}}$ (G-I) Representative traces and quantification of tetrodotoxin (TTX)-sensitive changes in $\mathrm{I}_{\mathrm{Na}, \mathrm{L}}$. (I) $\mathrm{NAD}^{+}, \mathrm{NADH}$, and $\mathrm{NAD}^{+} / \mathrm{NADH}$ ratio quantified in rat myocytes after 24-hour $\mathrm{NR}$ treatment $(500 \mu \mathrm{M}$ or $5 \mathrm{mM})$. Differences between groups were statistically determined utilizing unpaired t-tests $\left(* \mathrm{p}<0.05,{ }^{* *} \mathrm{p}<0.01,{ }^{* * *} \mathrm{p}<0.001\right)$. 


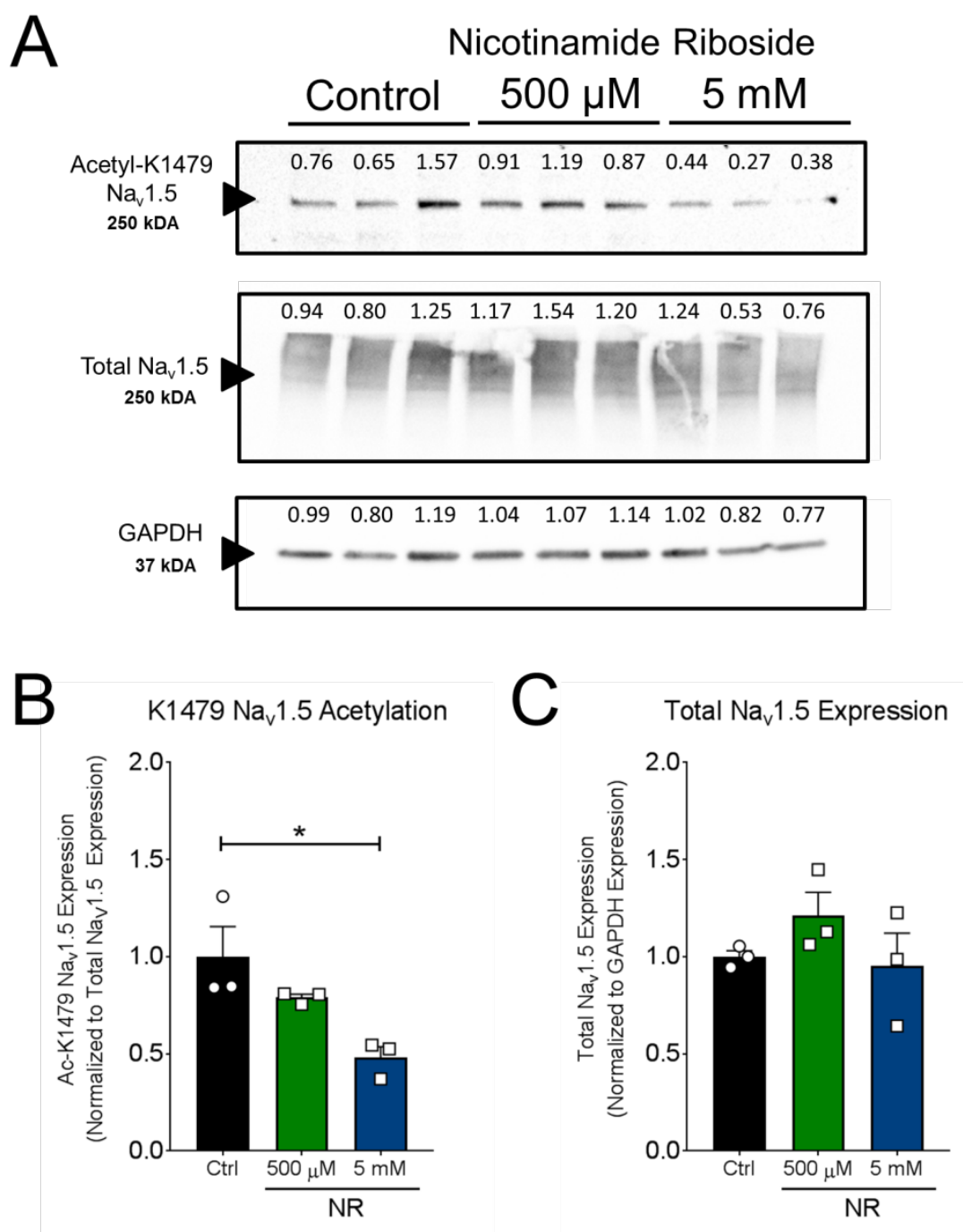

Figure 3. Nicotinamide Riboside supplementation decreases K1479 acetylation in Nav1.5HEK293 cells. (A) Acetylated K1479 $\mathrm{Na}_{\mathrm{V}} 1.5$, total $\mathrm{Na}$ 1.5, and GAPDH expression in HEK293 cells transiently-transfected cells Nav1.5 and treated with $\mathrm{NR}(500 \mu \mathrm{M}$ or $5 \mathrm{mM}, 48$ hours $)$ or $\mathrm{H}_{2} \mathrm{O}$. (B) Acetylated K1479 was normalized to total $\mathrm{Na}_{V} 1.5$ expression and (C) total $\mathrm{Na}_{V} 1.5$ expression was normalized to GAPDH expression. Differences between groups were statistically determined utilizing One-Way ANOVA tests with multiple comparisons $\left({ }^{*} p<0.05\right)$. 
A

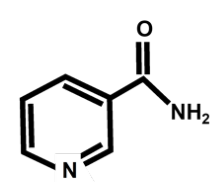

Nicotinamide (NAM)
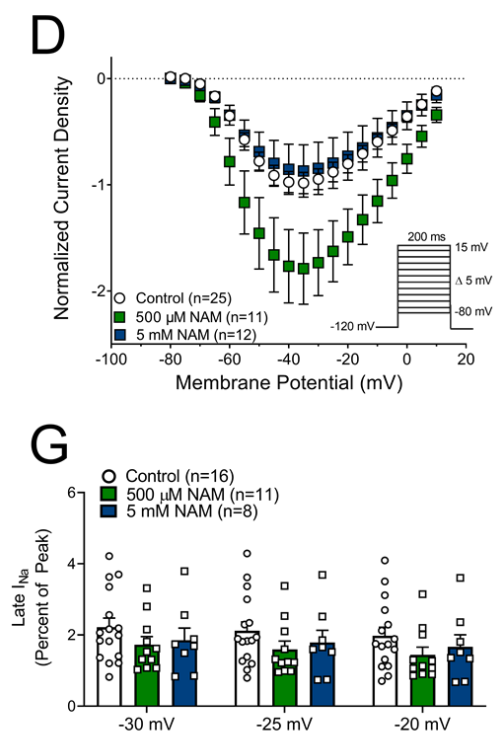
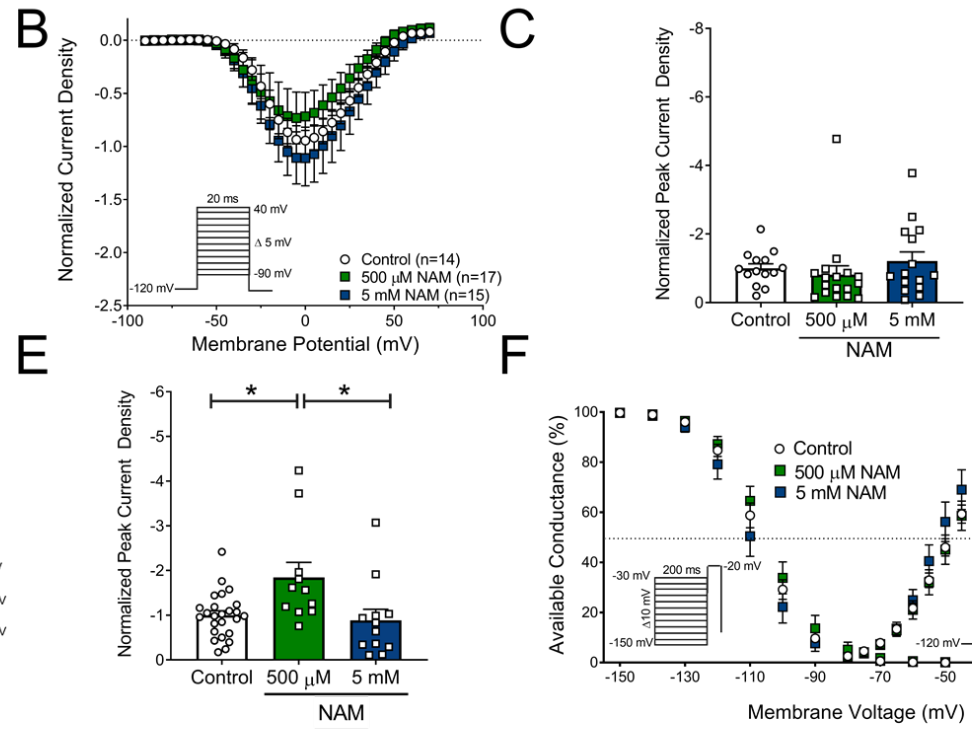

$\mathrm{F}$

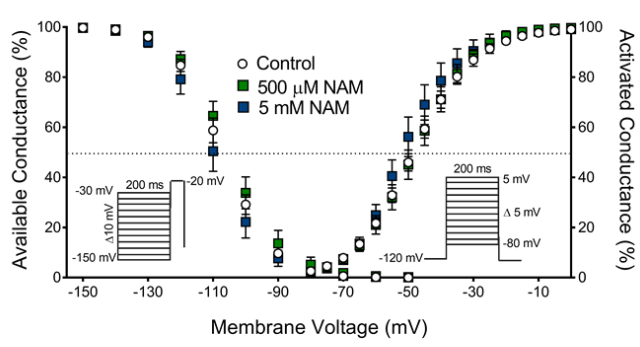

$\mathrm{H}$

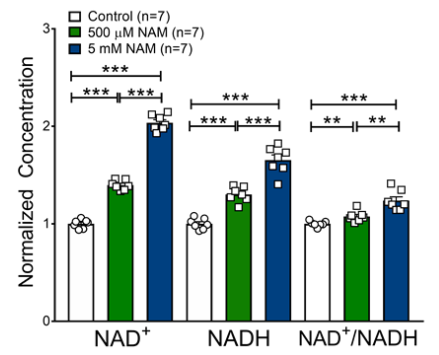

Figure 4. Nicotinamide (NAM), an alternative $\mathrm{NAD}^{+}$precursor, does not modulate Nav1.5 in HEK293 cells transiently transfected with Nav1.5 but dose-dependently modulates Nav1.5 in RNCMs (A) Structure of NAM, (B) I-V curve, and (C) normalized peak current density of HEK293 cells transiently transfected with $\mathrm{Na}_{\mathrm{v}} 1.5$ and administered NAM $(500 \mu \mathrm{M}$ or $5 \mathrm{mM}, 48$ hours). (D, E) The effect of NAM supplementation ( $500 \mu \mathrm{M}$ or $5 \mathrm{mM}, 24$ hours) on I-V curve and normalized peak current density illustrates dose-dependent effects on Nav1.5 activity in RNCMs. $500 \mu \mathrm{M}$ NAM stimulates $\mathrm{I}_{\mathrm{Na}}$ whereas $5 \mathrm{mM}$ NAM has no effect on $\mathrm{I}_{\mathrm{Na}}$. (F) Gating properties of steady-state activation and inactivation. (G) Late current, $\mathrm{I}_{\mathrm{Na}, \mathrm{L}}$, in RNCMs treated with NAM (H) $\mathrm{NAD}^{+}, \mathrm{NADH}$, and $\mathrm{NAD}^{+} / \mathrm{NADH}$ ratio quantified in RNCMs after 24-hour NAM treatment. Differences between groups were statistically determined utilizing unpaired t-tests $\left({ }^{*} \mathrm{p}<0.05\right.$, $* * \mathrm{p}<0.01, * * * \mathrm{p}<0.001)$. 
A

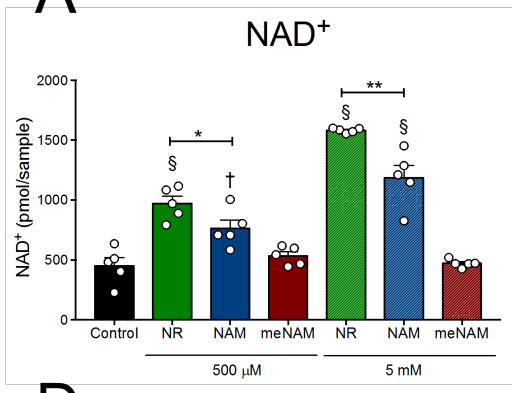

$\mathrm{D}$
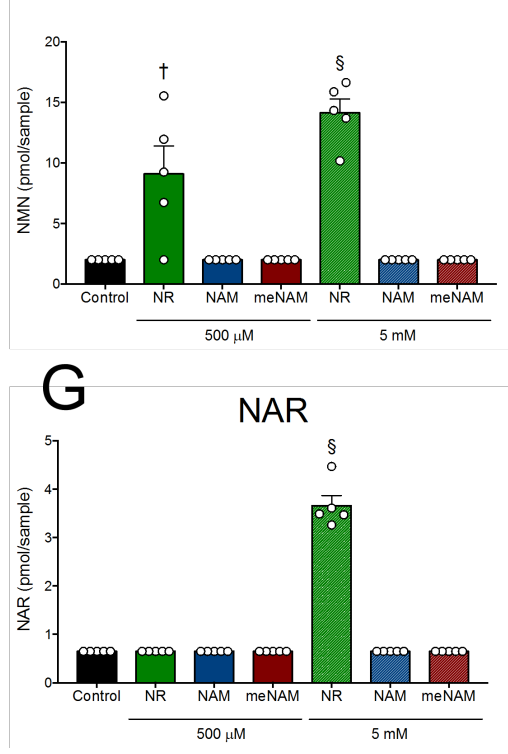

B

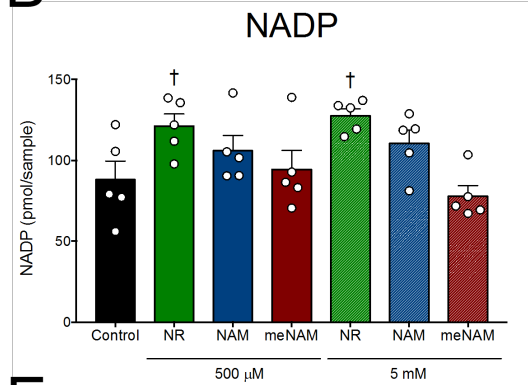

E

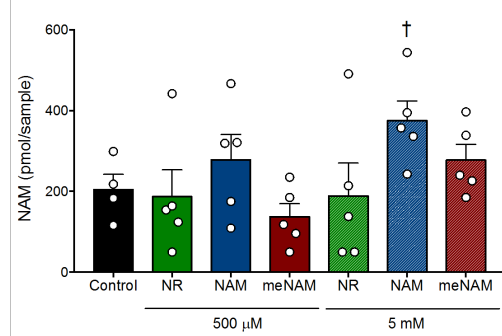

$\mathrm{H}$

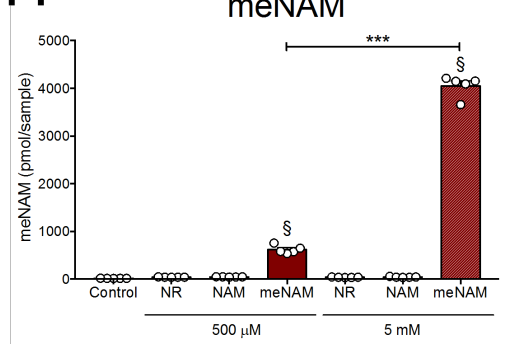

NAAD

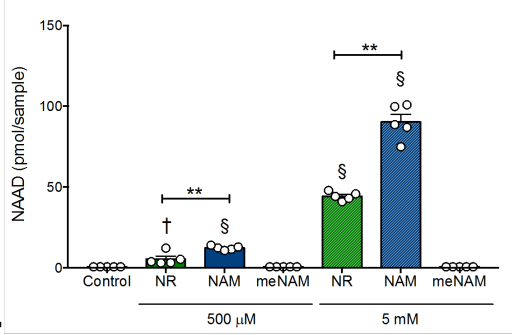

NR

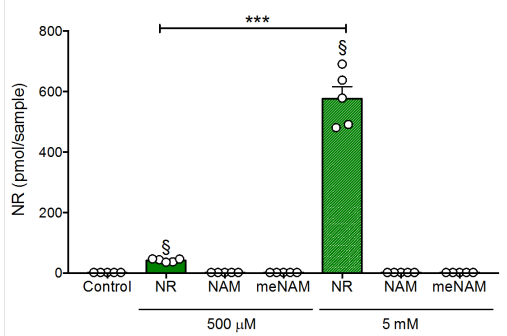

ADPR

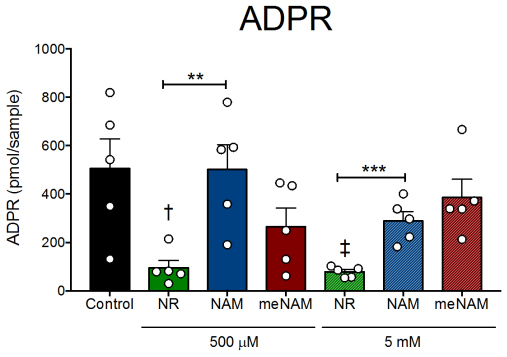

Figure 5. $\mathrm{NAD}^{+}$precursors Nicotinamide Riboside (NR) and Nicotinamide (NAM) increases NAD ${ }^{+}$Content in Neonatal Rat Cardiomyocytes. (A-I) NAD ${ }^{+}$, NADP, NAAD, NMN, NAM, NR, NAR, meNAM, and ADPR were assessed by LC-MS in cellular extracts of neonatal rat cardiomyocytes treated with either $\mathrm{H}_{2} \mathrm{O}, \mathrm{NR}, \mathrm{NAM}$, or meNAM ( $500 \mu \mathrm{M}$ or $5 \mathrm{mM}, 24$ hours). Differences between groups were statistically determined utilizing unpaired t-tests $\left({ }^{*} \mathrm{p}<0.05,{ }^{* *} \mathrm{p}<0.01,{ }^{* * *} \mathrm{p}<0.001 \mathrm{vs}\right.$. respective groups and ${ }^{\dagger} \mathrm{p}<0.05,{ }^{\star} \mathrm{p}<0.05,{ }^{\S} \mathrm{p}<0.001 \mathrm{vs}$. control). 
A

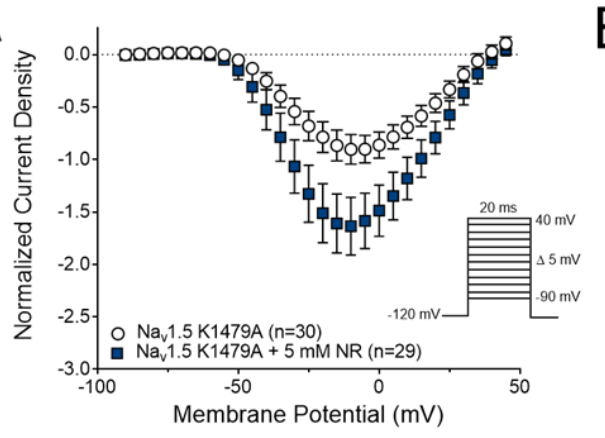

$\mathrm{D}$

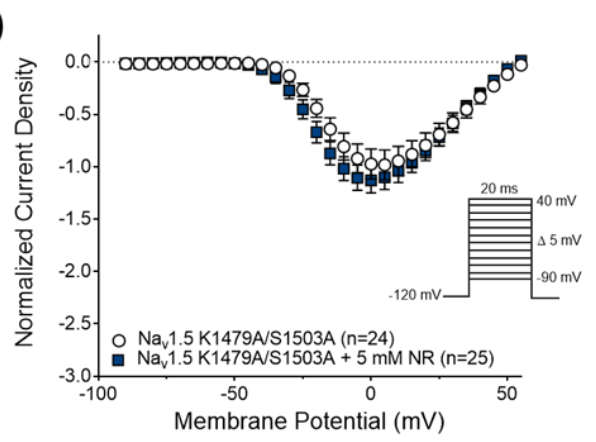

$\mathrm{G}$

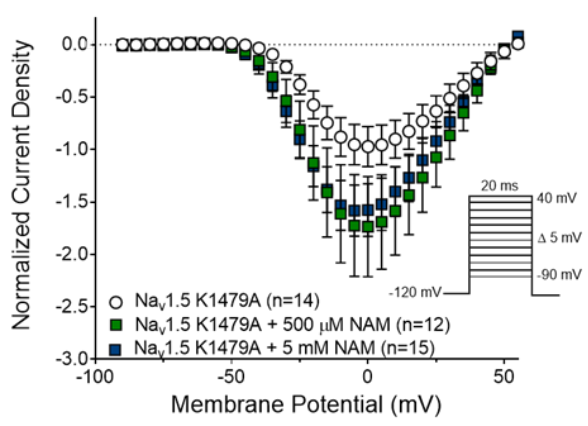

B

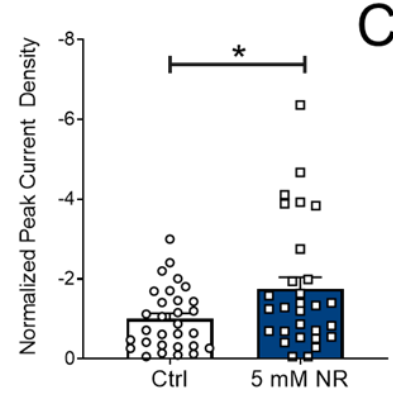

E $\quad F$

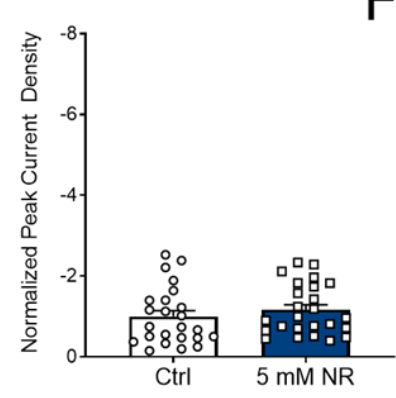

$\mathrm{H}$

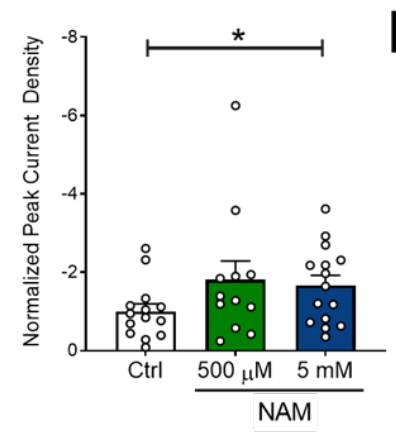

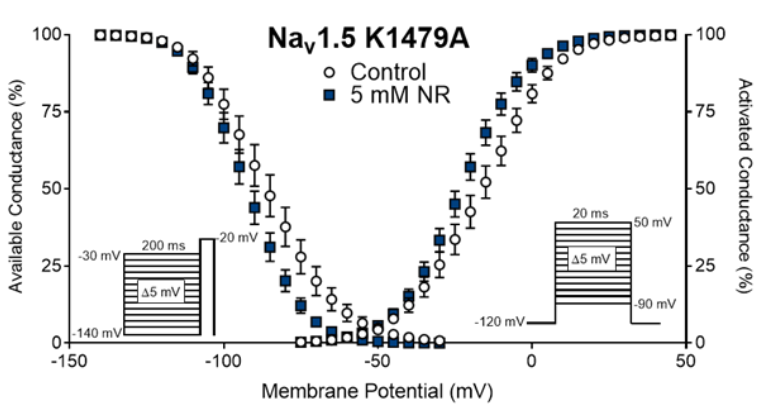

$\mathrm{F}$
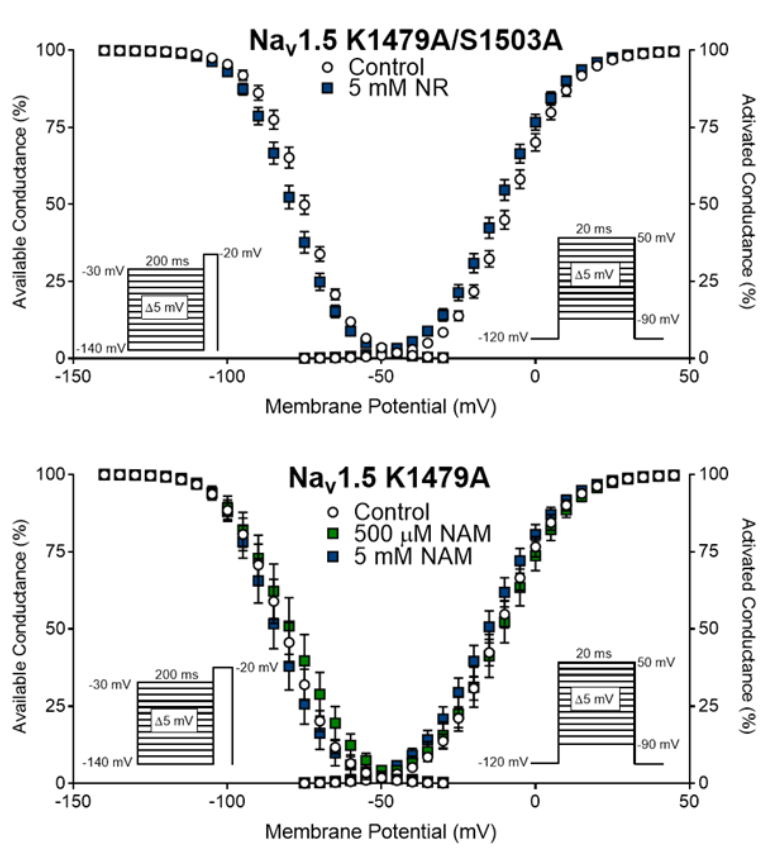

Figure 6. The Role of the Nav1.5 Acetylation K1479 and Phosphorylation S1503 sites in mediating the effect of $\mathrm{NAD}^{+}$precursors. The I-V relationship, peak current density, and steady-state activation and inactivation of HEK293 cells transiently transfected with: (A-C) the mutant Nav1.5 K1479A channel with and without the administration of NR (5 mM, 48 hours), (D-F) the mutant Nav1.5 K1479A/S1503A channel with and without the administration of NR ( $5 \mathrm{mM}, 48$ hours), and (G-I) the mutant Nav1.5 K1479A channel with and without the administration of NAM $(500 \mu \mathrm{M}$ or $5 \mathrm{mM}, 48$ hours). Differences between normalized peak current densities were statistically determined utilizing unpaired t-tests $(* \mathrm{p}<0.05)$. 


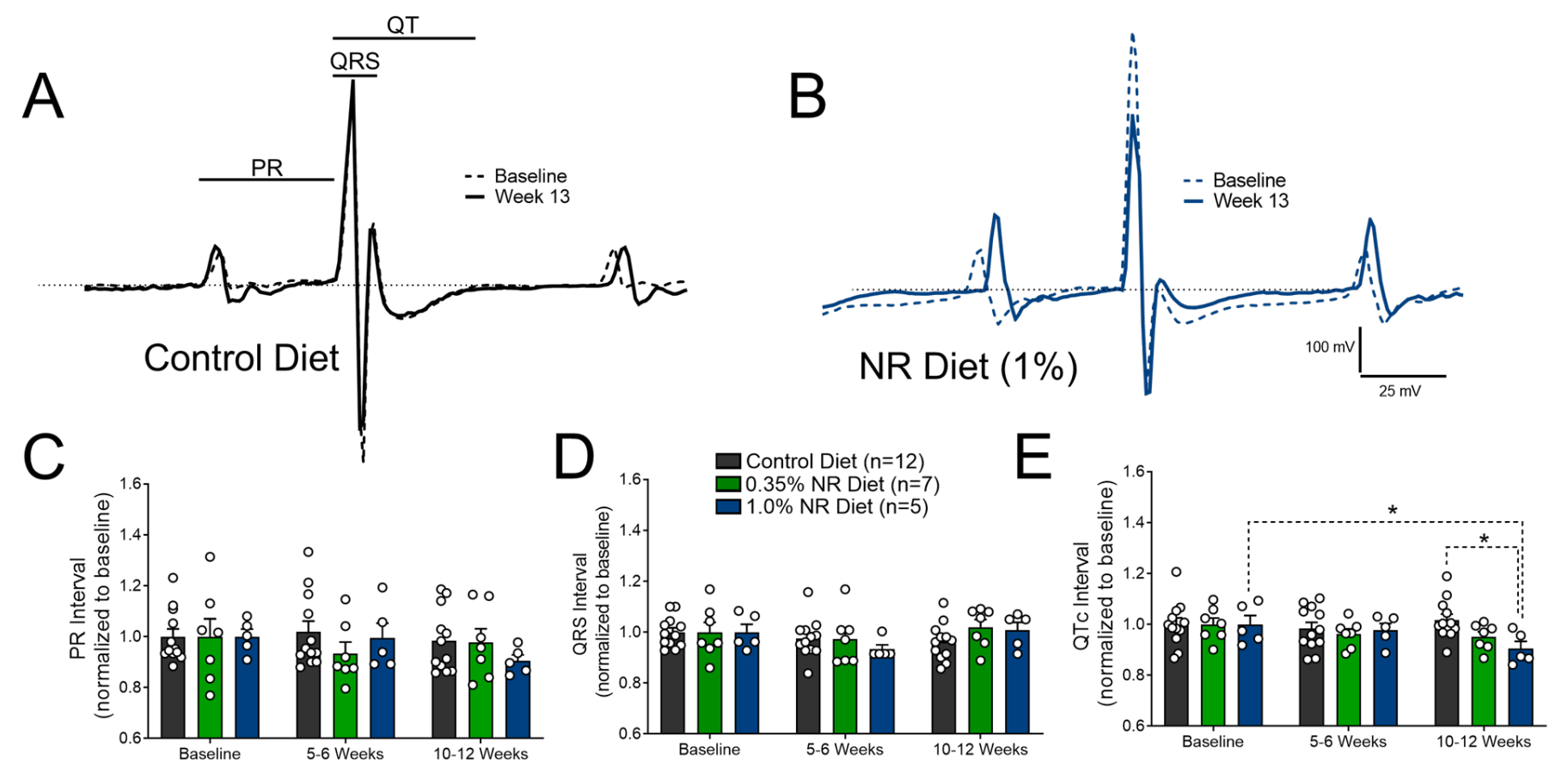

Figure 7. Dietary Supplementation of Nicotinamide Riboside Modulates Cardiac Repolarization. 4-6 month old wild-type C57BL/6 mice were randomly placed on either a control diet or diet supplemented with NR ( $0.35 \%$ or $1 \%)$. Cardiac electrophysiological changes were assessed by EKG. (A, B) Representative Lead II EKG traces overlaying baseline (dashed line) and 10-12 weeks post-diet (solid line) for mice on either control diet or diet supplemented with 1.0\% NR. (C) PR interval, (D) QRS interval, and (E) QTc duration were measured. Significance between groups and within a group at each timepoint was determined by Two-way ANOVA with Bonferroni post-hoc multiple-comparisons test. $\left({ }^{*} \mathrm{p}<0.05\right)$. 


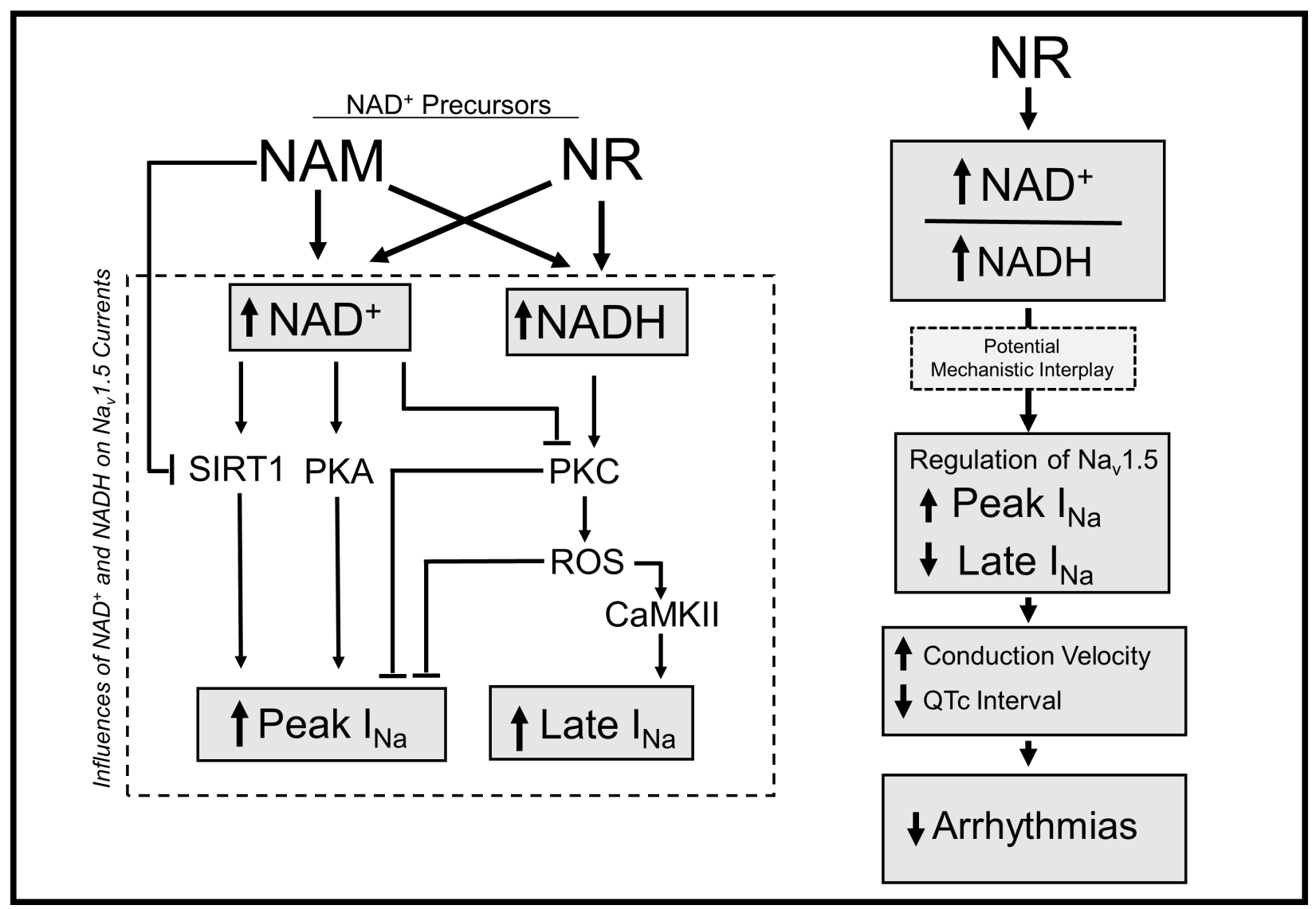

Figure 8. Model of NAD ${ }^{+}$Precursor Modulation of Nav1.5. 


\section{SUPPLEMENTARY DATA}
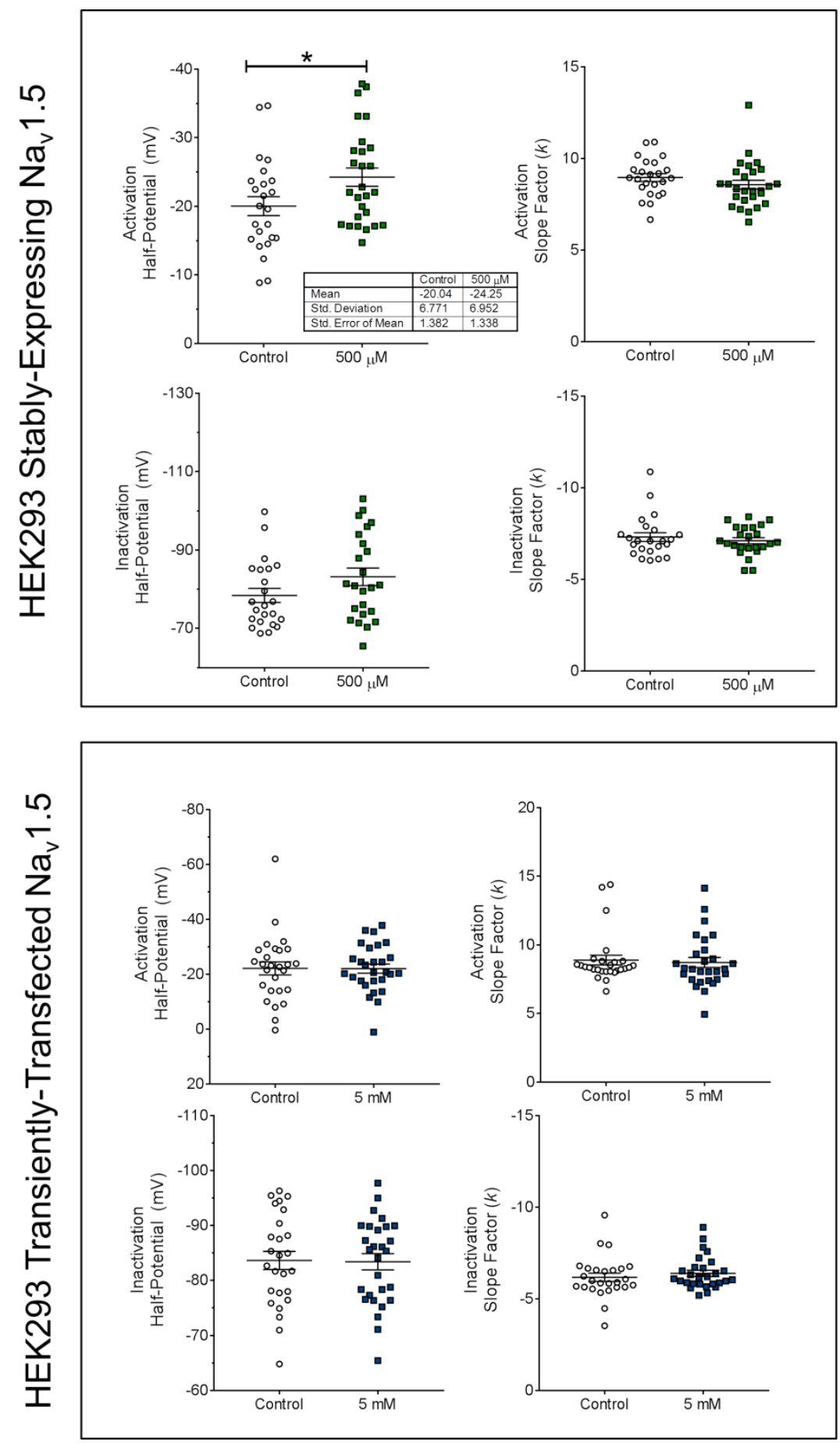

Figure S1. The Effect of Nicotinamide Riboside (NR) on Nav1.5 Gating Properties in HEK293 Cells. $\mathrm{Na}_{\mathrm{v}} 1.5$ Gating properties (including half-maximal potentials and slope factors) for steady-state activation and inactivation for (Top) HEK293 cells stably-expressing Nav1.5 and treated with $500 \mu \mathrm{M}$ for 48 hours and (Bottom) HEK293 cells transiently transfected with Nav1.5 and treated with $5 \mathrm{mM}$ NR for 48 hours. Differences between groups were statistically determined utilizing unpaired t-tests $(* \mathrm{p}<0.05)$. 

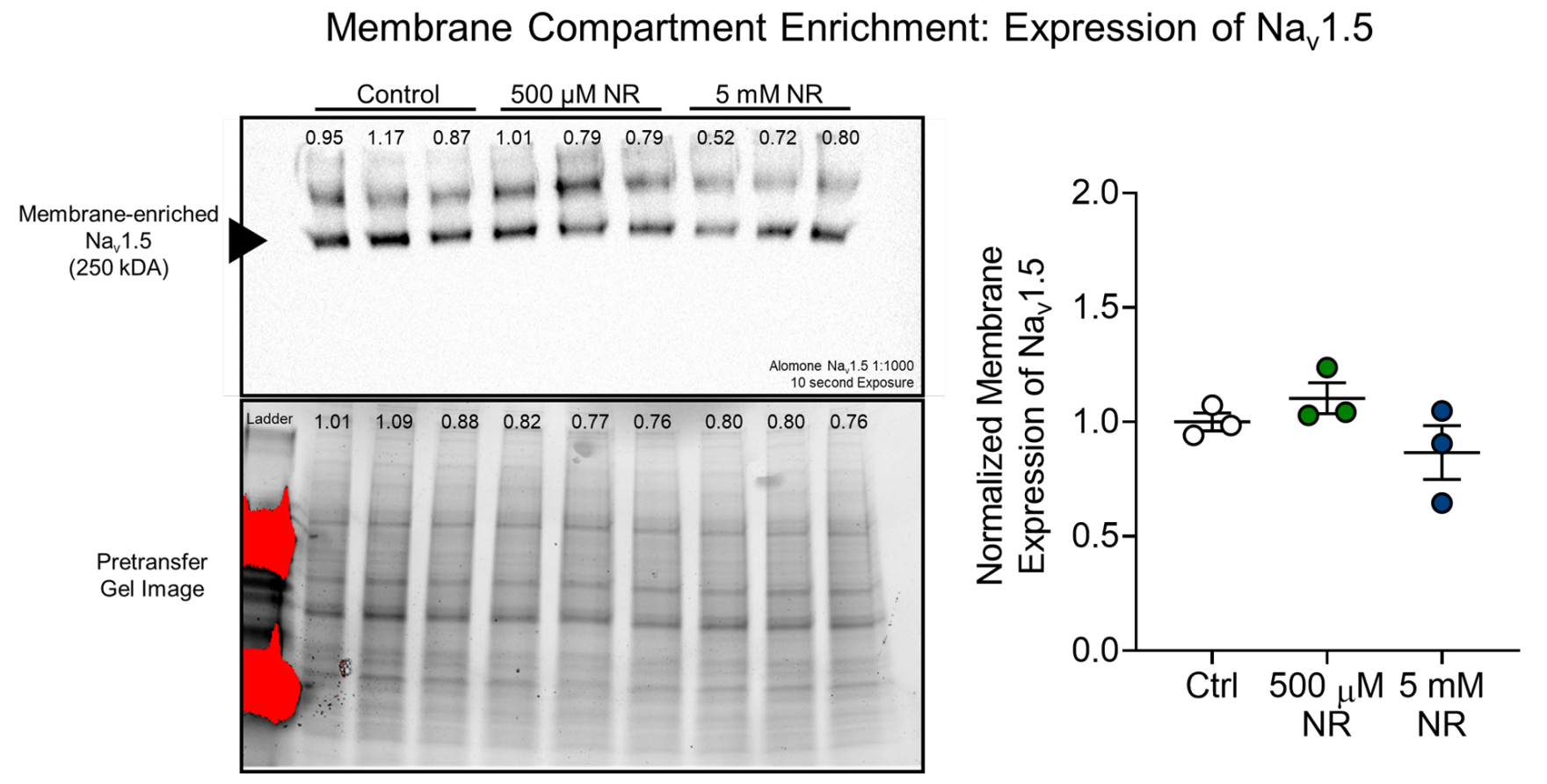

Figure S2. The Effect of Nicotinamide Riboside (NR) on Membrane Expression of $\mathrm{Na}_{\mathrm{v}} 1.5$ in HEK293 Cells stably-expressing Nav1.5. HEK293 cells stably expressing $\mathrm{Na}_{\mathrm{v}} 1.5$ were treated with $\mathrm{NR}(500 \mu \mathrm{M}$ or $5 \mathrm{mM}, 48$ hours) and the membrane-enriched protein fraction was harvested with the Compartmentalization Protein Extraction Kit (Millipore, Burlington, MA). Membrane-enriched $\mathrm{Na}_{\mathrm{v}} 1.5$ was blotted, quantified, and normalized to the stain-free gel image obtained prior to transfer to a polyvinylidene fluoride (PVDF) membrane. 


\title{
Control FLAG-Na 1.5 HEK293
}

\author{
$5 \mathrm{mMNR}$ \\ FLAG-Na 1.5 HEK293
}

HEK293 Control
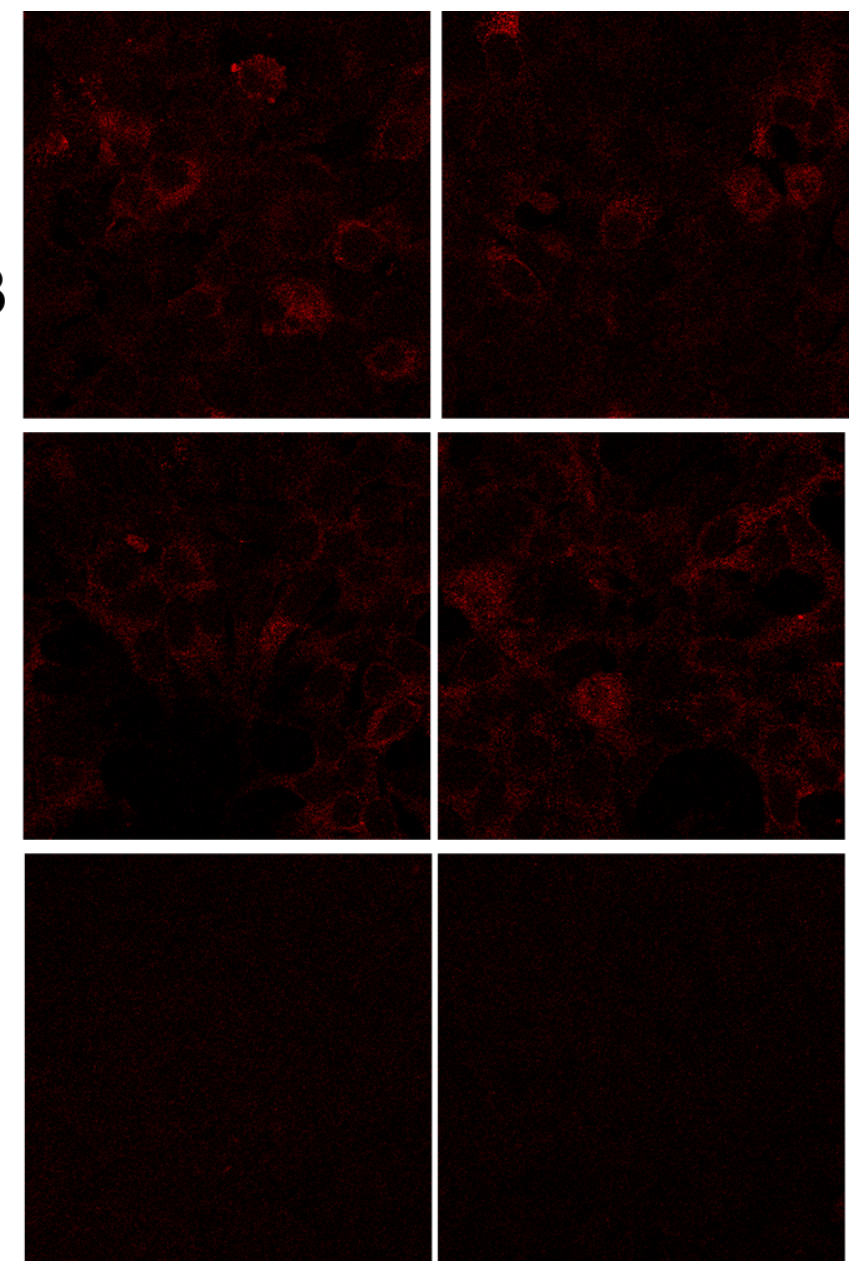

Figure S3. The Effect of Nicotinamide Riboside (NR) on Surface Expression of FLAG-Nav1.5. HEK293 cells stably-expressing Nav1.5 with a FLAG tag in the extracellular region of D1 was treated with $5 \mathrm{mM}$ NR for 48 hours (replenished at 24 hours) and assessed for surface expression by confocal microscopy. HEK293 cells without $\mathrm{Na}_{\mathrm{v}} 1.5$ were used as a control. 


\section{Voltage-Dependent Activation Gating Properties}
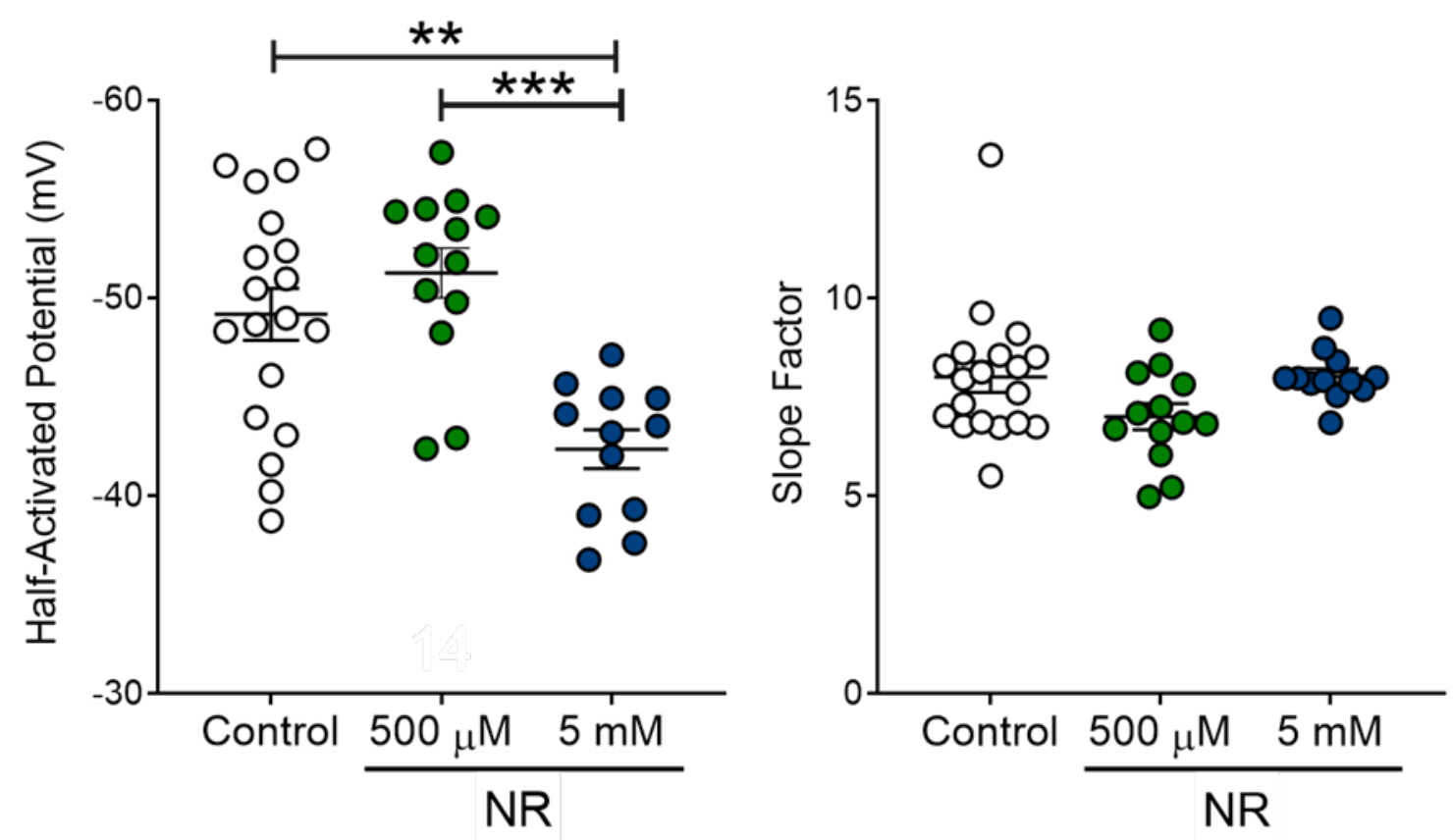

\section{Steady-State Inactivation Gating Properties}
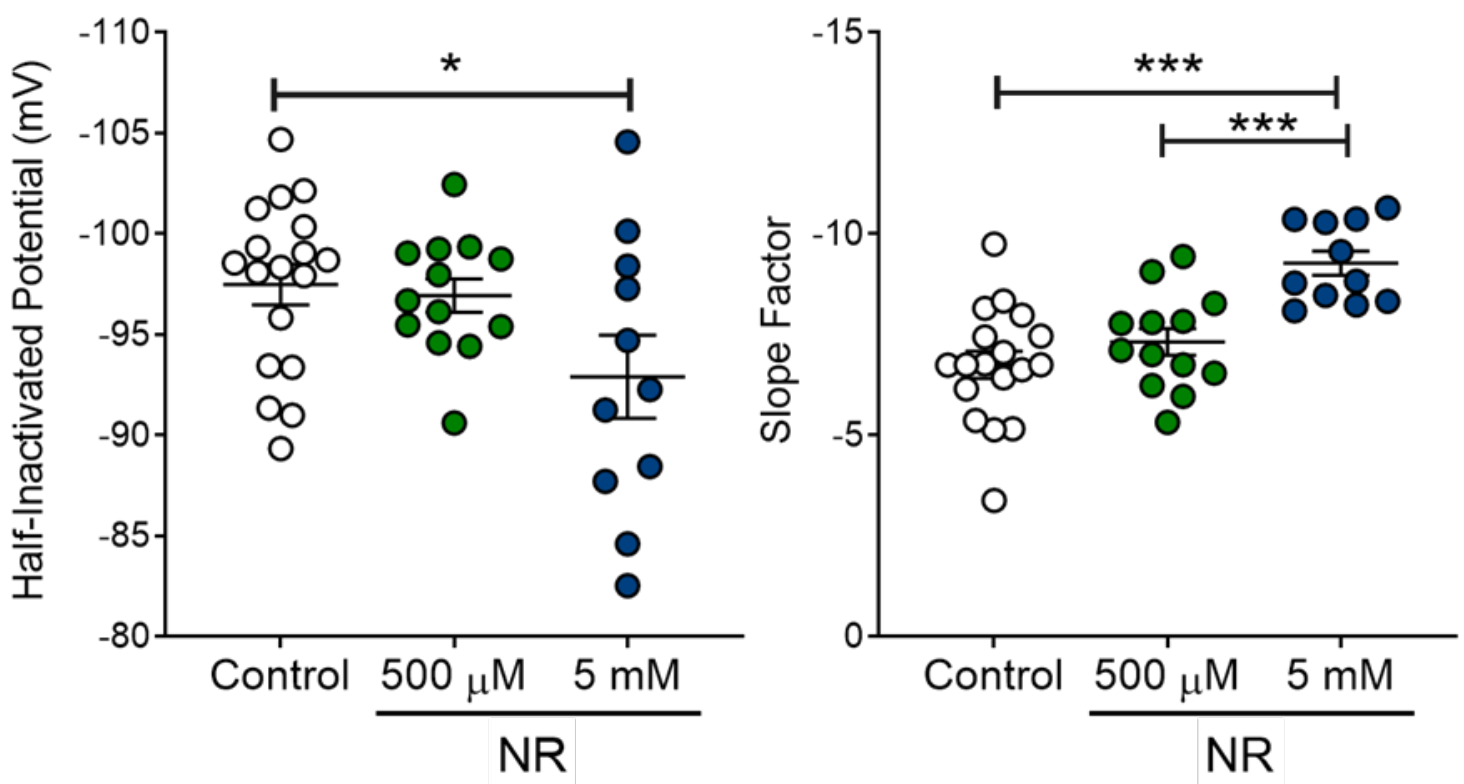

Figure S4. The Effect of Nicotinamide Riboside (NR) on Normalized $I_{\mathrm{Na}}$ Gating Properties in RNCMs. (Top) Steady-state activation and (Bottom) inactivation properties of neonatal rat cardiomyocytes (RNCMs) treated with $\mathrm{H}_{2} \mathrm{O}$ (vehicle) or NR at either $500 \mu \mathrm{M}$ or $5 \mathrm{mM}$ for 24 hours. Myocyte properties were normalized to vehicle litter-controlled myocytes to account for litter-to-litter variation in harvesting myocytes. Differences between groups were statistically determined utilizing unpaired t-tests $\left({ }^{*} \mathrm{p}<0.05,{ }^{* *} \mathrm{p}<0.01,{ }^{* * *} \mathrm{p}<0.001\right)$. 


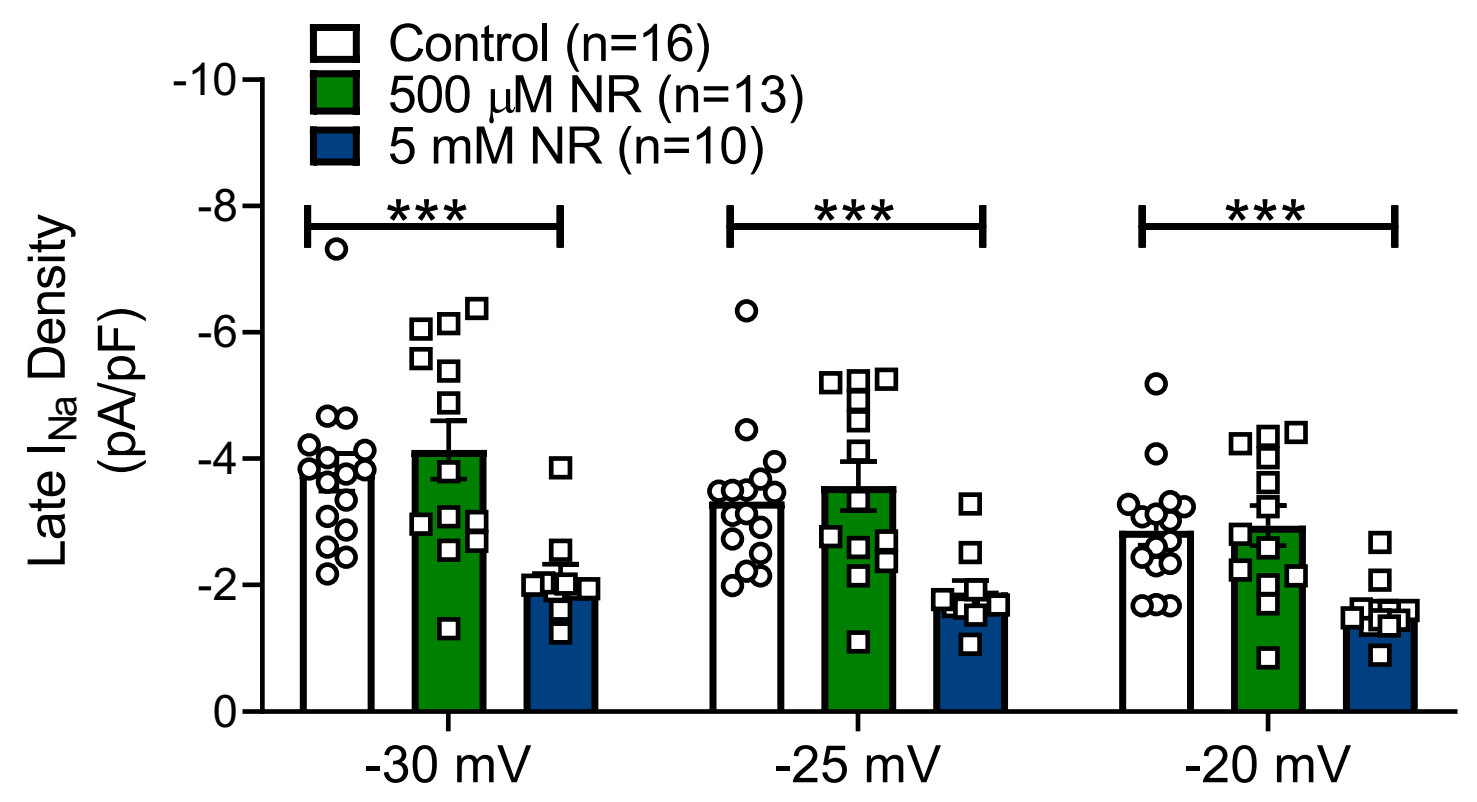

Figure S5. The Effect of Nicotinamide Riboside (NR) on Late Sodium Current Density in RNCMs at . Differences between groups were statistically determined utilizing unpaired t-tests $(* * * \mathrm{p}<0.001)$. 


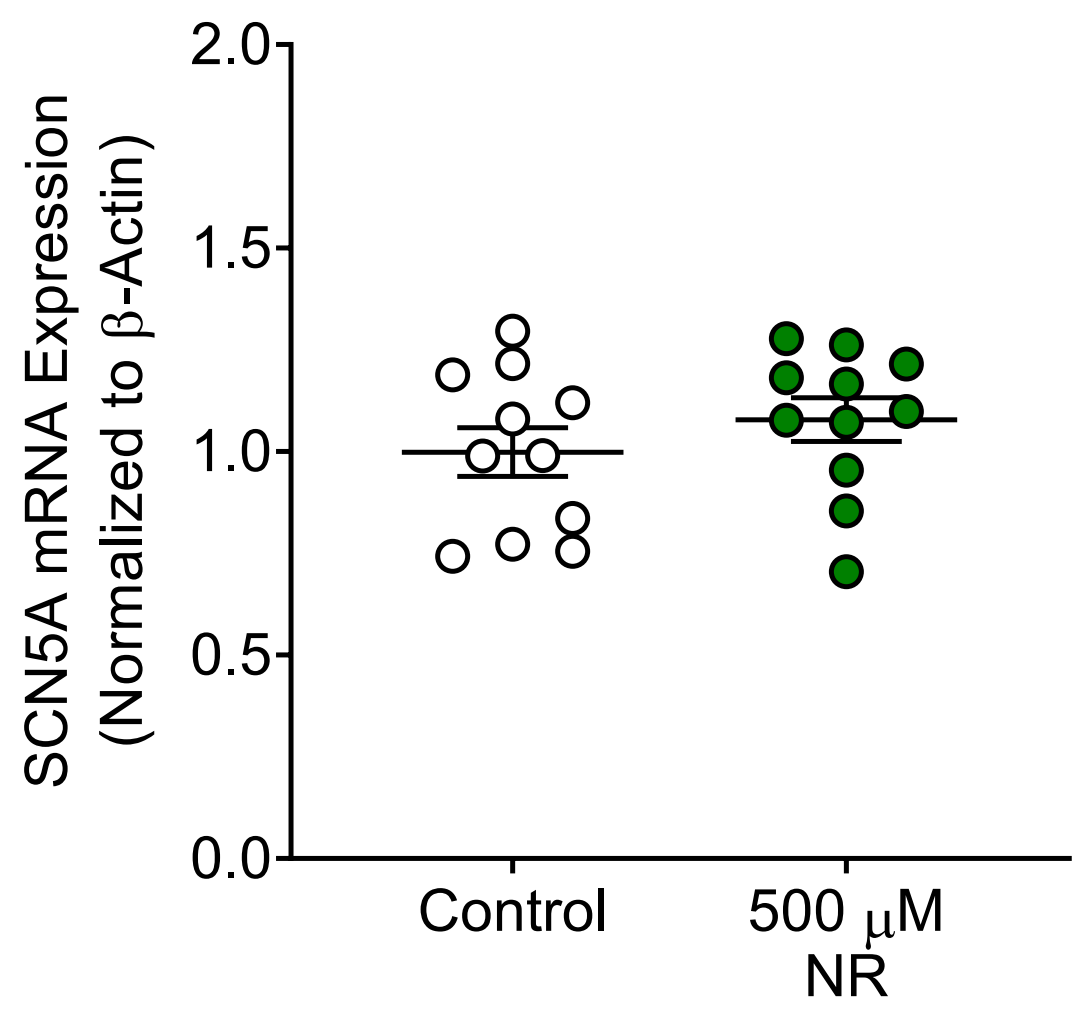

Figure S6. The Effect of Nicotinamide Riboside (NR) on Scn $5 a$ transcript expression in Neonatal Rat Cardiomyocytes. Scn5a transcript expression (normalized to beta-actin expression) was unchanged with administration of $500 \mu \mathrm{M}$ NR for 24 hours (Ctrl: $1.00 \pm 0.05$ vs. NR: $1.079 \pm 0.05, p=0.33$ unpaired t-test). 
A

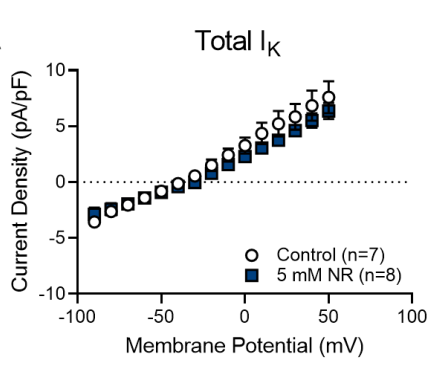

$E$

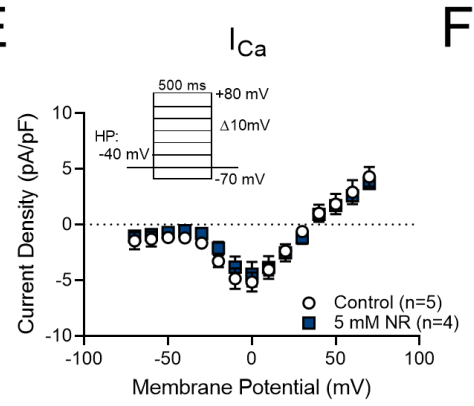

B

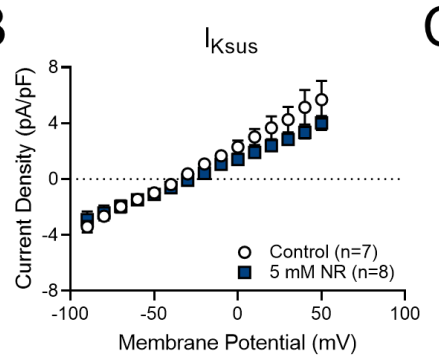

$\mathrm{F}$

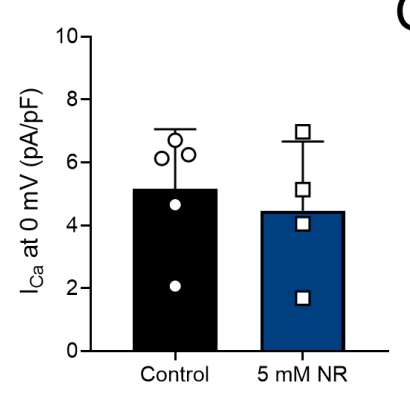

C

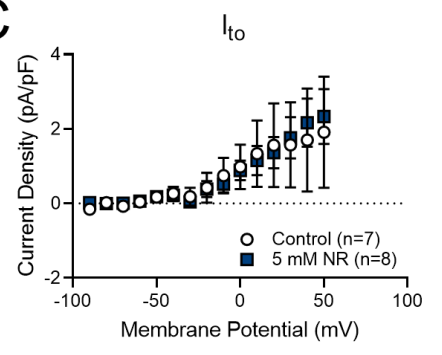

G

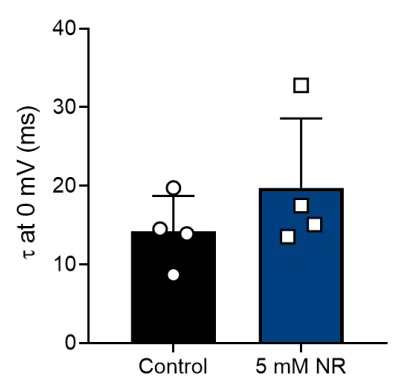

D

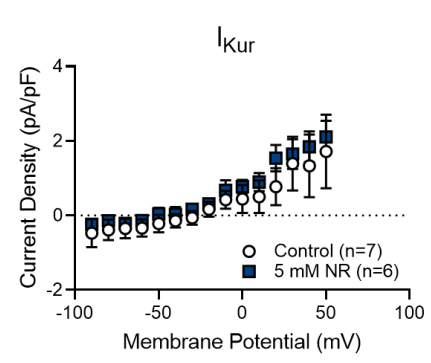

Figure S7. NR has no effect on $I_{K}$ and $I_{C a}$ Currents. (A-B) Whole-cell current-voltage relationships measured at $10 \mathrm{~ms}$ into depolarization ( $\mathrm{I}_{\mathrm{Ktotal}}$ ) and just prior to repolarization to measure the sustained $\mathrm{I}_{\mathrm{K}}$ ( $\mathrm{I}_{\mathrm{Ksus}}$ ) recorded from rat cardiomyocytes in control or NR-treated $(5 \mathrm{mM}, 24$ hours) myocytes. (C-D) Current-voltage relationship of transient outward $\mathrm{K}^{+}$current $\left(\mathrm{I}_{\mathrm{to}}\right)$ and ultra-rapid $\mathrm{K}^{+}$current $\left(\mathrm{I}_{\text {kur }}\right)$. No statistically difference between control and NR-treated cells was observed at various membrane potentials. (E) Current-voltage relationships for calcium currents recorded from neonatal rat cardiomyocytes. (F) The peak current density and (G) inactivation time constant $(\tau)$ estimated from exponential fits to currents measured at $0 \mathrm{mV}$ recorded from cells control or NRtreated (5 mM NR, 24 hours). Values are mean $\pm \mathrm{SE}$. 

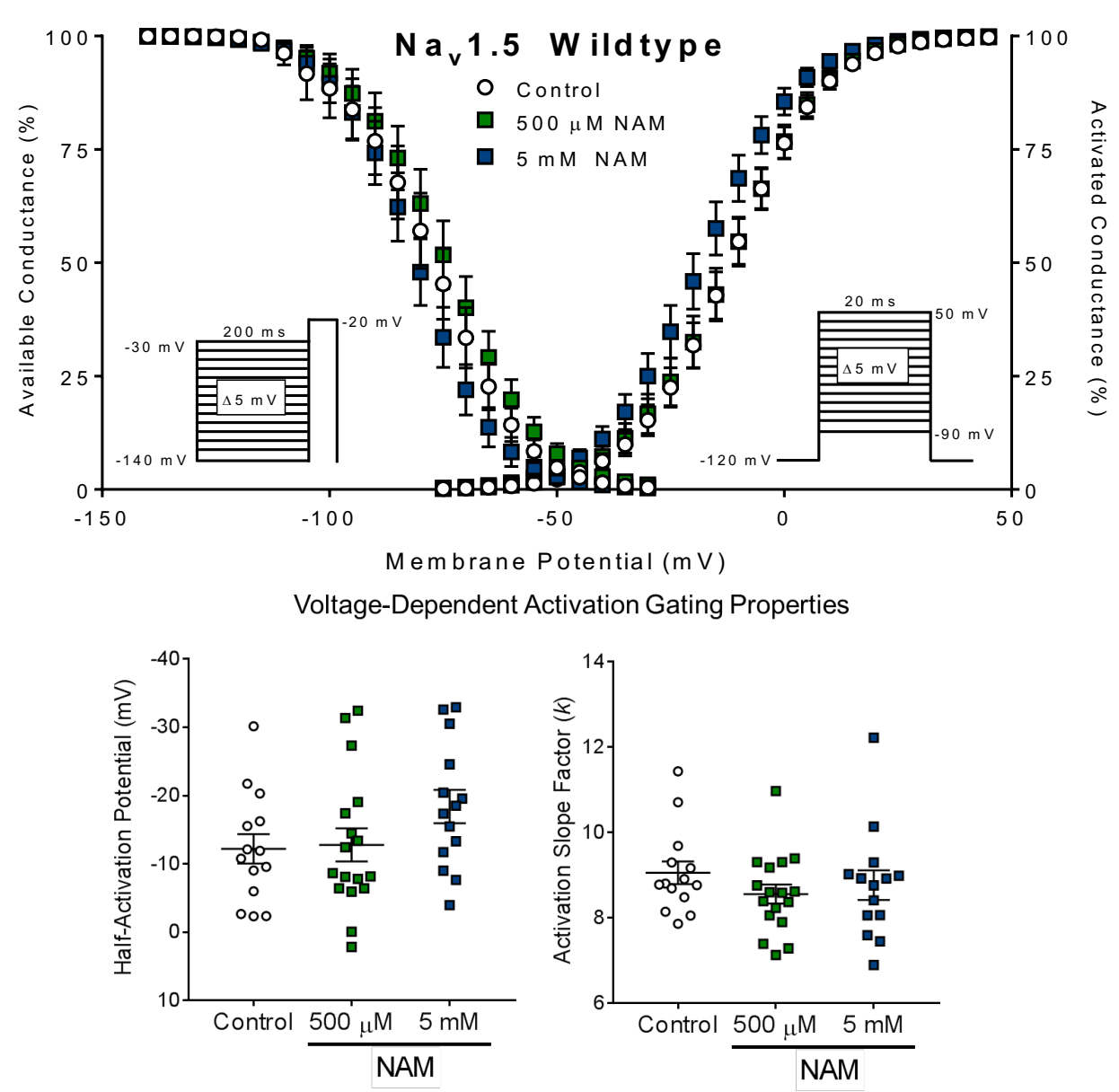

Steady-State Inactivation Gating Properties
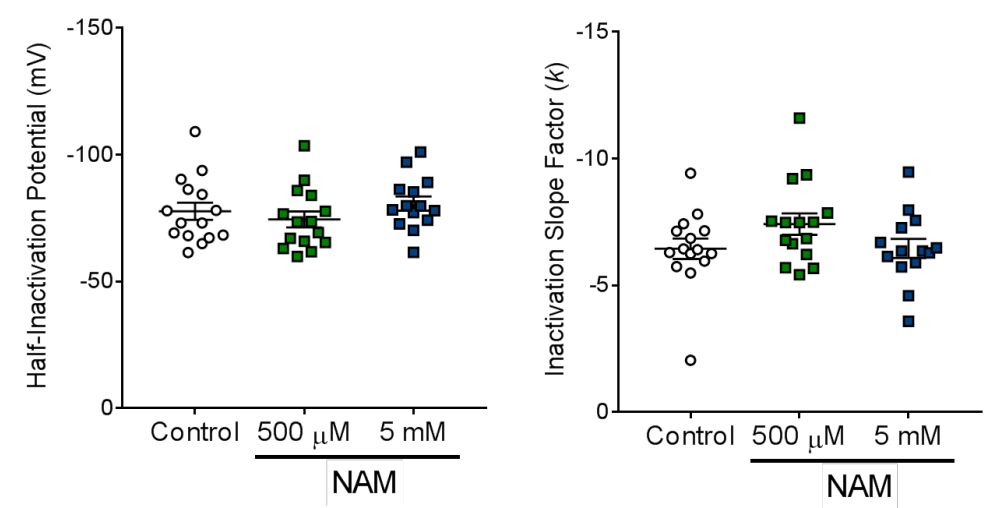

Figure S8. The Effect of Nicotinamide (NAM) on Nav1.5 Gating Properties in HEK293 Cells. (Top) Gating properties of steady-state activation and inactivation demonstrate are unchanged with NAM treatment. (Bottom) Nav1.5 gating properties (including half-maximal potentials and slope factors) for steady-state activation and inactivation of HEK293 cells transiently transfected with $\mathrm{Na}_{\mathrm{v}} 1.5$ and treated with $\mathrm{H}_{2} \mathrm{O}$ (vehicle), $500 \mu \mathrm{M}$ NAM, or 5mM NAM for 48 hours. 


\section{Voltage-Dependent Activation Gating Properties}
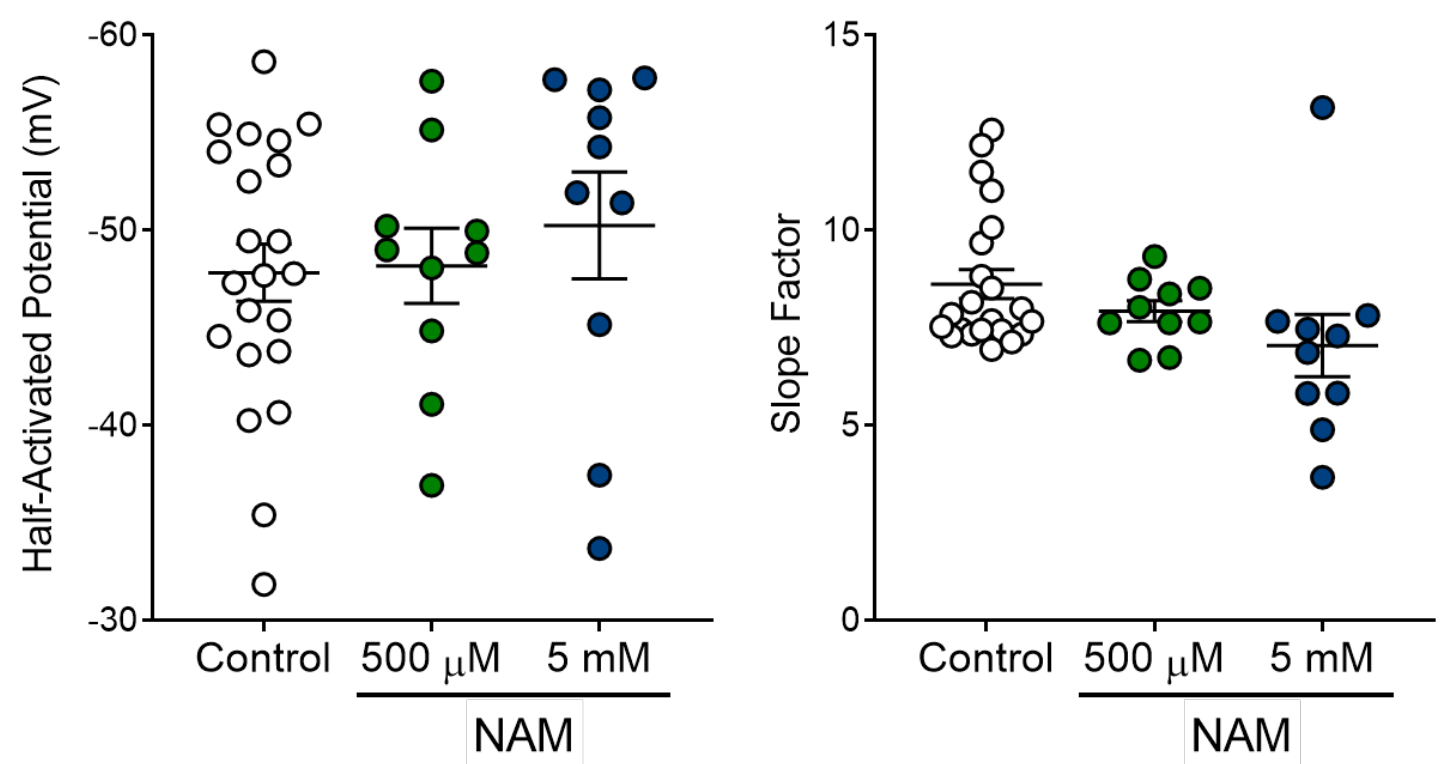

Steady-State Inactivation Gating Properties
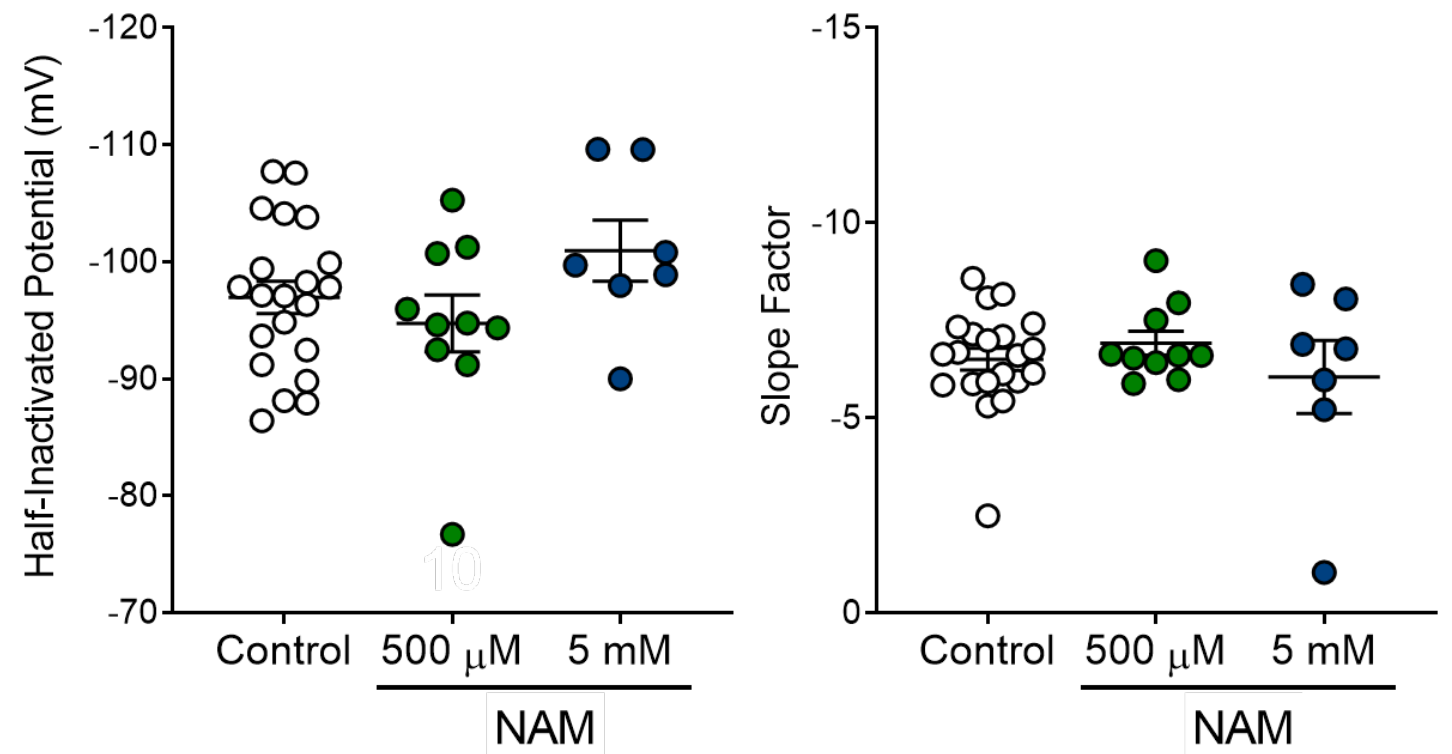

Figure S9. The Effect of Nicotinamide (NAM) on $\mathbf{I}_{\mathrm{Na}}$ Gating Properties in RNCMs. Steady-state activation and inactivation properties of neonatal rat cardiomyocytes (NRCMs) treated with $\mathrm{H}_{2} \mathrm{O}$ (vehicle) or NAM at either $500 \mu \mathrm{M}$ or $5 \mathrm{mM}$ for 24 hours. Myocyte properties were normalized to vehicle litter-controlled myocytes to account for litter-to-litter variation in harvesting myocytes. 
A<smiles>C[n+]1cccc(C(N)=O)c1</smiles>

$E$

Voltage-Dependent Activation Gating Properties

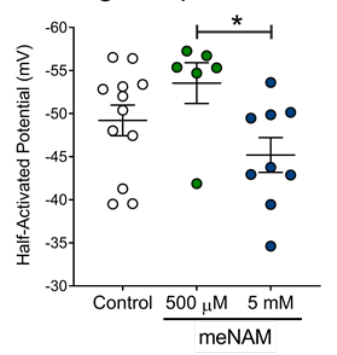

G

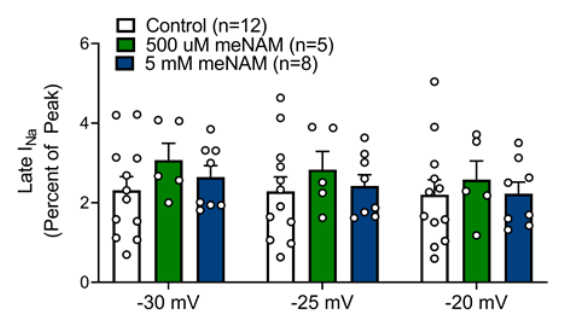

B
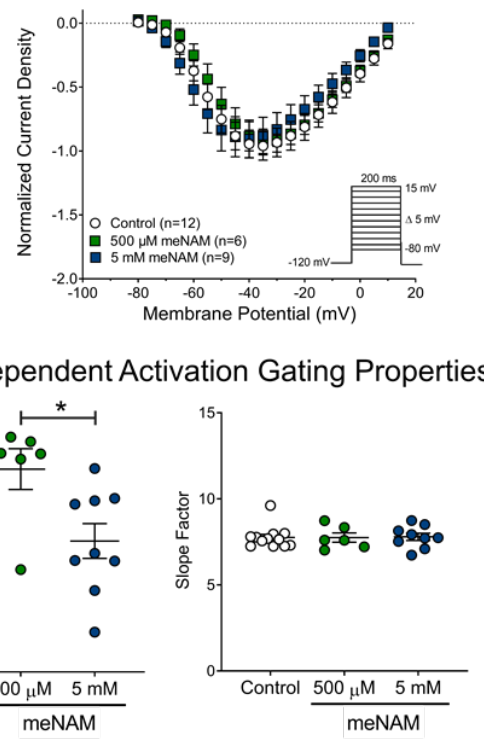

$\mathrm{H}$

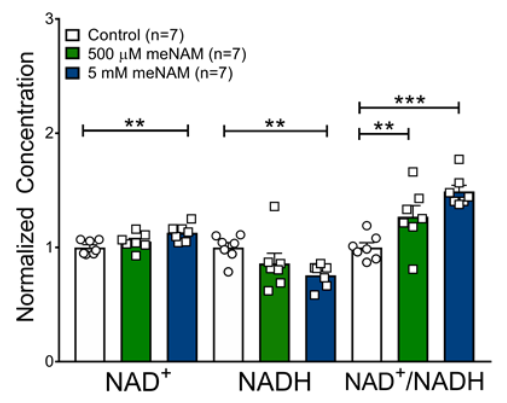

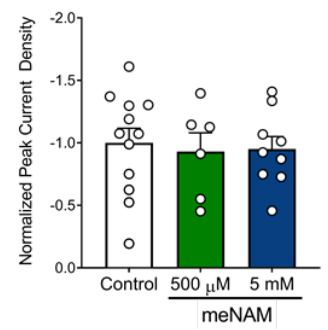

$\mathrm{F}$

Steady-State Inactivation Gating Properties
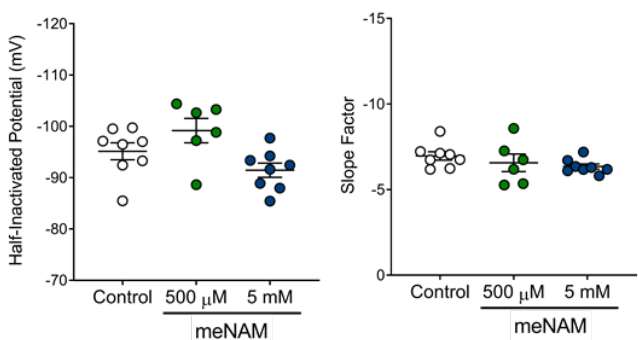

Figure S10. Inert $\mathrm{NAD}^{+}$Metabolite 1-Methyl-Nicotinamide has no effect on $\mathbf{I}_{\mathrm{Na}}$ in Neonatal Rat Cardiomyocytes. (A) The structure of 1-methyl-Nicotinamide (meNAM), an inert byproduct of Nicotinamide which cannot be utilized for $\mathrm{NAD}^{+}$synthesis. (B,C,D) meNAM has no to minimal effects on $\mathrm{I}_{\mathrm{Na}}$ indicated by I-V curve, normalized peak current density, and steady-state activation and inactivation curves. (E-F) Gating properties are unchanged after treatment with meNAM. (G) Late $\mathrm{I}_{\mathrm{Na}}$ was unaffected with meNAM supplementation. $(\mathbf{H}) \mathrm{NAD}^{+}, \mathrm{NADH}$, and $\mathrm{NAD}^{+} / \mathrm{NADH}$ ratio quantified in rat myocytes after 24-hour meNAM treatment. 
A

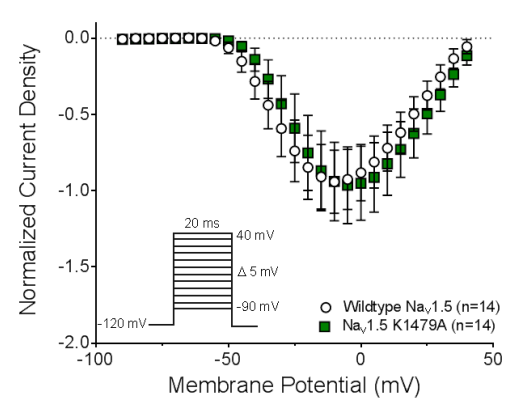

B

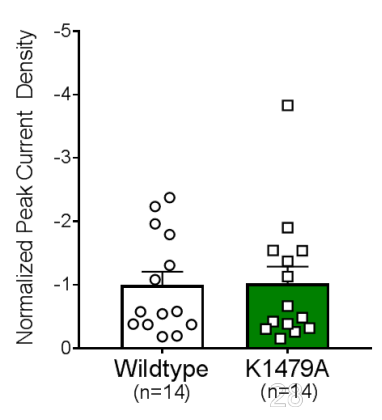

C

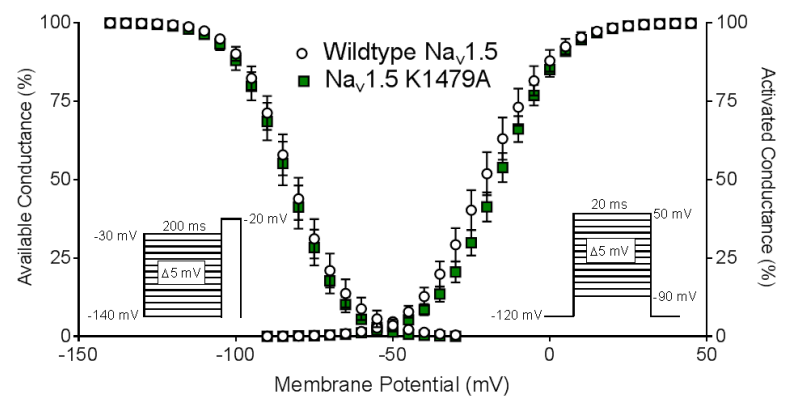

Steady-State Inactivation Gating Properties
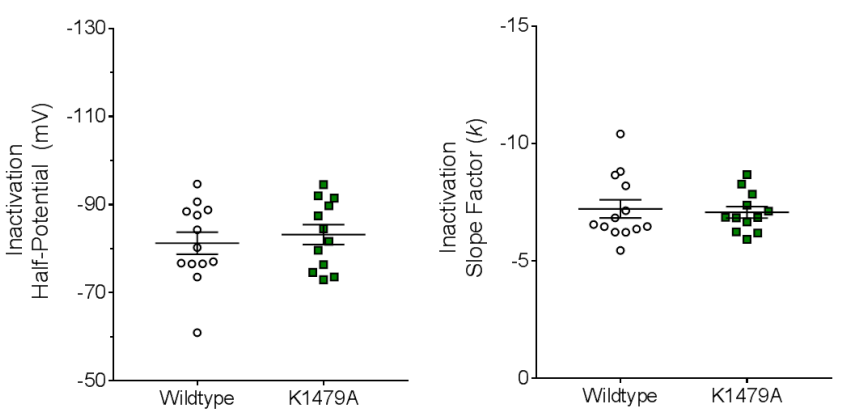

$\mathrm{F}$
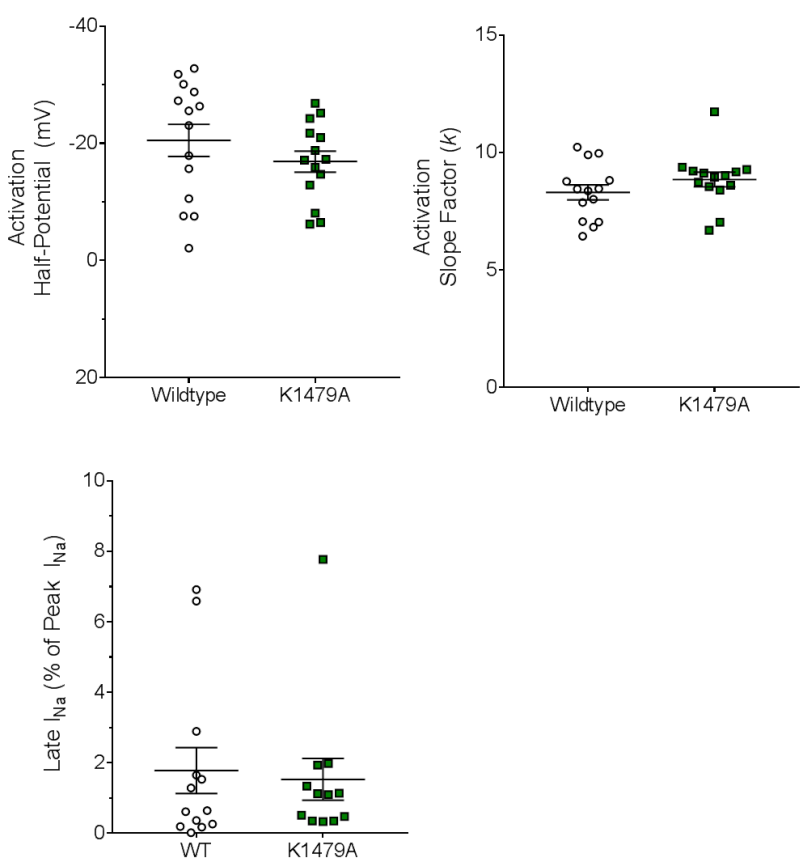

Figure S11. Electrophysiological Comparison of the Wild-type and Mutant K1479A Nav1.5 Channel. (A-C) The I-V relationship, peak current density, and steady-state activation and inactivation of HEK293 cells transiently transfected with either the wild-type or mutant Nav1.5 K1479A channel. (D-E) Nav1.5 gating properties (including half-maximal potentials and slope factors) for steady-state activation and inactivation of HEK293 cells transiently transfected with wild-type and K1479A Nav1.5. (F) Comparison of late $\mathrm{I}_{\mathrm{Na}}$ between wild-type and K1479A Nav1.5 as measured by the $10 \mathrm{~ms}$ average current at $200 \mathrm{~ms}$ post-deploarization at $-20 \mathrm{mV}$. 
NR on HEK 293 Cells Transiently Transfected with $\mathrm{Na}_{\mathrm{v}} 1.5 \mathrm{~K} 1479 \mathrm{~A}$

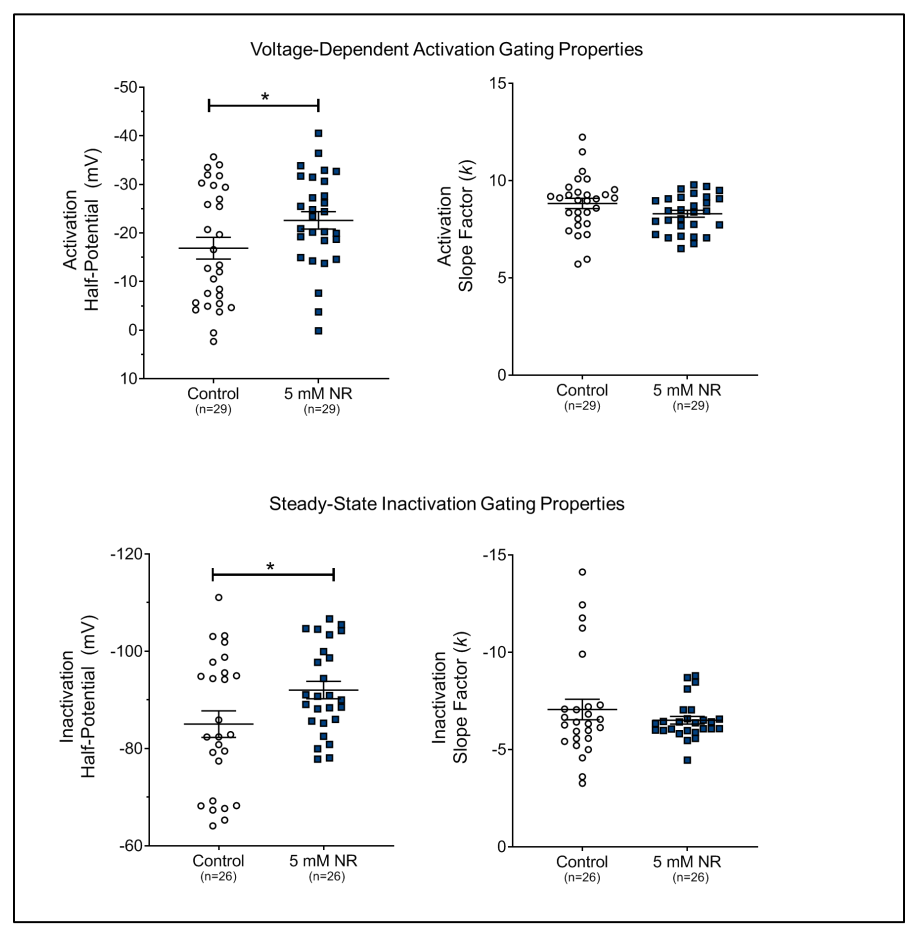

NAM on HEK 293 Cells Transiently Transfected with $\mathrm{Na}_{\mathrm{v}} 1.5$ K1479A

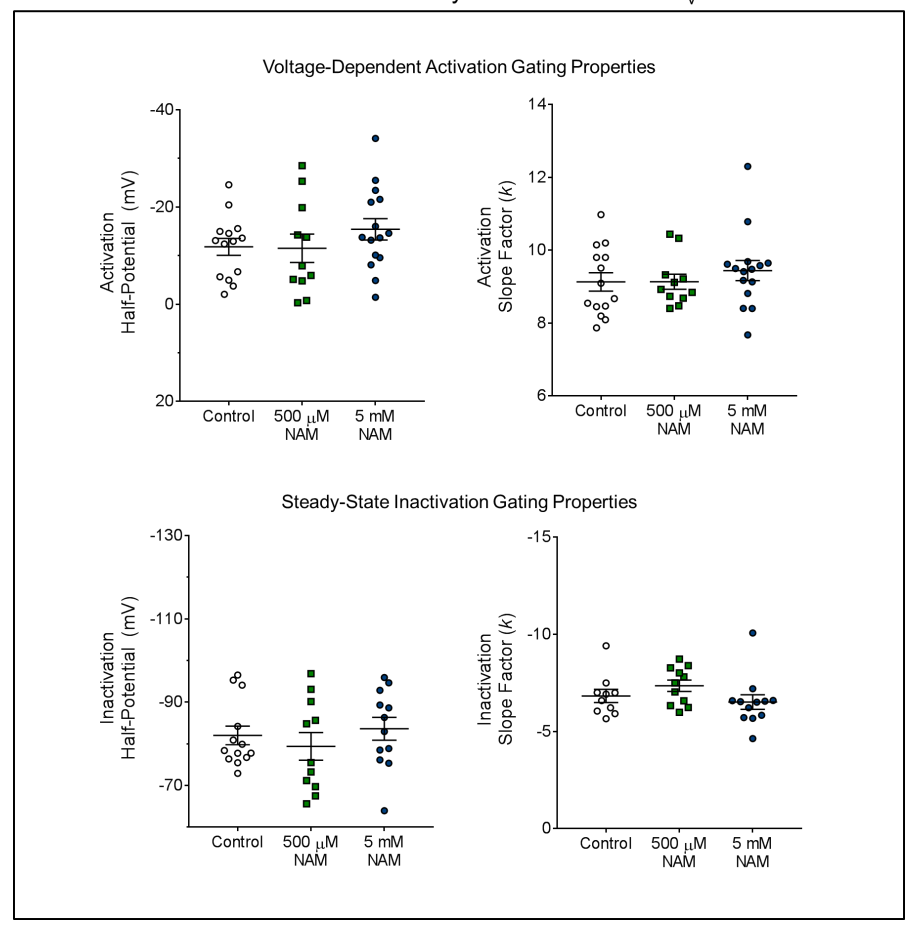

Figure S12. The Effect of Nicotinamide Riboside (NR) and Nicotinamide (NAM) on Nav1.5 K1479A Gating Properties in HEK293 Cells. Nav1.5 gating properties (including half-maximal potentials and slope factors) for steady-state activation and inactivation of HEK293 cells transiently transfected with Nav1.5 K1479A and treated with (Top) $\mathrm{H}_{2} \mathrm{O}$ (vehicle) or $5 \mathrm{mM} \mathrm{NR}$ or (Bottom) $\mathrm{H}_{2} \mathrm{O}$ (vehicle), $500 \mu \mathrm{M} \mathrm{NAM}$, or $5 \mathrm{mM}$ NAM for 48 hours. 


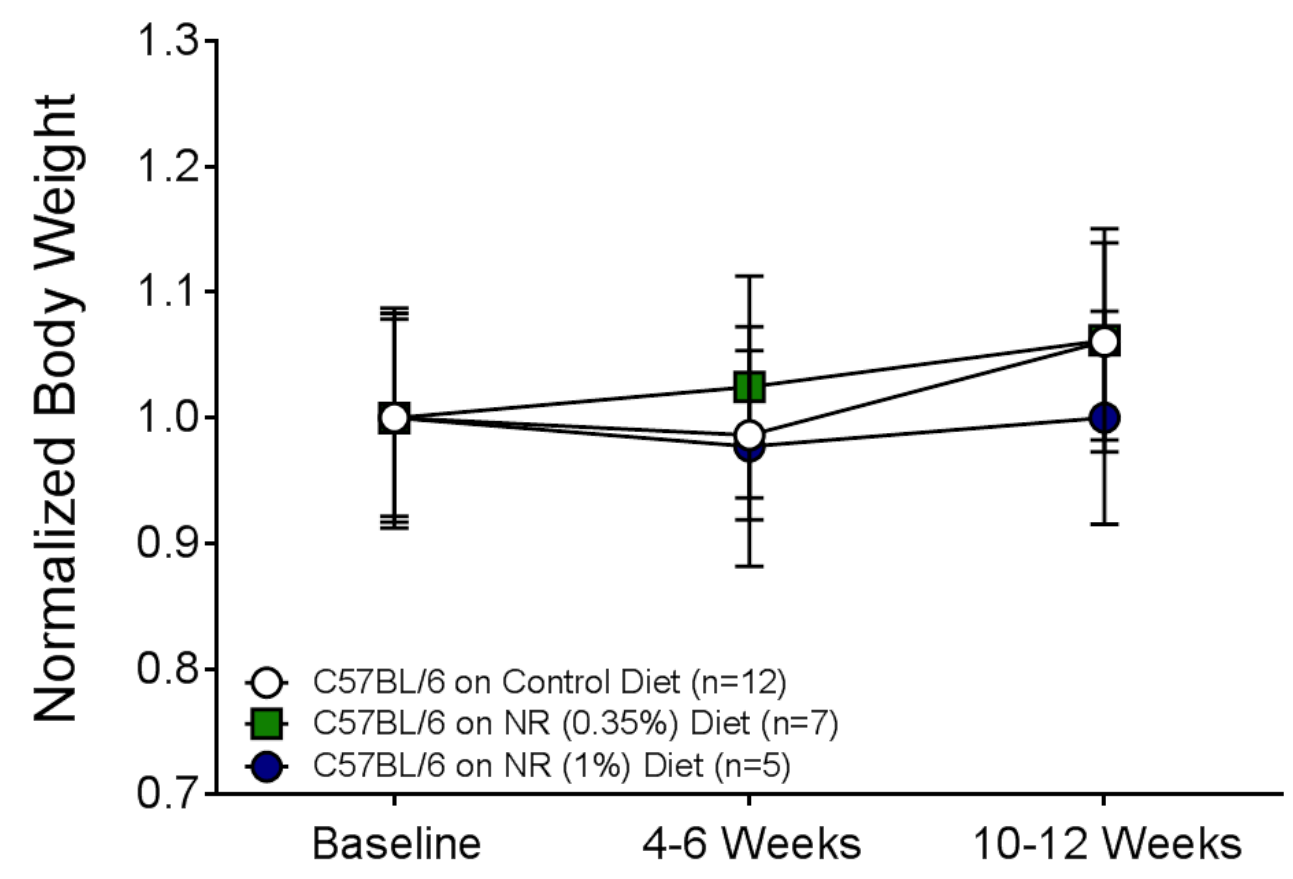

Figure S13. The Effect of Nicotinamide Riboside (NR) dietary supplementation on body weight in C57BL/6 wild-type mice. Body weights were assessed throughout the time course of NR supplementation. No changes in weight were observed between groups throughout the course of the experiment (Two-way ANOVA Bonferroni multiple comparisons post-hoc test). 


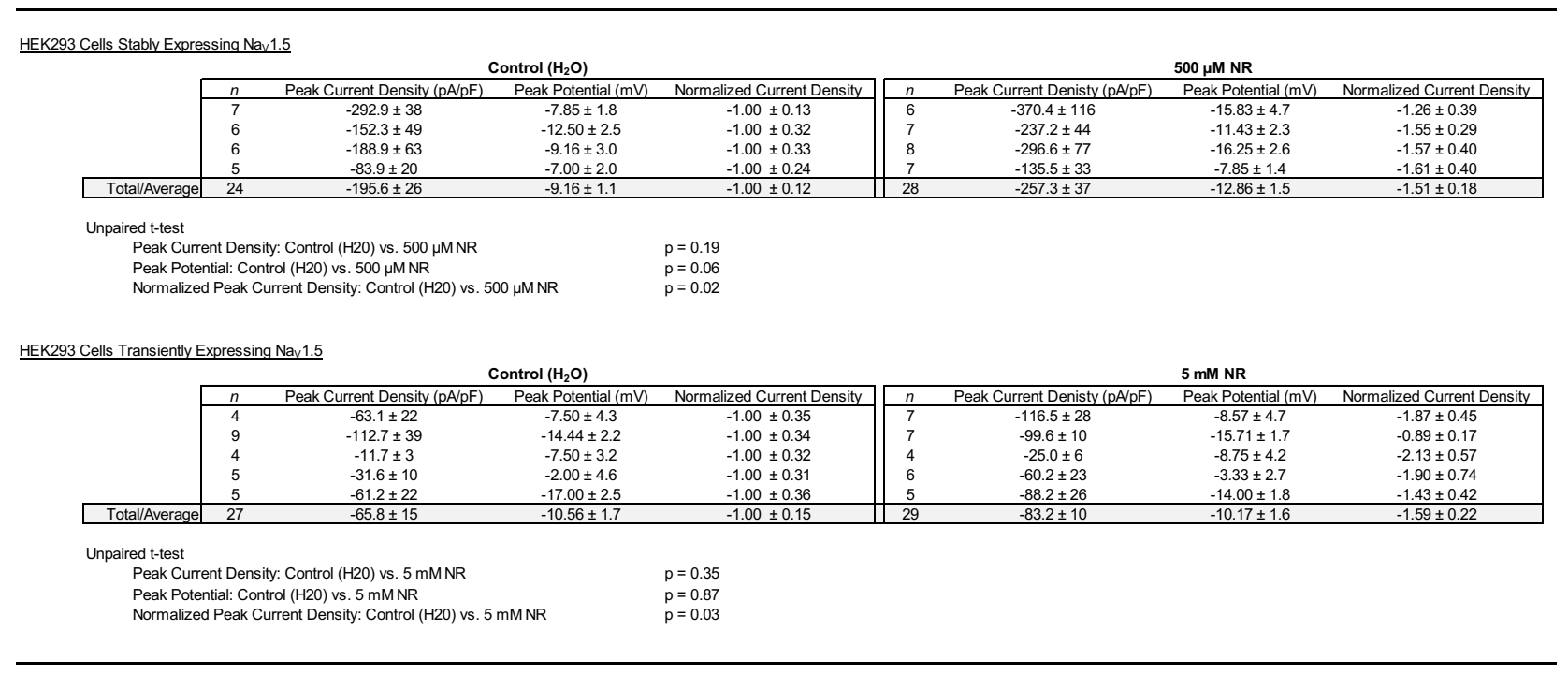

Table S1. Current Densities, Peak Potentials, and Normalized Current Densities for HEK293 cells stably and transiently expressing Nav1.5 treated with Nicotinamide Riboside (NR). 


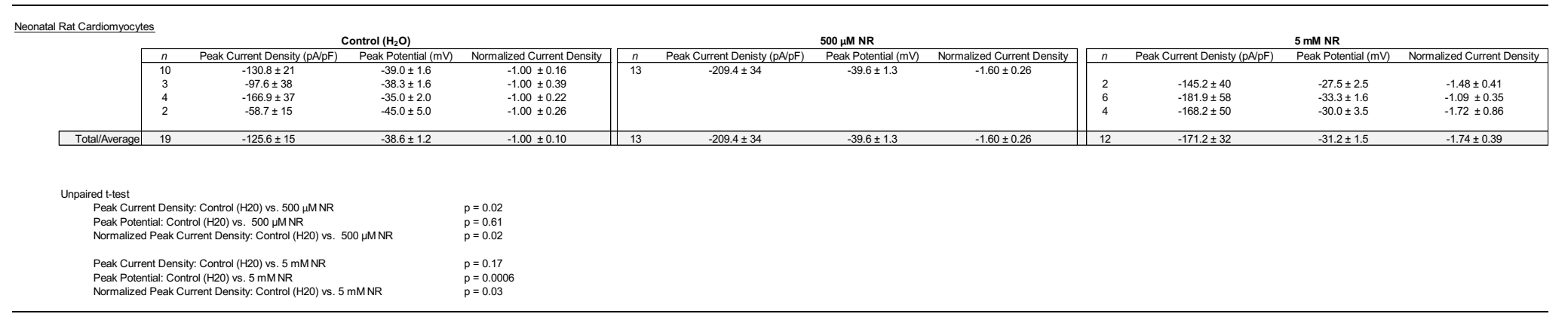

Table S2. Current Densities, Peak Potentials, and Normalized Currents for Neonatal Rat Cardiomyocytes treated with Nicotinamide Riboside (NR). 


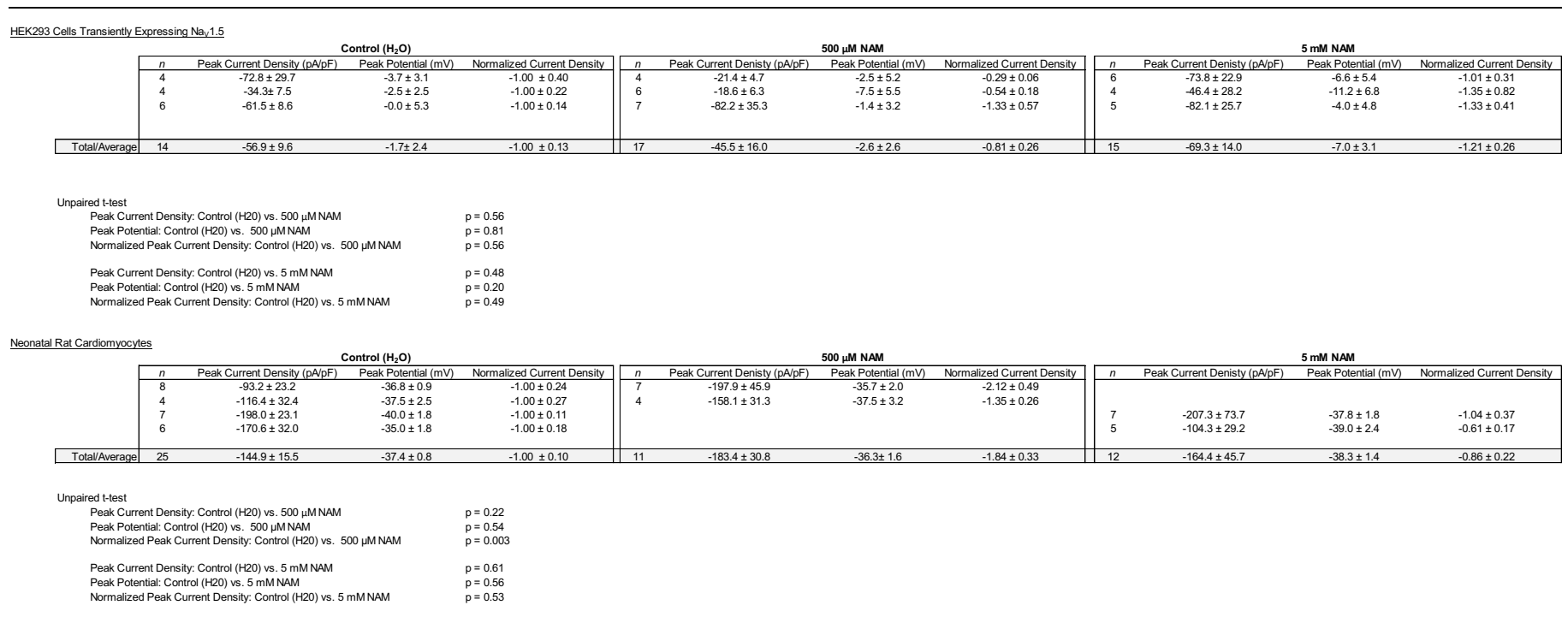

Table S3. Current Densities, Peak Potentials, and Normalized Currents for HEK293 cells transiently expressing Nav1.5 and Neonatal Rat Cardiomyocytes treated with Nicotinamide (NAM). 


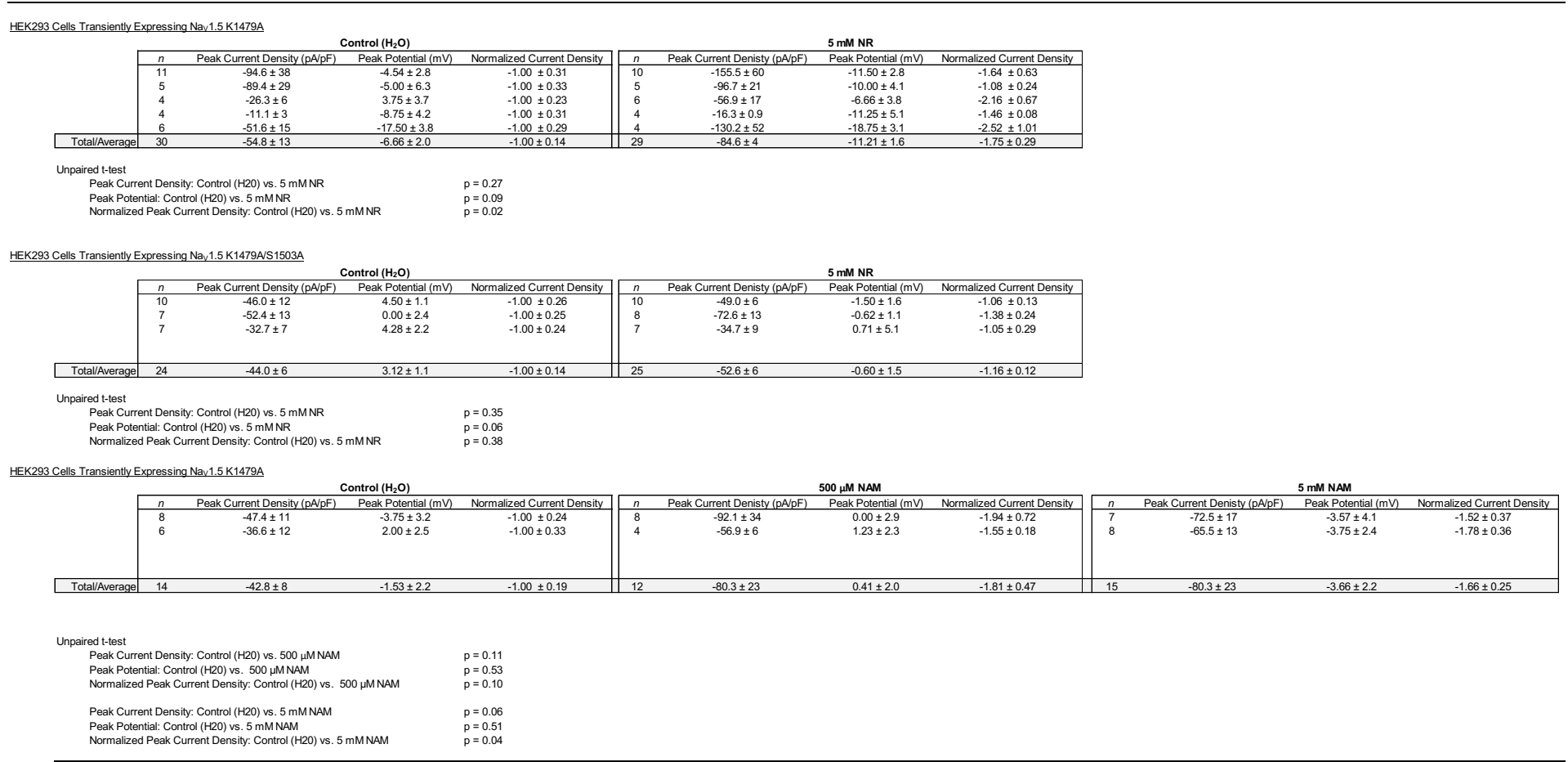

Table S4. Current Densities, Peak Potentials, and Normalized Currents for HEK293 cells transiently expressing mutant forms (K1479A and K1479A/S1503A) and treated with either Nicotinamide Riboside (NR) or Nicotinamide (NAM). 
bioRxiv preprint doi: https://doi.org/10.1101/2020.02.20.958066; this version posted February 24,2020 . The copyright holder for this preprint (which was not certified by peer review) is the author/funder. All rights reserved. No reuse allowed without permission.

\begin{tabular}{|c|c|c|c|c|c|c|}
\hline \multicolumn{3}{|c|}{ HEK293 Cells Stably Expressing Nav1.5 } & \multicolumn{2}{|c|}{ Activation Parameters } & \multicolumn{2}{|c|}{ Inactivation Parameters } \\
\hline Treatment Group & $n$ & Peak $I_{\mathrm{Na}}$ (Normalized Current) & Half Value $(\mathrm{mV})$ & Slope $(k)$ & Half Value $(\mathrm{mV})$ & Slope (k) \\
\hline Control $\left(\mathrm{H}_{2} \mathrm{O}\right)$ & 24 & $-1.00 \pm 0.12$ & $-20.04 \pm 1.38$ & $8.89 \pm 0.35$ & $-78.44 \pm 1.78$ & $-7.31 \pm 0.23$ \\
\hline $500 \mu \mathrm{M} \mathrm{NR}$ & 28 & $-1.51 \pm 0.18$ & $-24.25 \pm 1.33$ & $8.73 \pm 0.36$ & $-83.19 \pm 2.22$ & $-7.10 \pm 0.16$ \\
\hline \multicolumn{3}{|c|}{ HEK293 Cells Transiently Expressing Nav1.5 } & \multicolumn{2}{|c|}{ Activation Parameters } & \multicolumn{2}{|c|}{ Inactivation Parameters } \\
\hline Treatment Group & $n$ & Peak $I_{N a}$ (Normalized Current) & Half Value $(\mathrm{mV})$ & Slope (k) & Half Value $(\mathrm{mV})$ & Slope (k) \\
\hline Control $\left(\mathrm{H}_{2} \mathrm{O}\right)$ & 27 & $-1.00 \pm 0.15$ & $-22.15 \pm 2.35$ & $8.89 \pm 0.35$ & $-83.66 \pm 1.65$ & $-6.18 \pm 0.22$ \\
\hline $5 \mathrm{mM} \mathrm{NR}$ & 29 & $-1.59 \pm 0.22$ & $-22.07 \pm 1.64$ & $8.73 \pm 0.36$ & $-83.42 \pm 1.47$ & $-6.39 \pm 0.16$ \\
\hline \multicolumn{3}{|c|}{ HEK293 Cells Transiently Expressing Nav1.5 } & \multicolumn{2}{|c|}{ Activation Parameters } & \multicolumn{2}{|c|}{ Inactivation Parameters } \\
\hline Treatment Group & $n$ & Peak $I_{\mathrm{Na}}$ (Normalized Current) & Half Value $(\mathrm{mV})$ & Slope (k) & Half Value $(\mathrm{mV})$ & Slope (k) \\
\hline Control $\left(\mathrm{H}_{2} \mathrm{O}\right)$ & 14 & $-1.00 \pm 0.13$ & $-12.23 \pm 2.16$ & $9.06 \pm 0.26$ & $-77.72 \pm 3.35$ & $-6.45 \pm 0.40$ \\
\hline $500 \mu \mathrm{M}$ NAM & 17 & $-0.81 \pm 0.26$ & $-12.80 \pm 2.42$ & $8.56 \pm 0.22$ & $-74.51 \pm 3.13$ & $-7.42 \pm 0.42$ \\
\hline 5 mM NAM & 15 & $-1.21 \pm 0.26$ & $-18.42 \pm 2.45$ & $8.77 \pm 0.34$ & $-80.78 \pm 2.79$ & $-6.46 \pm 0.37$ \\
\hline \multicolumn{3}{|l|}{ Rat Cardiomyocytes } & \multicolumn{2}{|c|}{ Normalized Activation Parameters } & \multicolumn{2}{|c|}{ Normalized Inactivation Parameters } \\
\hline Treatment Group & $n$ & Peak $I_{N a}$ (Normalized Current) & Half Value $(\mathrm{mV})$ & Slope & Half Value $(\mathrm{mV})$ & Slope \\
\hline Control $\left(\mathrm{H}_{2} \mathrm{O}\right)$ & 19 & $-1.00 \pm 0.10$ & $-49.17 \pm 1.31$ & $8.01 \pm 0.38$ & $-97.49 \pm 1.00$ & $-6.75 \pm 0.33$ \\
\hline $500 \mu \mathrm{M} \mathrm{NR}$ & 13 & $-1.60 \pm 0.26$ & $-51.31 \pm 1.16$ & $6.93 \pm 0.314$ & $-96.94 \pm 0.83$ & $-7.31 \pm 0.33$ \\
\hline $5 \mathrm{mMNR}$ & 12 & $-1.74 \pm 0.39$ & $-42.36 \pm 0.97$ & $8.03 \pm 0.18$ & $-92.91 \pm 2.06$ & $-9.27 \pm 0.29$ \\
\hline Treatment Group & $n$ & Peak $I_{\mathrm{Na}}$ (Normalized Current) & Half Value $(\mathrm{mV})$ & Slope & Half Value $(\mathrm{mV})$ & Slope \\
\hline Control $\left(\mathrm{H}_{2} \mathrm{O}\right)$ & 25 & $-1.00 \pm 0.10$ & $-47.83 \pm 1.47$ & $8.62 \pm 0.37$ & $-96.98 \pm 1.37$ & $-6.50 \pm 0.27$ \\
\hline $500 \mu \mathrm{M}$ NAM & 11 & $-1.84 \pm 0.33$ & $-48.19 \pm 1.92$ & $7.93 \pm 0.26$ & $-94.76 \pm 2.43$ & $-6.91 \pm 0.30$ \\
\hline 5 mM NAM & 12 & $-0.86 \pm 0.22$ & $-50.26 \pm 2.74$ & $7.05 \pm 0.79$ & $-101.0 \pm 2.60$ & $-6.05 \pm 0.93$ \\
\hline Treatment Group & $n$ & Peak $I_{\mathrm{Na}}$ (Normalized Current) & Half Value $(\mathrm{mV})$ & Slope & Half Value (mV) & Slope \\
\hline Control $\left(\mathrm{H}_{2} \mathrm{O}\right)$ & 12 & $-1.00 \pm 0.11$ & $-49.21 \pm 1.77$ & $7.75 \pm 0.18$ & $-95.15 \pm 1.65$ & $-6.96 \pm 0.24$ \\
\hline $500 \mu \mathrm{M}$ meNAM & 6 & $-0.93 \pm 0.14$ & $-53.54 \pm 2.36$ & $7.75 \pm 0.26$ & $-99.18 \pm 2.38$ & $-6.56 \pm 0.51$ \\
\hline $5 \mathrm{mM}$ meNAM & 9 & $-0.95 \pm 0.09$ & $-45.19 \pm 2.01$ & $7.79 \pm 0.21$ & $-91.47 \pm 1.37$ & $-6.35 \pm 0.15$ \\
\hline \multicolumn{7}{|c|}{ HEK293 Cells Transiently Expressing Nav1.5 K1479A } \\
\hline Treatment Group & $n$ & Peak $I_{\mathrm{Na}}$ (Normalized Current) & Half Value $(\mathrm{mV})$ & Slope & Half Value $(\mathrm{mV})$ & Slope \\
\hline Control $\left(\mathrm{H}_{2} \mathrm{O}\right)$ & 29 & $-1.00 \pm 0.14$ & $-13.70 \pm 2.38$ & $8.72 \pm 0.32$ & $-81.47 \pm 2.73$ & $-7.51 \pm 0.60$ \\
\hline $5 \mathrm{mM} \mathrm{NR}$ & 30 & $-1.75 \pm 0.29$ & $-21.29 \pm 1.93$ & $8.34 \pm 0.18$ & $-90.42 \pm 1.81$ & $-6.68 \pm 0.20$ \\
\hline \multicolumn{7}{|c|}{ HEK293 Cells Transiently Expressing Nav1.5 K1479AS1503A } \\
\hline Treatment Group & $n$ & Peak $I_{\mathrm{Na}}$ (Normalized Current) & Half Value $(\mathrm{mV})$ & Slope & Half Value $(\mathrm{mV})$ & Slope \\
\hline Control $\left(\mathrm{H}_{2} \mathrm{O}\right)$ & 24 & $-1.00 \pm 0.14$ & $-7.89 \pm 1.22$ & $8.73 \pm 0.19$ & $-75.43 \pm 1.03$ & $-7.33 \pm 0.27$ \\
\hline $5 \mathrm{mM} \mathrm{NR}$ & 25 & $-1.16 \pm 0.12$ & $-11.83 \pm 1.45$ & $9.07 \pm 0.23$ & $-79.08 \pm 1.21$ & $-7.39 \pm 0.20$ \\
\hline \multicolumn{7}{|c|}{ HEK293 Cells Transiently Expressing Nav1.5 K1479A } \\
\hline Treatment Group & $n$ & Peak $I_{\mathrm{Na}}$ (Normalized Current) & Half Value $(\mathrm{mV})$ & Slope & Half Value $(\mathrm{mV})$ & Slope \\
\hline Control $\left(\mathrm{H}_{2} \mathrm{O}\right)$ & 14 & $-1.00 \pm 0.19$ & $-11.81 \pm 1.73$ & $9.13 \pm 0.25$ & $-82.03 \pm 1.73$ & $-6.82 \pm 0.33$ \\
\hline $500 \mu \mathrm{M}$ NAM & 12 & $-1.81 \pm 0.47$ & $-11.51 \pm 2.91$ & $9.13 \pm 0.20$ & $-79.39 \pm 3.33$ & $-7.35 \pm 0.29$ \\
\hline 5 mM NAM & 15 & $-1.66 \pm 0.25$ & $-15.41 \pm 2.20$ & $9.44 \pm 0.27$ & $-83.63 \pm 2.72$ & $-6.51 \pm 0.37$ \\
\hline
\end{tabular}

\section{Table S5. Gating Properties for Whole Cell Patch Clamp Experiments in HEK293 cells and Neonatal Rat Cardiomyocytes.}


bioRxiv preprint doi: https://doi.org/10.1101/2020.02.20.958066; this version posted February 24, 2020. The copyright holder for this preprint (which was not certified by peer review) is the author/funder. All rights reserved. No reuse allowed without permission.

In Vivo Cardiac Electrophysiology Data

\begin{tabular}{|c|c|c|c|c|c|c|}
\hline & \multicolumn{6}{|c|}{ Baseline } \\
\hline & Heart Rate & Heart Rate & & & & \\
\hline & $\begin{array}{l}\text { Lead I } \\
\text { (bpm) }\end{array}$ & $\begin{array}{l}\text { QT Measurement } \\
(\mathrm{bpm})\end{array}$ & $\begin{array}{l}\text { PR Interval } \\
\quad(\mathrm{ms})\end{array}$ & $\begin{array}{l}\text { QRS Duration } \\
\text { (ms) }\end{array}$ & $\begin{array}{l}\text { QT } \\
(\mathrm{ms})\end{array}$ & $\begin{array}{l}\text { QTc } \\
\text { (ms) }\end{array}$ \\
\hline Control Diet $(n=12)$ & $530 \pm 9$ & $498 \pm 11$ & $46.7 \pm 1.4$ & $15.0 \pm 0.2$ & $94.2 \pm 2.8$ & $85.3 \pm 2.1$ \\
\hline $0.35 \%$ NR Diet $(n=7)$ & $539 \pm 24$ & $510 \pm 21$ & $49.1 \pm 3.4$ & $14.9 \pm 0.5$ & $103.0 \pm 3.9$ & $93.9 \pm 2.3$ \\
\hline \multirow[t]{3}{*}{$1.0 \%$ NR Diet $(n=5)$} & $552 \pm 30$ & $516 \pm 18$ & $46.8 \pm 1.3$ & $14.7 \pm 0.4$ & $88.1 \pm 3.0$ & $81.6 \pm 2.8$ \\
\hline & \multicolumn{6}{|c|}{ 5-6 Weeks Post-Diet } \\
\hline & $\begin{array}{l}\text { Lead I Heart Rate } \\
\text { (bpm) }\end{array}$ & $\begin{array}{l}\text { Heart Rate } \\
\text { (bpm) }\end{array}$ & $\begin{array}{l}\text { PR Interval } \\
(\mathrm{ms})\end{array}$ & $\begin{array}{l}\text { QRS Duration } \\
\text { (ms) }\end{array}$ & $\begin{array}{c}\mathrm{QT} \\
(\mathrm{ms})\end{array}$ & $\begin{array}{l}\text { QTc } \\
\text { (ms) }\end{array}$ \\
\hline Control Diet $(n=12)$ & $534 \pm 15$ & $492 \pm 10$ & $47.6 \pm 1.9$ & $14.7 \pm 0.3$ & $92.7 \pm 2.0$ & $83.9 \pm 2.0$ \\
\hline $0.35 \%$ NR Diet $(n=7)$ & $537 \pm 14$ & $502 \pm 11$ & $45.8 \pm 2.2$ & $14.5 \pm 0.5$ & $99.1 \pm 2.3$ & $90.4 \pm 1.8$ \\
\hline \multirow[t]{3}{*}{$1.0 \%$ NR Diet $(n=5)$} & $566 \pm 21$ & $535 \pm 32$ & $46.6 \pm 2.7$ & $13.7 \pm 0.2$ & $85.6 \pm 3.9$ & $79.8 \pm 2.1$ \\
\hline & \multicolumn{6}{|c|}{ 10-12 Weeks Post-Diet } \\
\hline & $\begin{array}{l}\text { Lead I Heart Rate } \\
\text { (bpm) }\end{array}$ & $\begin{array}{l}\text { Heart Rate } \\
\text { (bpm) }\end{array}$ & $\begin{array}{l}\text { PR Interval } \\
(\mathrm{ms})\end{array}$ & $\begin{array}{l}\text { QRS Duration } \\
\text { (ms) }\end{array}$ & $\begin{array}{l}\mathrm{QT} \\
(\mathrm{ms})\end{array}$ & $\begin{array}{l}\text { QTc } \\
\text { (ms) }\end{array}$ \\
\hline Control Diet $(n=12)$ & $532 \pm 12$ & $516 \pm 11$ & $45.9 \pm 1.6$ & $14.5 \pm 0.3$ & $94.0 \pm 2.4$ & $86.9 \pm 1.9$ \\
\hline $0.35 \%$ NR Diet $(n=7)$ & $558 \pm 16$ & $526 \pm 11$ & $48.0 \pm 2.6$ & $15.2 \pm 0.4$ & $95.6 \pm 2.4$ & $89.3 \pm 1.8$ \\
\hline 1.0\% NR Diet $(n=5)$ & $502 \pm 35$ & $476 \pm 24$ & $42.3 \pm 1.1$ & $14.8 \pm 0.4$ & $83.4 \pm 4.0$ & $73.8 \pm 2.2$ \\
\hline
\end{tabular}

Table S6. Effect of Nicotinamide Riboside on Cardiac Electrophysiology in C57BL/6 wild-type mice. 
Echocardiographic Assessment

\begin{tabular}{|c|c|c|c|c|c|c|c|}
\hline & \multicolumn{7}{|c|}{ Baseline } \\
\hline & $\begin{array}{l}\text { Heart Rate } \\
\text { (beats/min) }\end{array}$ & $\begin{array}{l}\text { EDV } \\
(\mu \mathrm{L})\end{array}$ & $\begin{array}{l}\text { ESV } \\
(\mu \mathrm{L})\end{array}$ & $\begin{array}{l}\text { Mass } \\
(\mathrm{mg})\end{array}$ & $\begin{array}{l}\text { SV } \\
(\mu \mathrm{L})\end{array}$ & $\begin{array}{c}\text { CO } \\
(\mu \mathrm{L} / \mathrm{min})\end{array}$ & $\begin{array}{l}\text { EF } \\
(\%)\end{array}$ \\
\hline Control Diet $(n=12)$ & $679 \pm 9$ & $27.4 \pm 2.1$ & $5.3 \pm 0.5$ & $74.9 \pm 4.4$ & $22.1 \pm 2.2$ & $14888 \pm 1399$ & $79 \pm 3$ \\
\hline $0.35 \%$ NR Diet $(n=7)$ & $701 \pm 12$ & $23.7 \pm 3.7$ & $4.3 \pm 0.6$ & $70.6 \pm 2.9$ & $18.3 \pm 3.9$ & $12802 \pm 2727$ & $73 \pm 6$ \\
\hline \multirow[t]{3}{*}{$1.0 \%$ NR Diet $(n=5)$} & $686 \pm 19$ & $32.5 \pm 3.7$ & $5.3 \pm 0.6$ & $82.1 \pm 5.4$ & $28.2 \pm 2.9$ & $19352 \pm 2041$ & $87 \pm 2$ \\
\hline & \multicolumn{7}{|c|}{ 10-12 Weeks } \\
\hline & $\begin{array}{l}\text { Heart Rate } \\
\text { (beats/min) }\end{array}$ & $\begin{array}{l}\text { EDV } \\
(\mu \mathrm{L})\end{array}$ & $\begin{array}{l}\text { ESV } \\
(\mu \mathrm{L})\end{array}$ & $\begin{array}{l}\text { Mass } \\
(\mathrm{mg})\end{array}$ & $\begin{array}{l}\text { SV } \\
(\mu \mathrm{L})\end{array}$ & $\begin{array}{c}\text { CO } \\
(\mu \mathrm{L} / \mathrm{min})\end{array}$ & $\begin{array}{l}\text { EF } \\
(\%)\end{array}$ \\
\hline Control Diet $(n=12)$ & $691 \pm 10$ & $25.4 \pm 1.5$ & $4.9 \pm 0.5$ & $72.5 \pm 3.4$ & $20.4 \pm 1.3$ & $14095 \pm 928$ & $80 \pm 2$ \\
\hline $0.35 \%$ NR Diet $(n=7)$ & $637 \pm 46$ & $24.8 \pm 2.4$ & $4.9 \pm 0.7$ & $72.5 \pm 3.1$ & $19.8 \pm 2.3$ & $12259 \pm 1418$ & $79 \pm 3$ \\
\hline 1.0\% NR Diet $(n=5)$ & $675 \pm 16$ & $28.4 \pm 5.9$ & $5.2 \pm 1.3$ & $77.0 \pm 9.1$ & $19.8 \pm 2.3$ & $15699 \pm 3276$ & $82 \pm 2$ \\
\hline
\end{tabular}

Table S7. Effect of Nicotinamide Riboside on Cardiac Function in C57BL/6 wild-type mice. Heart Rate, Enddiastolic volume (EDV), End-systolic volume (ESV), Mass, Stroke volume (SV), Cardiac Output (CO), Ejection Fraction (EF). 